\title{
Implications of motivational interviewing and oral hygiene instruction for the reduction of oral health disparities among pregnant women
}

\author{
Renata K. Martins \\ West Virginia University
}

Follow this and additional works at: https://researchrepository.wvu.edu/etd

\section{Recommended Citation}

Martins, Renata K., "Implications of motivational interviewing and oral hygiene instruction for the reduction of oral health disparities among pregnant women" (2008). Graduate Theses, Dissertations, and Problem Reports. 4402.

https://researchrepository.wvu.edu/etd/4402

This Dissertation is protected by copyright and/or related rights. It has been brought to you by the The Research Repository @ WVU with permission from the rights-holder(s). You are free to use this Dissertation in any way that is permitted by the copyright and related rights legislation that applies to your use. For other uses you must obtain permission from the rights-holder(s) directly, unless additional rights are indicated by a Creative Commons license in the record and/ or on the work itself. This Dissertation has been accepted for inclusion in WVU Graduate Theses, Dissertations, and Problem Reports collection by an authorized administrator of The Research Repository @ WVU.

For more information, please contact researchrepository@mail.wvu.edu. 
Implications of Motivational Interviewing and Oral Hygiene Instruction for the Reduction of Oral Health Disparities among Pregnant Women

\title{
Renata K. Martins
}

Dissertation Submitted to the Eberly College of Arts and Sciences at West Virginia University in partial fulfillment of the requirements for the degree of

\author{
Doctor of Philosophy \\ in \\ Psychology
}
Daniel W. McNeil, Ph.D., Chair Steven Branstetter, Ph.D. Amy Fiske, Ph.D. Marcia Gladwin, R.D.H., Ed.D. Kent Parker, Ph.D.

\section{Department of Psychology}

\section{Morgantown, West Virginia 2008}

Keywords: Motivational Interviewing, Oral Health, Pregnancy, Oral Hygiene Instruction, Dentistry Copyright 2008 Renata K. Martins 


\section{ABSTRACT \\ Implications of Motivational Interviewing and Oral Hygiene Instruction for the Reduction of Oral Health Disparities among Pregnant Women}

\section{Renata K. Martins}

Pregnancy is a "teachable moment" during which women may be particularly amenable to making health behavior changes that can have significant impact, not only on themselves, but also on their offspring. Dental complications during pregnancy, such as periodontal disease, have been linked to low birth weight and premature birth. Additionally, mothers' oral health status has been related to childhood caries, through the direct transmission of oral pathogens. Motivational Interviewing (MI) is a promising intervention in the oral health care arena. MI has been empirically supported as a treatment for substance abuse, as well as other health issues including, diabetes, HIV, hypertension, and smoking. This study sought to understand the effectiveness of motivational interviewing and oral hygiene instruction $(\mathrm{OHI})$ to increase motivation to engage in positive oral health behaviors (e.g., proper oral hygiene and needed treatment). The hypotheses of this study were addressed by assessing oral health care behaviors, oral health values, and issues related to dental care utilization in 85 pregnant women using a 2 (intervention group: motivational interviewing or oral hygiene instruction) X 2 (time of measurement: pre-test vs. follow-up) mixed design with random assignment. It was hypothesized that level of Streptococcus mutans would significantly decrease and that tooth brushing, flossing, and dental visit frequency, and dental knowledge would significantly increase after the interventions. It was hypothesized that oral health values would significantly improve after MI and OHI. MI was predicted to contribute to greater change in the dependent variables compared to OHI. There were four variables that were included for exploratory purposes: dental fear, oral health quality of life, toothpaste use, and floss use. Participants were asked to provide a saliva sample to estimate the number of Streptococcus mutans using the Dentocult strip-test, and to complete the Dental Neglect Survey (DNS), the Dental Fear Survey (DFS), the Oral Health Impact Profile-14 (OHIP-14), and the Dental Knowledge Inventory. Two follow-up phone calls were conducted, at two weeks and one month after the initial assessment, during which motivation and oral health behavior was assessed. Participants provided another saliva sample, and completed the DNS, DFS, and OHIP-14 at follow-up six weeks later. Data analysis was conducted in six phases: (a) preliminary examination of data, (b) exploration of the psychometric properties of the primary dependent variable instruments, (c) examination of groups at baseline, (d) group comparisons, (e) exploratory analyses, and (f) correlational analyses. The present study examined six primary dependent measures: (a) tooth brushing frequency, (b) flossing frequency, (c) dental visit frequency, (d) oral health values, (e) dental knowledge, and (f) level of Streptococcus mutans. Tooth brushing frequency, flossing frequency, oral health values, and dental knowledge were significantly higher at follow-up among participants. Amount of toothpaste and floss returned were significantly lower at follow-up among participants. OHI was found to significantly increase dental knowledge among women. No significant differences in level of Streptococcus mutans, dental fear, dental visit frequency, or oral health quality of life were noted at follow-up; $\mathrm{MI}$ and OHI interventions generally were found to similarly affect the dependent variables. Several study limitations were noted and future research in this area is encouraged. Effective interventions with this group may have preventive implications related to oral health care, such as increased utilization of dental care services and the reduction of treatment barriers, for a group that is in need. 


\section{ACKNOWLEDGEMENTS}

I would like to thank the members of my dissertation committee: Daniel W. McNeil, Ph.D., Steven Branstetter, Ph.D., Amy Fiske, Ph.D., Marcia Gladwin, R.D.H, Ed.D., and Kent Parker, Ph.D. Their advice, guidance, and assistance during the completion of this project was invaluable. I would like to especially thank my mentor and friend, Dr. Daniel McNeil, for his dedication to my education, for his unwavering support, and for his generosity throughout my training. He is a good soul and I am grateful for all that he has taught me. I also would like to thank Laura Aliff for her dedication and attention to detail which was essential to the successful completion of this project. In addition to my dissertation committee, I would like to the members of the Anxiety, Psychophysiology, and Pain Research Laboratory for their support, encouragement, and feedback throughout this study. 
TABLE OF CONTENTS

TITLE PAGE

ABSTRACT

ii

ACKNOWLEDGEMENTS

iii

LIST OF TABLES

vii

LIST OF FIGURES

viii

LIST OF APPENDICES

$\mathrm{X}$

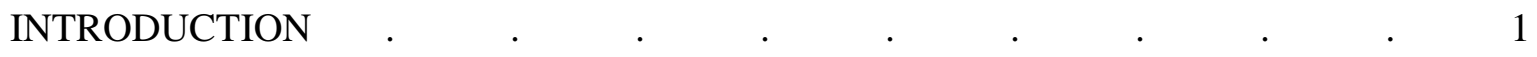

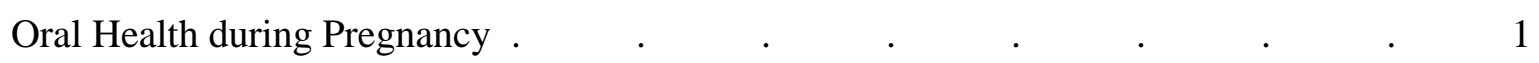

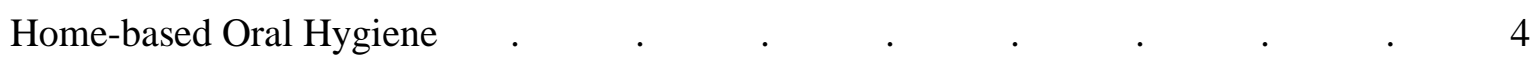

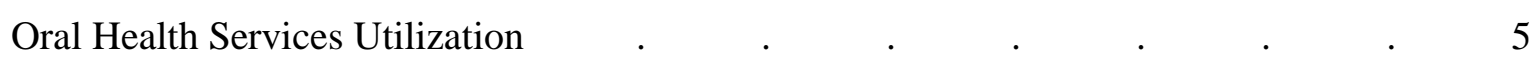

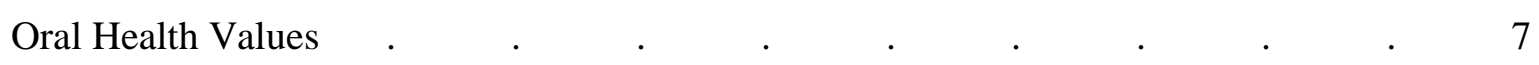

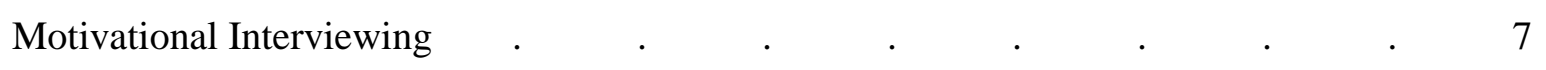

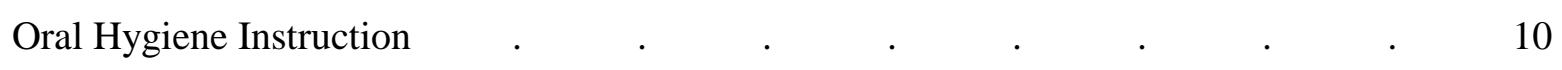

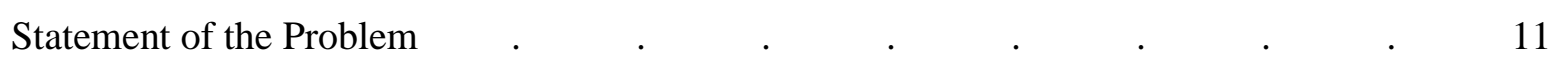

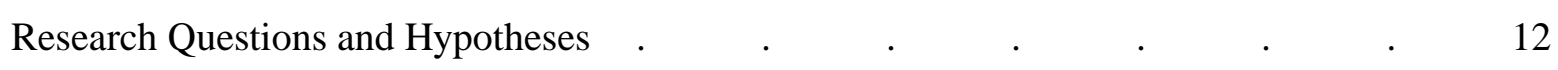

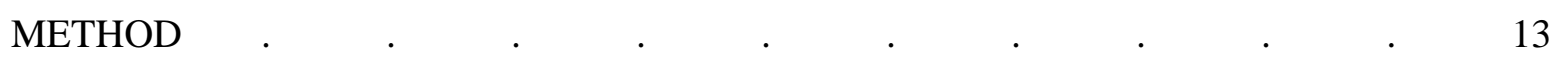

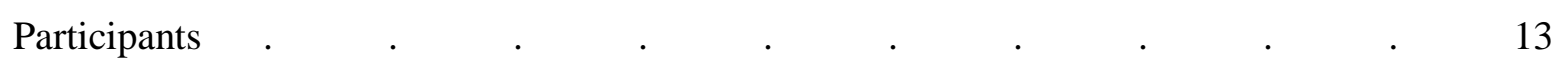

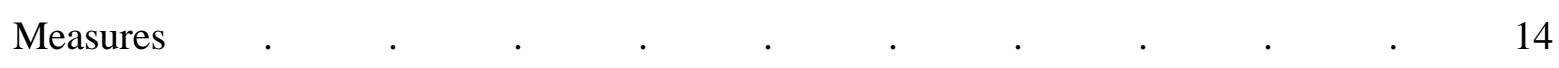

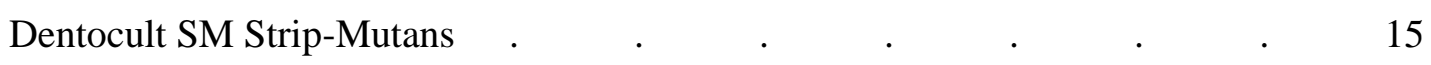

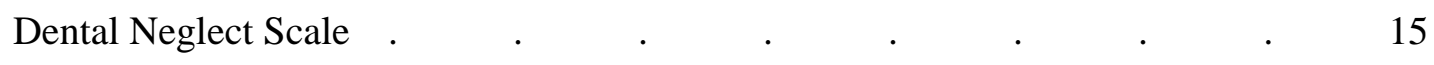

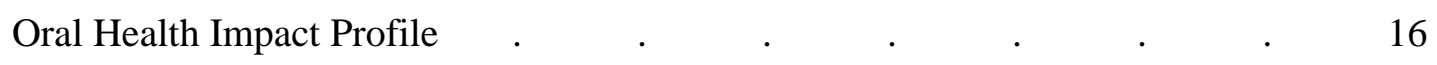

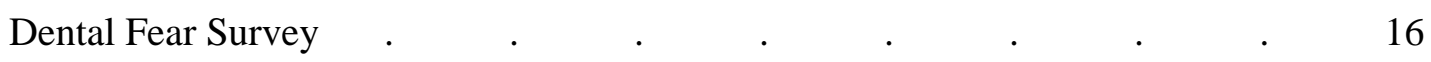

Tooth Brushing, Flossing, and Dental Visit Behavior . $\quad . \quad$. $\quad . \quad 16$

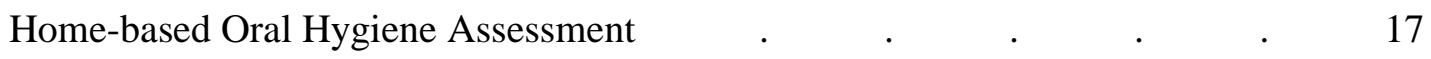




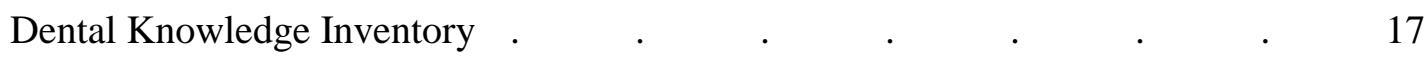

Hollingshead Four-Factor Index of Social Status $\quad . \quad$. $\quad . \quad$. 17

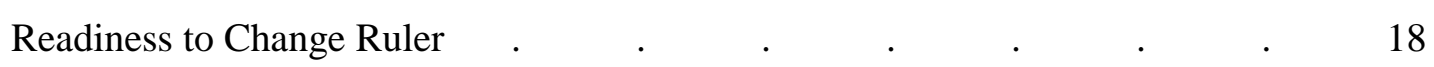

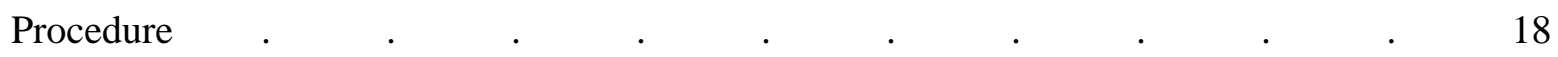

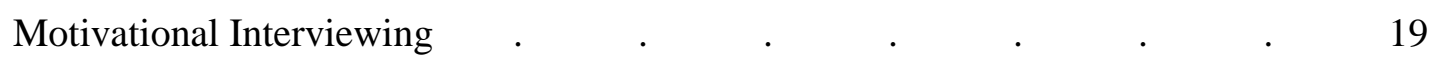

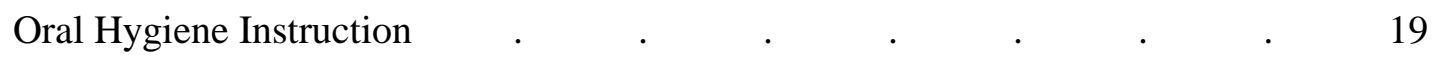

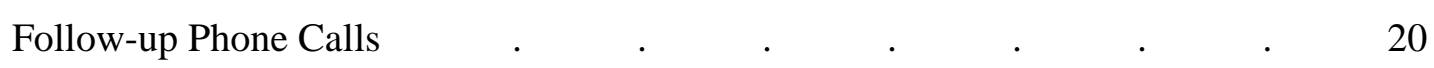

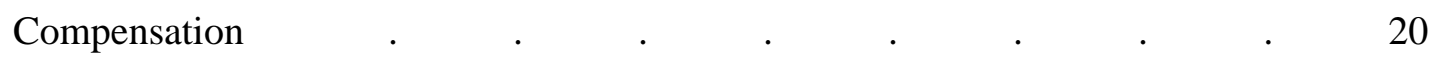

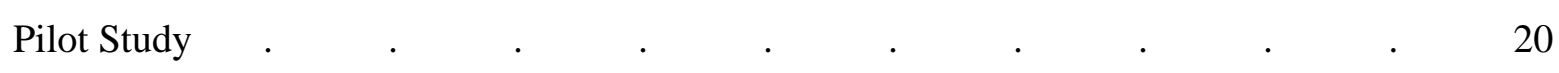

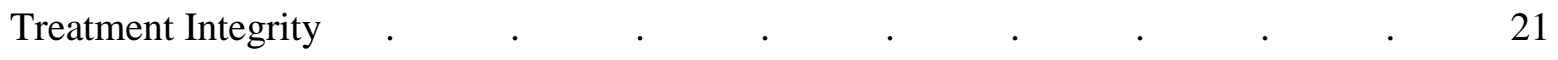

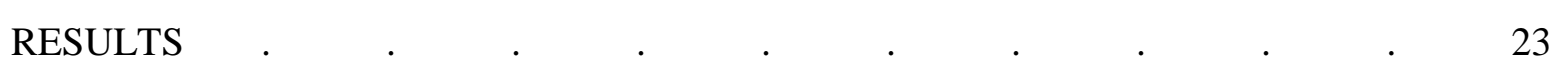

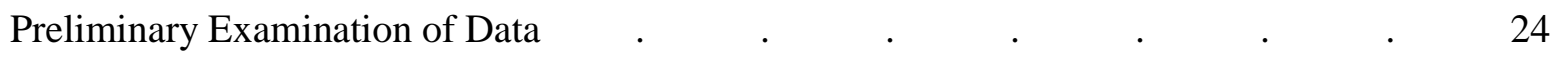

Exploration of the Psychometric Properties of the Primary Dependent Variables $\quad$. $\quad 24$

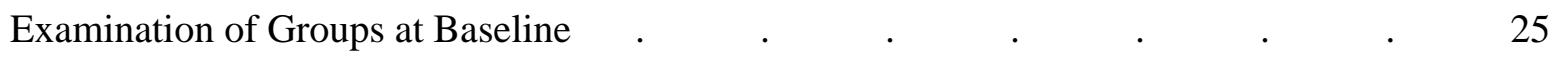

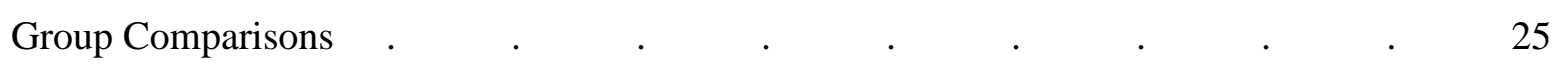

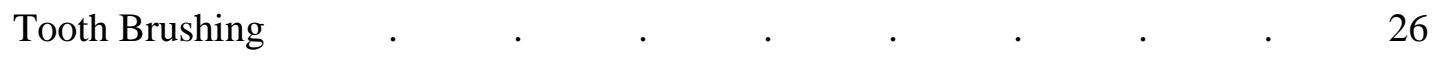

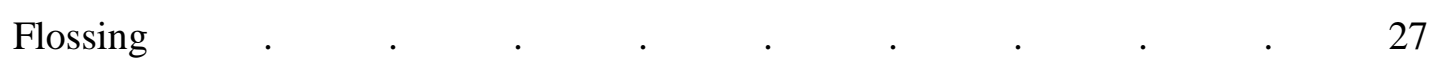

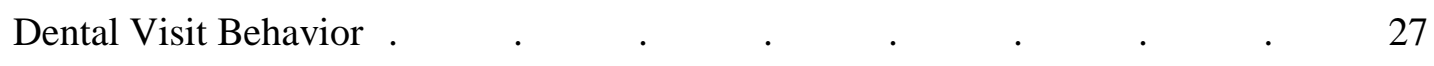

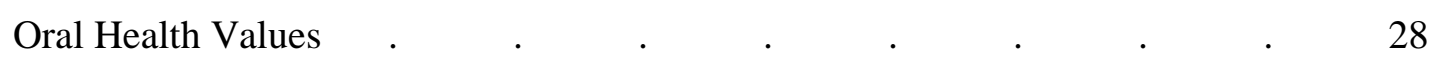

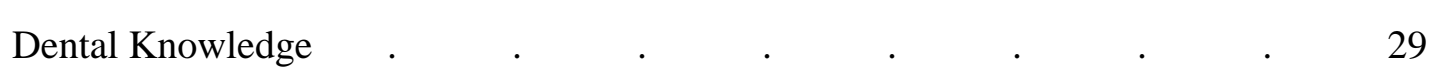

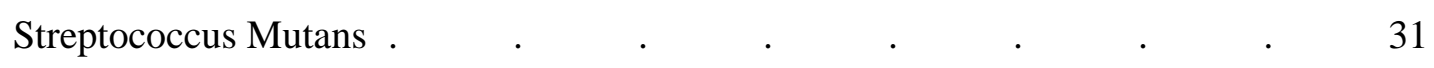

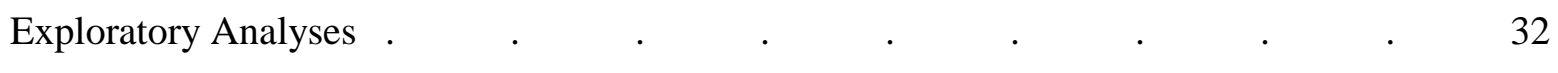

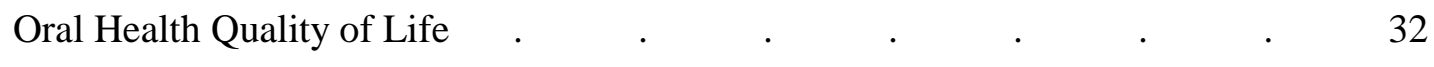

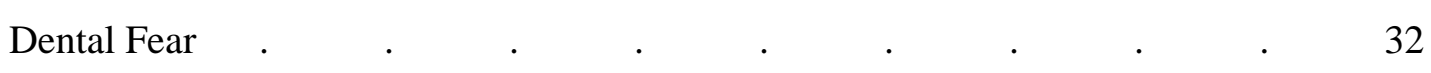

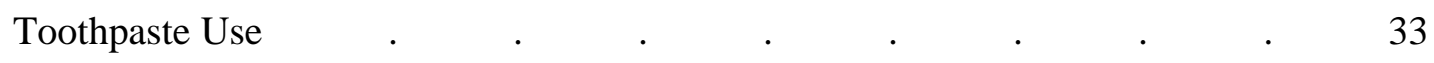




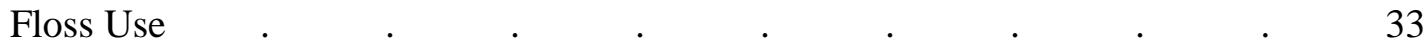

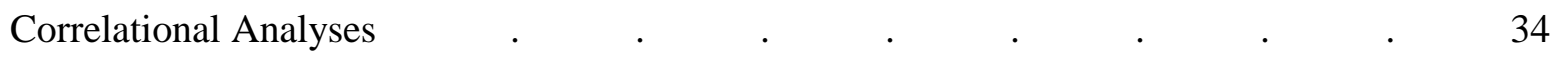

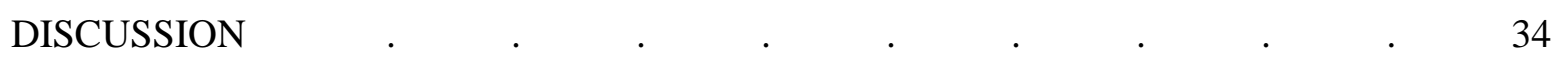

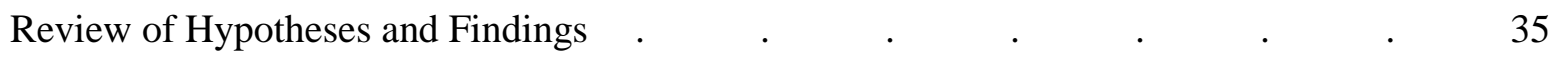

Association of Study with Previous Research and Limitations . _ . . . . 37

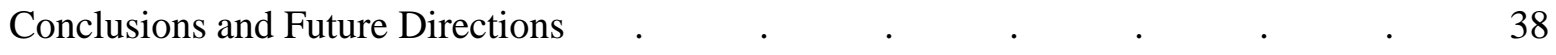

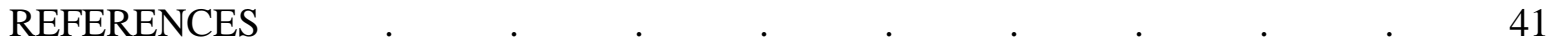




\section{LIST OF TABLES}

1. Summary of Participant Recruitment Sources . $\quad$. $\quad$. $\quad$. $\quad$. 53

2. Summary of Motivational Interviewing Goals for Each Participant . . $\quad 54$

3. Summary of Missing Data per Participant $\quad$. $\quad$. $\quad$. $\quad$. $\quad$. $\quad 55$

4. Skewness and Kurtosis of Primary Dependent Variables and Exploratory

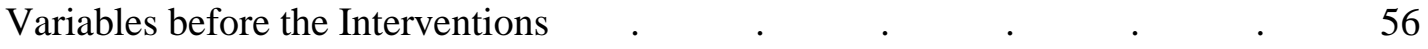

5. Skewness and Kurtosis of Primary Dependent Variables and Exploratory

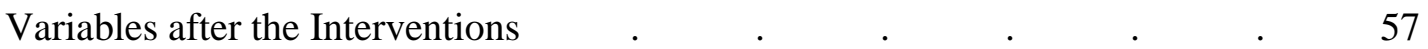

6. Correlations of Primary Dependent Variable Instruments $\quad . \quad$. $\quad$. 58

7. Mean (Standard Deviation) Values for the Primary Dependent and Exploratory

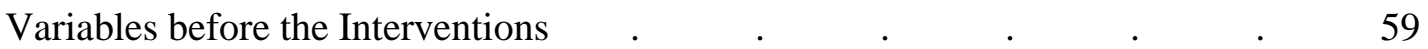

8. $\quad t$ Test Values for Primary Dependent and Exploratory Variables before

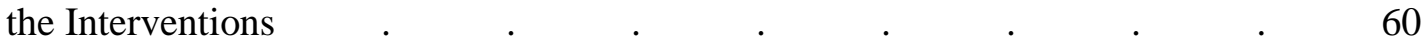

9. Intercorrelations among Possible Covariates and Dependent Variables . $\quad 61$

9. Intercorrelations among Possible Covariates and Dependent Variables (cont.) . 62

9. Intercorrelations among Possible Covariates and Dependent Variables (cont.) . 63 


\section{LIST OF FIGURES}

1. Mean tooth brushing behavior pre-intervention and at follow-up for motivational interviewing and oral hygiene instruction groups $\quad . \quad$. $\quad 66$

2. Mean flossing behavior at pre-intervention and at follow-up for motivational interviewing and oral hygiene instruction groups $\quad . \quad$. $\quad 67$

3. Mean dental visit behavior pre-intervention and at follow-up for motivational interviewing and oral hygiene instruction groups $\quad . \quad$. $\quad 68$

4. Mean Dental Neglect Scale scores pre-intervention and at follow-up for motivational interviewing and oral hygiene instruction groups .

5. Mean Dental Knowledge Inventory total scores pre-intervention, post-intervention, and at follow-up for motivational interviewing

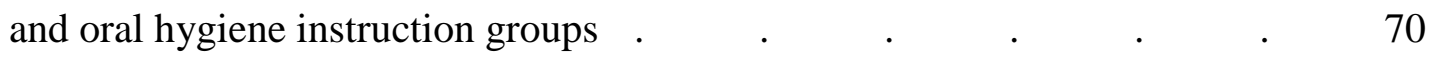

6. Mean Dental Knowledge Inventory dental hygiene scores pre-intervention, post-intervention, and at follow-up for motivational interviewing and oral hygiene instruction groups . . . .

7. Mean Dental Knowledge Inventory pregnancy scores pre-intervention, post-intervention, and at follow-up for motivational interviewing and oral hygiene instruction groups $\quad . \quad$. $\quad . \quad$. .

8. Mean Dentocult scores pre-intervention and at follow-up for motivational interviewing and oral hygiene instruction groups . . . .

9. Mean Oral Health Impact Profile scores pre-intervention and at follow-up for motivational interviewing and oral hygiene instruction groups .

10. Mean Dental Fear Survey scores pre-intervention and at follow-up for motivational interviewing and oral hygiene instruction groups 
11. Mean toothpaste use in grams pre-intervention and at follow-up for motivational interviewing and oral hygiene instruction groups $\quad . \quad$. 76

12. Mean floss use in inches pre-intervention and at follow-up for motivational

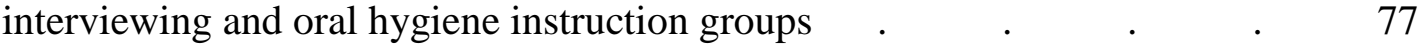




\section{LIST OF APPENDICES}

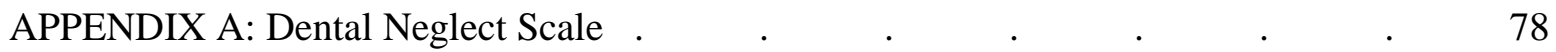

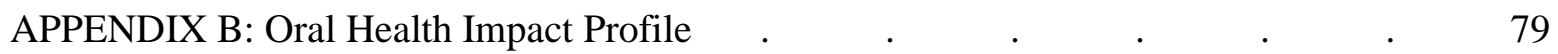

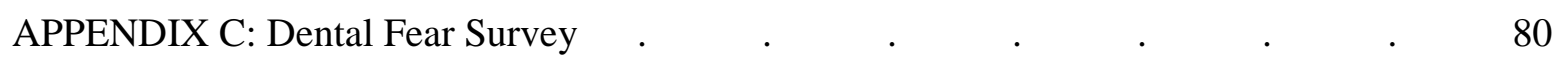

APPENDIX D: Tooth brushing, Flossing, and Dental Visit Behavior . _ . . $\quad 81$

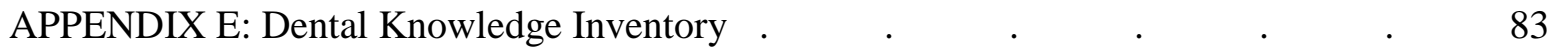

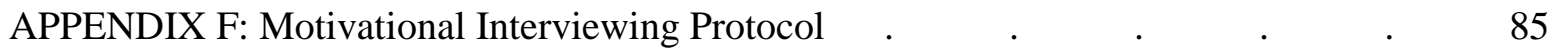

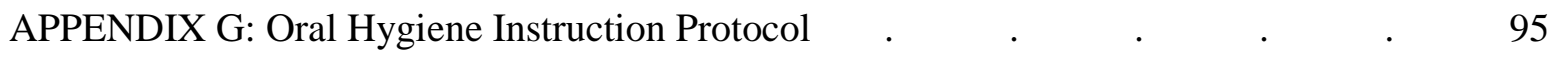


Implications of Motivational Interviewing and Oral Hygiene Instruction for the Reduction of

$$
\text { Oral Health Disparities among Pregnant Women }
$$

In recent years, oral health has been linked to low birth weight (Jeffcoat, Guers, Reddy et al., 2001) premature birth (Jeffcoat, Guers, Reddy, Cliver et al., 2001; Offenbacher et al., 2006), respiratory illness (Mojon, 2002), cardiovascular disease (Beck \& Offenbacher, 2005; Genco, Offenbacher, \& Beck, 2002), and diabetes (Jansson, Lindholm, Lindh, Groop, \& Bratthall, 2006). The 2000 Surgeon General report on oral health in America identified oral health as a "silent epidemic" and encouraged research that can "enhance education, services, and research and eliminate barriers to care (U.S. Department of Health and Human Services [U.S. DHHS], 2000, p.v)." Similarly, the Healthy People 2010 document announced the reduction of health disparities (i.e., a significant difference in health between one population and another; U.S. DHHS, 2006b) as one of its goals (U.S. DHHS, 2000b). Significant barriers to oral health were emphasized, including lack of understanding and awareness about oral health, general health risk factors (e.g., poor nutrition), and lack of access to care due to various reasons, such as lack of transportation or health insurance, cost, or income status (U.S. DHHS, 2000; U.S. DHHS, 2000b). As a result of these constraints, home oral health maintenance and the prevention of future oral health problems become less of a priority than other needs (Chen, 1995).

\section{Oral Health during Pregnancy}

One consistent finding within the oral health literature is that poor oral health during pregnancy can negatively affect both the mother and the child. For example, poor oral hygiene, untreated gingivitis and periodontal disease, and poor nutrition all have been associated with higher rates of preterm births, low birth weight (Offenbacher, 2004), and early childhood caries (Weinstein, Harrison, \& Benton, 2004). In recent years, significant theoretical and 
methodological advances have been made in the fields of behavioral dentistry and oral health care in general. Widespread alterations to the dissemination of education and dental services, however, have yet to be made. For instance, although dentists and other health care workers have been urged, through several different sources, to provide prenatal dental education and oral treatment when necessary to pregnant women, a gap still exists between these guidelines and what happens in the field.

Engaging in appropriate oral health care not only can prevent many dental problems but also other health problems that may be associated with the care of teeth, such as diabetes, heart and lung disease, and stroke (Peterson, 2003). A healthy maternal oral environment during pregnancy helps promote positive health effects, and reduce negative health effects, in both the mother and the child. This environment is best maintained by adequate oral hygiene (e.g., brushing, flossing), preventative oral health care (e.g., dental examination), and prompt dental treatment for acute problems that arise (Little, Falace, Miller, \& Rhodus, 2002; Mills \& Moses, 2002). Proper nutrition, of course, enhances oral and general health in pregnant women. Vitamins A, C, and D, calcium, protein, fluoride, and prenatal vitamins are recommended for the overall health of the mother and baby (Fitzsimons, Dwyer, Palmer, \& Boyd, 1998; Little et al., 2002).

Hormonal and vascular changes during pregnancy make oral health care even more important during such a vulnerable time (Little et al., 2002). Oral complications during pregnancy include gingivitis, dry mouth, or excess saliva production, and periodontal disease (Wilkins, 2005). Some changes in oral health status are believed to stem from hormonal changes during pregnancy, whereas others are due to behaviors such as poor oral hygiene. Gingival inflammation is the most common oral health complication during pregnancy (Little et al., 
2002); changes usually occur in the second month of pregnancy; however, it is most common during the middle of the third trimester and remains a concern until about three to six months postpartum (Jensen, Lilijmark, \& Bloomquist, 1981; Löe, 1965). Gingival inflammation usually results from gum irritation or poor oral hygiene and has been linked to increased amounts of estrogen and progesterone (Löe, 1965). If left untreated, localized gingivitis can lead to pyogenic granuloma, or pregnancy tumor (Little et al., 2002) in about 5\% of pregnant women (Rose \& Kaye, 1983).

Oral conditions, such as untreated periodontal disease, have been linked to low birth weight (i.e., < 2500 grams) (Offenbacher et al., 1998), fetal growth restriction (Dasanayake, 1998; Jeffcoat et al., 2001; Offenbacher, 2004), and premature birth, particularly in women who lack a protective serum antibody response (Madianos et al., 2001). Periodontal disease can develop during pregnancy even with no prior condition (Moss, Beck, \& Offenbacher, 2005), or can worsen conditions present before pregnancy (Laine, 2002). Timing of treatment is important, since periodontal pockets can increase with progressing stages of pregnancy (Tanni, Habashneh, Hammad, \& Batieha, 2003).

Further, the transmission of oral bacteria (e.g., Streptococcus mutans or lactobacilli) from the mother to the child due to poor oral hygiene is believed to increase the experience of childhood caries (Weinstein \& Riedy, 2001). Streptococcus mutans and lactobacilli, microorganisms located in dental plaque and saliva, are present, at some level, in children (Alaluusua \& Renkonen, 1983; Carlsson, Grahnen, \& Jonsson, 1975; Köhler, Bjarnason, Care, Mackevica, \& Rence, 1995), adolescents (Alaluusua et al., 1990), adults, and older adults (Närhi, Kurki, \& Ainamo, 1999). Elevated levels of Streptococcus mutans and lactobacilli have been associated with increased risk for dental caries (Richardson, McKibbins, Seibert, \& Tyus, 1995), 
and as a result have been associated with increased numbers of decayed teeth, increased number of fillings, missing teeth (Jalil, 1995), and root canals (Närhi et al.,1999). Streptococcus mutans can be transmitted from person to person directly (e.g., mouth to mouth contact), or indirectly (e.g. sharing eating utensils) (Madigan, Murray, Houpt, Catalanotto, \& Feuerman, 1997). Mothers are considered the primary source of infection for the child (Berkowitz, Jordan, \& White, 1975; Masuda, Shimamoto, Kitamura, Sobue, \& Hamada, 1985), further indicating the need for improved oral health during pregnancy and motherhood, in general. Children are at greatest risk for Streptococcus mutans infection between eight months and 3 years of age when teeth are emerging (Caufield, Cutter, \& Dasanayake, 1993). Early detection of high levels of Streptococcus mutans may help prevent future decay in mothers (Köhler et al., 1995) and may delay the establishment of Streptococcus mutans in infants and children (Köhler, Bratthall, \& Krasse, 1983).

Although Streptococcus mutans and lactobacilli may indicate the presence of disease (e.g., caries), it is not a perfect predictor of future caries experience. Low levels of Streptococcus mutans and lactobacilli have been associated with fewer caries, but evidence for the predictive value of high levels of bacteria is limited (Kingman et al., 1988). Further Streptococcus mutans and lactobacilli are not the only factors associated with oral disease (Offenbacher, 1996). For example, poor nutrition, particularly a diet low in vitamins and high in cariogenic foods (e.g., soda), can act as a risk factor possibly increasing the likelihood of experiencing caries (Burt \& Eklund, 2005).

\section{Home-based Oral Hygiene}

Home-based oral hygiene practiced is recommended by the American Dental Hygienists' Association [ADHA] to prevent (e.g., caries, periodontal disease) and/or improve oral health 
conditions, such as gingivitis (ADHA, 2006; Bouwsma, Caton, Polson, \& Espeland, 1988; Lobene, Soparkar, \& Newman, 1982). Oral hygiene usually includes tooth brushing, flossing, interdental brushes, and the use of mouthwash, but also may include specialized instruments such as a water-pik or tongue cleaner (Ray, 2005). Specifically, the ADHA recommends that adults brush their teeth at least two times a day, for about 2 minutes, at a $45^{\circ}$ angle, with a softbristled toothbrush (2006). Adults should floss once a day using about 18" of dental floss utilizing a zigzag motion (ADHA, 2006b).

\section{Oral Health Services Utilization}

Oral health care utilization is commonly measured by frequency of visits to dentists or dental clinics (U.S. Census, 2006). Only about 69\% of the United States population visited a dentist or dental clinic within one year of a survey conducted by the Center for Disease Control (CDC, 2004). In West Virginia, dental visits were reported by $61.5 \%$ of the population, indicating slightly less dental care utilization than the national percentage (CDC, 2004). Pregnant women underutilize oral health services more than other groups in the general population (U.S. DHHS, 2000). Several factors act as barriers to oral health services utilization and include poverty, lack of health care insurance, specifically dental insurance, and difficulty finding dental care providers who accept Medicaid (National Rural Health Association [NRHA], 2005). In fact, the frequency of dental care visits has been found to be positively correlated with family income (U.S. Census, 2006). Emotional status also may present difficulties in obtaining health care (Zambrana, Ell, Dorrington, Wachsman, \& Hodge, 1994). For example, individuals suffering from depression and anxiety may be less likely to seek health care services. Dental fear and fear of pain also have been identified as barriers to care (Vowles et al., 2005). Other 
barriers include long waits at health clinics and an inability to attend appointments due to work schedules (Zambrana et al., 1994).

About half of West Virginian population $(825,070)$ live in rural areas (United States Department of Agriculture [USDA], 2006), in which geographic isolation, inadequate transportation, and dental service provider shortages contribute to reduced oral health care utilization (NRHA, 2005; U.S. DHHR, 2006). As a result, individuals living in rural areas are more likely to lose their teeth and to have untreated dental problems (NRHA, 2005). Finally, culture may contribute to lack of oral health utilization in West Virginia which is located in the Appalachian Mountains. Not only are many individuals residing in Appalachia geographically isolated, they often are reluctant to utilize medical and dental services except for emergencies (U.S. DHHR, 2006). Only about 50\% of all individuals living in West Virginia obtain regular dental care, and utilization rates are even lower among individuals with low income (U.S. DHHR, 2006).

Traditionally, conditions such as those discussed above have gone untreated in pregnant women. Dental treatment can be administered at any time during pregnancy, if necessary, although the second trimester through mid-third trimester is considered the safest time (American Dental Association [ADA], 1995); if possible, treatment should be avoided during the first trimester, because the fetus is particularly vulnerable during this time (Ferris, 1993). The American Academy of Periodontology (2004) and the American Dental Association both urge pregnant women to seek diagnosis and treatment for periodontal infections during pregnancy; however it still can be difficult to find a dentist willing to provide treatment. In one study, more than a third of West Virginian dentists reported being reluctant or unwilling to provide 
preventative oral health services or treatment to pregnant women (Williams, Stevens, Marti, Koelbl, \& Wearden, 2005).

\section{Oral Health Values}

Oral health values are defined as the importance placed on oral health care and maintenance of oral health (Lawrence, 2005). Oral health values can considerably impact oral health service utilization and engagement in positive oral care behaviors (e.g., brushing, flossing, and preventive dental visits). The value one places on retaining the natural dentition, and maintaining overall oral health, has been demonstrated to relate positively to actual behavior, including number of dental visits (Lawrence, 2005; McGrath \& Bedi, 2001). Individuals of higher socioeconomic status take care of their general health and oral health care more than those of lower socioeconomic status, perhaps because fewer barriers are present (e.g., financial barriers) (Lawrence, 2005).

\section{Motivational Interviewing}

The motivational interviewing (MI) literature suggests that increasing motivation and reducing perceived barriers for change facilitates positive behavior change. Miller and Rollnick (2002) defined MI as "a client-centered, directive method for enhancing intrinsic motivation to change by exploring and resolving ambivalence" (p. 25). Motivational interviewing is a directive psychosocial intervention used to identify and resolve discrepancies between desired behaviors and actual behaviors and to increase motivation to facilitate behavior change (Miller \& Rollnick). Concepts such as reflective listening are balanced with a directive approach.

Motivational interviewing consists of two phases. During the first phase, intrinsic motivation for change is enhanced whereas in phase two, commitment to change is strengthened (Miller \& Rollnick, 2002). The Transtheoretical Model of Change developed by DiClemente and 
Prochaska (1985) provides a theoretical focus for stages of change targeted by MI. Motivational interviewing is a collaborative process focused on a common goal of increasing motivation to change based on the client's stage of change, as described by DiClemente and Prochaska. They describe five stages of behavior change: (a) precontemplation, during which the individual does not acknowledge a problem and does not recognize a need for change, (b) contemplation, during which the individual is ambivalent about making a change, (c) preparation, during which the individual wants to make a change and plans to do so soon, (d) action, during which the individual makes actual change, and (e) maintenance, during which the client attempts to prevent relapse (DiClemente \& Prochaska). The goal of MI is to strengthen the importance of change from the client's perspective (Burke et al., 2003) according to their stage of change.

Four basic principles of MI are utilized to enhance motivation: (a) expression of empathy, (b) development of discrepancy, (c) rolling with resistance, and (d) the support of self-efficacy. Acceptance and understanding facilitate change while the discrepancy between desired behaviors or goals and actual behaviors is developed. The client presents reasons for change while the facilitator supports her. Alternately, if the client is resistant to change, the facilitator "rolls" with it instead of fighting against it. If and when the client is ready to initiate a change, the facilitator supports that decision (Miller \& Rollnick, 2002).

MI incorporates the Transtheoretical Model of Change with a client-centered approach to consultation. MI adheres to the concept that behavior change is not the sole responsibility of the client, but is a shared endeavor. Practitioners are in a unique position to either enhance the client's motivation to change or contribute to resistance (Rollnick, Mason, \& Butler, 2002). Traditionally, in health care settings, recommendations for behavior change are delivered through brief advice-giving in which overt recommendations are presented in an imperative 
mood using verbs of obligation (Heritage \& Sefi, 1992). Motivational interviewing challenges traditional intervention delivery methods by suggesting that clients know what is best for themselves and professionals should work with clients to determine what behavior change strategies will work best while acknowledging freedom of choice. A menu of choices is one way in which recommendations can be given while maintaining the client's freedom of choice (Rollnick et al., 2002).

MI is an empirically supported intervention for the treatment of substance abuse and has shown positive effects in other health arenas as well (Martins \& McNeil, 2008). Support for the use of brief MI interventions in the areas of substance abuse and diet and exercise was provided through 29 empirical studies reviewed by Dunn et al. (2001). Dunn and colleagues reported that although support was indicated for MI in the areas of substance abuse, as well as diet and exercise, the data in the areas of smoking cessation and HIV-risk behaviors were insufficient to determine efficacy. Burke et al. (2002) conducted a meta-analysis of 26 studies and found moderate effect sizes (i.e., from .25 to .57) when MI was compared to no treatment or treatment as usual for substance abuse, as well as diet and exercise; support for MI for smoking cessation and reduction of HIV-risk behaviors, however, was limited. Hettema et al. (2005) reviewed 72 articles examining the efficacy of MI in the areas of alcohol, smoking, HIV/AIDS, drug abuse, treatment compliance, gambling, intimate relationships, water purification/safety, eating disorders, and diet and exercise and found a range of effect sizes (i.e., from .30 to .77). Across the various reviews, MI often was more effective than no treatment; however, it was not always superior to traditional interventions.

MI is relatively new to oral health, but it seems to be a promising tool to improve oral health status, based on the available studies. Significant to the current study, Weinstein, 
Harrison, and Benton (2004) compared the effects of MI and traditional health education on prevention of caries (i.e., cavities) in children of South Asian immigrants at high risk of developing early childhood caries in a South Asian, Punjabi-speaking, community in Surrey, British Columbia. Mothers in the health education group were given a pamphlet and viewed an 11-minute video, available in five languages, entitled "Preventing Tooth Decay for Infants and Toddlers." The pamphlet and the video were modified to include both dietary and non-dietary strategies to prevent early childhood caries. Participants in the MI group received the same pamphlet and viewed the same video, but also received a 45-minute MI session, two brief follow-up phone calls (two weeks and one month after initial contact), four phone calls up to six months after initial contact, and two postcard reminders. Children whose parents received MI had .71 carious surfaces, whereas those whose parents were in the health education group had 1.91 carious surfaces. The results showed a significant effect for age and treatment condition, indicating that MI has promise in preserving the oral health of infants, with the intervention targeted at their parents or other caregivers (Weinstein, Harrison, \& Benton, 2004). MI also seems to have potential to address the self-care of adolescents and adults, with particular applications to special populations (e.g., pregnant women) whose oral health status may affect other health areas (e.g., length of pregnancy). Delay or avoidance of timely dental care is an important area that MI may ultimately help to address, although the present data are quite preliminary.

\section{Oral Hygiene Instruction}

Research linking oral health to systematic health increased the urgency of prevention and information dissemination in the late 1990s (Kimbrough \& Henderson, 2006). Barriers such as cost and lack of dental insurance have increased the need for oral home care (e.g., brushing teeth 
or flossing). Oral hygiene instruction often consists of assessment of oral health problems, oral health information dissemination and recommendations for improved oral health (e.g., improved nutrition), and is usually provided by dental hygienists. Dental hygienists that provide instruction use strategies such as active listening and learning materials (e.g., handouts or flipbooks) to help individuals remember and use the information provided (Kimbrough \& Henderson, 2006).

Oral hygiene instruction often is provided in the form of community oral health promotion programs designed to address problems of primary concern for a particular population. Oral health promotion usually is delivered by volunteers with previous training in dental education (e.g., dental hygienists). Oral health promotion can be informal (e.g., information delivered to a classroom of children) or formal (e.g., a state-sponsored program to disseminate information to low-income families) (Drury \& Snowden, 1995).

Although oral home care is not without cost, the prevention of future oral health disease is economical compared to dental emergency care (Kimbrough \& Henderson, 2006). Water fluorination may reduce the experience of caries resulting in significant cost savings (Burt \& Eklund, 2005; Griffin, Jones, \& Tomar, 2001). Prevention and treatment of oral health conditions also may reduce time taken off from work, school, or other activities, perhaps even more so among low socioeconomic groups (Gift, Reisine, \& Larach, 1992). Oral health promotion in the workplace may improve oral hygiene and thus reduce dental care costs (Ide, Mizoue, Tsukiyama, Ikeda, \& Yoshimura, 2001).

\section{Statement of the Problem}

Understanding oral health care among pregnant women has important implications for the delivery of dental services, access to and utilization of dental care services, and engagement 
in healthy oral self-care behaviors. There is amble evidence that dental education improves oral health knowledge (e.g., Kay \& Locker, 1998; Sorrell et al., 2003). Evidence supporting the efficacy of motivational interviewing in the area of oral health is more limited, but nonetheless promising (e.g., Skaret, Weinstein, Kvale, \& Raadal, 2003; Weinstein, Harrison, \& Benton, 2004). The present study examined the effectiveness of motivational interviewing or didactic oral hygiene instruction to promote oral health values and positive oral health behaviors (e.g., brushing, flossing, preventive dental care) among pregnant women. Identification of preventative interventions that can be delivered by health care professionals (e.g., dentists, physicians, child-birth educators, midwives) would increase exposure to important oral health information among pregnant women. This study sought to further understand oral health care needs, and utilization of dental services among pregnant women, and the effectiveness of motivational interviewing and oral hygiene instruction to increase positive oral health behaviors (e.g., proper oral hygiene and needed treatment).

\section{Research Questions and Hypotheses}

The present study examined six primary dependent measures: (a) tooth brushing frequency, (b) flossing frequency, (c) dental visit frequency, (d) oral health values, (e) dental knowledge, and (f) level of Streptococcus mutans. There were four variables that were included for exploratory purposes: dental fear, oral health dysfunction, toothpaste use, and floss use.

RQ1 Do motivational interviewing and oral hygiene instruction improve oral health behaviors as demonstrated by behavior change measured by frequency of tooth brushing and flossing, and dental visit frequency, and number of salivary Streptococcus mutans?

H1. Pregnant women would have a lower number of salivary Streptococcus mutans 
and would report engaging in a greater a frequency of tooth brushing and flossing, and an increased number of dental visits after receiving motivational interviewing and oral hygiene instruction.

H2. Motivational interviewing would contribute to a greater reduction in number of salivary Streptococcus mutans and a greater increase in tooth brushing and flossing frequency, and dental visit attendance compared to oral hygiene instruction.

RQ2 Do motivational interviewing and oral hygiene instruction affect oral health values?

H1. Pregnant women would report improved oral health values after both the motivational interviewing and oral hygiene instruction interventions.

H2. Pregnant women who received motivational interviewing would report improved oral health values compared to women who received oral hygiene instruction.

RQ3 Do motivational interviewing and oral hygiene instruction affect dental knowledge?

H1. Pregnant women would demonstrate increased dental knowledge after both the motivational interviewing and oral hygiene instruction interventions.

H2. Pregnant women who received oral hygiene instruction would demonstrate increased dental knowledge compared to women who received motivational interviewing.

\section{Method}

\section{Participants}

For this study recruited 92 pregnant women were recruited and consented to participate in the study through a variety of health and social service agencies and programs (as shown in Table 1), media advertisements, and by word of mouth. Women who were more than 34 weeks 
along in their pregnancy, who were under the age of 18 , who had neurological disorders or any physical condition that prevented oral self-care, were excluded from the study. Four initial pilot participants were not considered in any analyses. In sum, seven (7.6\%) women did not complete the study; six in the motivational interviewing group and one in the oral hygiene instruction group. Of the women in the motivational interviewing group who did not complete the study, one had a miscarriage, one delivered early and chose not to complete the study, one stated she was too busy with work to complete the project, two had disconnected telephone numbers, and one failed to complete for unknown reasons. The one woman who did not complete the study in the oral hygiene instruction group delivered early and chose not to complete the study.

With regard to the 85 women (40 in the motivational interviewing group, and 45 in the oral hygiene instruction group) who completed the study, $76(89.4 \%)$ were Caucasian, $2(2.4 \%)$ were African American, 3 (3.5\%) were Asian, 1 (1.2\%) was Hispanic, 1 was (1.2\%) Pacific Islander, and $2(2.4 \%)$ identified themselves as other. Mean age and education were 27 years $(S D=5.5$ years; range: $18-40$ years $)$ and 15 years $(S D=3.5$ years; range $9-30$ years $)$, respectively. Women resided in both rural (fewer than 2,500 residents) (40\%) and urban (more than 2,500 residents) (60\%) areas of West Virginia and Pennsylvania. Most (72.9\%) participants were married (single, $14.1 \%$; living with a partner, $12.9 \%$ ), and reported an average of .68 children $(S D=.88)$. Forty-five participants $(52.9 \%)$ were expecting their first child, $27(31.8 \%)$ were expecting their second child, $8(9.4 \%)$ were expecting their third child, and $5(5.9 \%)$ were expecting their fourth child. Women were an average of 22.5 weeks along in their pregnancies $(S D=7.6$ weeks; range: $6-34$ weeks).

\section{Measures}


Dentocult SM Strip-Mutans. (Orion Diagnostica, Helsinki, Finland) (Jensen \& Bratthall, 1989). The Dentocult SM Strip-Mutans is a commercially-available dip-slide test used to estimate the number of salivary Streptococcus mutans in the saliva. Participants were asked to chew on a paraffin pellet for one minute. They then swallowed the excess saliva in their mouths and pressed the round-tipped strip against the saliva remaining on their tongue. The strip was removed through their gently closed lips and placed in a selective culture vial that was labeled with the participant's number. The vial was incubated at $35^{\circ} \mathrm{C}-37^{\circ} \mathrm{C}$ for 48 hours (Orion Diagnostica). After 48 hours elapsed, the strips were dried. The strips were visually interpreted using the manufacturer's guide after they dried and were be rated on a scale from 0 , indicating very low levels saliva Streptococcus mutans, to 3, indicating high levels of saliva Streptococcus mutans. Two criterion-trained individuals (i.e., the primary investigator and a research assistant) independently rated the samples and independent ratings were compared to determine inter-rater reliability. The Dentocult SM test has proven an effective and reliable method of measuring Streptococcus mutans in preschool children (Richardson et al., 1995; Shi, Liang, Hayashi, Yakusiji, \& Machida, 1998; Twetman \& Frostner, 1991) and pregnant women (Günay, DmochBockhorn, Günay, \& Geurtsen, 1998). Dentocult SM also has been used with individuals from a variety of ethnicities and socio-economic backgrounds (Richardson et al., 1995).

Dental Neglect Scale (DNS). (Thomson, Spencer, \& Gaughwin, 1996). The DNS is a 6item Likert-type scale designed to assess oral health values, including self-care oral health behaviors, dental care utilization, and the importance of oral health in general (Thomson \& Locker, 2000) (see Appendix A). Dental neglect is defined as the failure to engage in oral health behaviors that maintain good oral health and failure to seek dental treatment when necessary (Jamieson \& Thomson, 2002). A Dental Neglect score is obtained by summing responses to all 
six items, after reverse scoring item 3. Scores range from 6 to 30 (Thomson et al., 1996). The DNS has been demonstrated to co-vary across and within populations, and is related to dental visit behavior, such that greater oral health values are associated with a higher frequency of dental visits (McNeil, Crout, Lawrence, Shah, \& Rupert, 2004).

Oral Health Impact Profile (OHIP). (Slade \& Spencer, 1994). The OHIP, in its original form, is a 49-item Likert-type scale designed to assess self-reported dysfunction, discomfort and disability related to oral conditions, and oral health quality of life (see Appendix B). Seven subscale scores are computed, with scores ranging from 0 to 40 for each subscale. The 14-item OHIP used in the present study was developed to measure health-related quality of life, and is reported to be as valid as the OHIP-49 (Allen \& Locker, 2002). The OHIP has well documented psychometric properties.

Dental Fear Survey (DFS). (Kleinknecht, Klepac, \& Alexander, 1973). The Dental Fear Survey consists of 20 items rated on a five-point Likert-type scale (see Appendix C). Designed to comprehensively assess three components of dental fear and anxiety (i.e., behavioral avoidance, psychophysiological responsivity, and reaction to specific dental stimuli such as needles), it has an extensive background of psychometric data (e.g., McGlynn, McNeil, Gallagher, \& Vrana, 1987).

Tooth brushing, flossing, and dental visit behavior (TFD). (CDC, 1993). Wording from the National Health and Nutrition Examination Survey (NHANES) (CDC, 1993) was used to measure tooth brushing frequency, flossing frequency, and dental visit frequency among participants at the time of assessment (see Appendix D). For example, "How long ago was your last visit to a dentist or a dental hygienist?" 
Home-based oral hygiene assessment. (McGylnn, LeCompte, Thomas, Corts, \& Melamed, 1987). Participants were given a toothbrush, a tube of fluoridated toothpaste, and a container of floss (each coded) for their use at home after the intervention session. They were asked to keep a daily log of oral hygiene (e.g., when they brush their teeth). Participants were asked not to share the oral health products, and to bring these items and the daily log to the follow-up session. The tube of toothpaste was weighed at follow-up to measure how much toothpaste was used. The container of floss was unraveled and measured to determine how much floss was used. Participants were provided with a new toothbrush, tube of toothpaste, and container of floss at the follow-up appointment.

Dental knowledge inventory. (Sorrell et al., 2003). The dental knowledge inventory consists of 10 questions used to measure an individual's general oral health and oral hygiene knowledge during pregnancy (see Appendix E). Women were asked to complete this inventory before the intervention, after the intervention, and at the follow-up appointment.

Hollingshead Four-Factor Index of Social Status (HI). (Hollingshead \& Redlich, 1958). The Hollingshead Four-Factor Index of Social Status is based on education, occupation, sex and marital status. Information to calculate this index was collected through an interview. Education is based on the level of educational attainment and also is scored on a 7-point scale. Occupation is identified based on a listing of occupations and is scored on a 9-point scale. Scores on both scales are weighted (occupation is given a weight of 5 and education is given a weight of 3 ) and are summed to determine an overall $\mathrm{HI}$ score. Weighted and summed $\mathrm{HI}$ scores range from 8 to 66. A higher HI score indicates a higher social class whereas a lower HI score indicates a lower social class. Adequate inter-rater reliability and validity of the $\mathrm{HI}$ have been demonstrated (Cirino et al., 2002). 
Readiness to change ruler. (Miller \& Rollnick, 2002). The participant's stage of change was measured using the readiness to change ruler described by Miller and colleagues, which assesses the importance and the confidence associated with behavior change on a scale of 0 (i.e., not at all important, or not at all confident) to 10 (i.e., extremely important, or extremely confident) (Miller \& Rollnick, 2002), before and after the intervention and at follow-up.

\section{Procedure}

During an initial telephone, or in-person contact, information about the study was provided, and women were screened for exclusion criteria. If the participant wanted to participate in the study, she was randomly assigned using sealed envelopes previously prepared by the investigator to one of two intervention conditions: motivational interviewing or oral hygiene instruction. A date and time was arranged to complete the intervention. Informed consent was obtained from women who agreed to participate, including consent to audiotape the motivational interviewing and oral hygiene instruction intervention sessions. Demographic and health information, such as age, educational attainment, number of prior pregnancies/births, number of children in the household, martial/relationship status, employment status, occupation, number of adults in household, were collected through an interview. Participants were asked to provide a saliva sample, and complete the Dental Neglect Survey, the Oral Health Impact Profile, and the Dental Fear Survey before the intervention and at a follow-up session. They also were asked to complete the Dental Knowledge Inventory before the intervention, after the intervention, and during the follow-up session. The participant's stage of change was measured using the readiness to change ruler described by Miller and colleagues, which assesses the importance and the confidence associated with behavior change on a scale of 0 (i.e., not at all 
important, or not at all confident) to 10 (i.e., extremely important, or extremely confident)

(Miller \& Rollnick, 2002), before and after the intervention and at follow-up.

Motivational interviewing. Participants in the motivational interviewing condition

received a 30 minute ( \pm 5 minutes) intervention provided by the primary investigator, who has received Motivational Interviewing Network of Trainers (MINT) certified training in MI. A detailed protocol was developed and used to deliver MI. The participant's oral health wishes were explored and a menu of oral health care options was provided (Weinstein, 2002; Weinstein, Harrison, \& Benton, 2004). The oral health menu of preventive care options was tailored to each participant and included options such as nutrition improvement (e.g., limit snacking between meals), increased brushing and flossing, and preventive dental care. The participant was encouraged to consider both small (e.g., increase brushing behavior) and large (e.g., increase dental care visits) behavior changes (Miller \& Rollnick, 2002). If desired by the participant, a change plan was completed detailing the participant's behavior change goals, why making those changes were important to them, and how they planned to obtain their goals. Participants were given a copy of the change plan to take home. A summary of the goals chosen by participants in this study is provided in Table 2 .

Oral hygiene instruction. Participants in the oral health instruction condition received 30 minutes ( \pm 5 minutes) of oral hygiene instruction provided by a certified dental hygienist, who was trained to deliver an oral hygiene instruction presentation using a detailed protocol, developed by the primary investigator in junction with a certified dental hygienist. All oral hygiene instruction sessions included education about proper teeth brushing and flossing techniques utilizing teeth models and visual aids (i.e., flipbook), education about the importance of oral health care (e.g., positive of good oral hygiene and the negatives about poor oral 
hygiene), dietary advice, and general recommendations about how to improve oral health care at home (e.g., brushing teeth or flossing).

Follow-up phone calls. Two follow-up phone calls were conducted, at two weeks and one month after the initial session, during which oral health behavior were assessed (Weinstein, Harrison, \& Benton, 2004). Each phone call lasted about 10 minutes. For those in the motivational interviewing condition, the follow up phone calls were conducted by the primary investigator, and served as enhancement sessions, during which participants were reminded of their previous goals and new barriers to their goal attainment were assessed and addressed. For participants in the oral hygiene instruction group, the follow-up phone calls were conducted by the dental hygienist, and served as a reminder about the oral health information and recommendations presented during the oral hygiene instruction session. At the conclusion of the one month follow-up phone call, participants were asked to return for an in-person appointment to provide another saliva sample and to complete the Dental Neglect Survey, the Oral Health Impact Profile, the Dental Fear Survey, and the Dental Knowledge Inventory.

Compensation. Participants received a baby gift after the initial session, and $\$ 50$ for completing the both the initial intervention session, two follow-up phone calls and a follow-up assessment session. Participants also received a toothbrush, a tube of toothpaste, a container of floss, a minute sand timer, a children's tooth-themed book, instructions regarding proper tooth brushing and flossing techniques, and a pamphlet discussing oral health during pregnancy.

\section{Pilot Study}

Four women participated in the pilot study to evaluate materials and procedures. Informed consent was obtained from women who agreed to participate, including consent to audiotape the session. Demographic and health information, such as age, educational attainment, 
number of prior pregnancies/births, number of children in the household, martial/relationship status, employment status, occupation, and number of adults in household, were collected through an interview. Participants were asked to provide a saliva sample, and complete the Dental Neglect Survey, the Oral Health Impact Profile, and the Dental Fear Survey. They also were asked to complete the Dental Knowledge Inventory before and after a 45-minute motivational interviewing intervention. The participant's stage of change was measured using the readiness to change ruler described by Miller and colleagues, which assesses the importance and the confidence associated with behavior change on a scale of 0 (i.e., not at all important, or not at all confident) to 10 (i.e., extremely important, or extremely confident) (Miller \& Rollnick, 2002), before and after the intervention. Pilot data were not included in any analyses. Several changes were made based on the results of the pilot study. Specifically, follow-up appointments were scheduled during the initial meeting instead of during a follow-up phone call and interventions were decreased from 45 minutes to 30 minutes.

\section{Treatment Integrity}

The motivational interviewing and oral hygiene instruction sessions were audiotaped to ensure treatment integrity. Approximately $10 \%$ of the motivational interviewing and the oral hygiene instruction sessions were independently reviewed. The motivational interviewing sessions were reviewed by Daniel W. McNeil, Ph.D and the oral hygiene instruction sessions were reviewed by Marcia Gladwin, R.D.H., Ed.D.

A standardized checklist for the evaluation of motivational interviewing and oral hygiene instruction sessions was used by reviewers. Motivational interviewing treatment integrity was assessed using the Motivational Interviewing Treatment Integrity (MITI) code Version 2.0 developed by Moyers, Martin, Manuel, and Miller (2005) to assess 10 elements of MI. MITI is 
considered appropriate to assess treatment integrity, provide feedback, and improve training based on the behavior of the clinician. The MITI coder used a standardized checklist to provide global scores on a 7-point Likert scale characterizing the interaction between the investigator and the participant based on empathy, MI Spirit, and didactic instruction, and to count particular behaviors consistent with MI (i.e., asking permission, affirmations, providing support, and emphasizing control). A similar checklist was developed to assess oral hygiene instruction sessions. The reviewer used the checklist to provide global scores on a 7-point Likert scale characterizing the interaction between the investigator and the participant based on empathy, OHI Spirit, and didactic instruction, and to count particular behaviors consistent with OHI (i.e., giving advice/directing, giving information, and providing an opinion). Other behaviors, including the use of open-ended and closed-ended questions, simple and complex reflections, also were counted.

A series of $t$-tests were used to compare the differences in global ratings and behavior counts of MI and OHI sessions. Similar global ratings of empathy were found in both the MI ( $M$ $=6.75, S D=.5)$ and $\mathrm{OHI}(M=6.25, S D=.5)$ interventions, $t(6)=1.41, p=.21$. MI was found to have significantly higher spirit ratings $(M=6.5, S D=.58)$ than $\mathrm{OHI}(M=4.5, S D=.58), t(6)=$ 4.90, $p<.01$. Higher didactic expression ratings were found in $\mathrm{OHI}$ sessions $(M=6, S D=.00)$ than in MI sessions $(M=1, S D=.00)$.

OHI sessions were found to be adherent to behaviors consistent with OHI. More advice or direction was given to participants in the $\mathrm{OHI}$ condition $(M=33, S D=14.31)$ than in the MI condition $(M=2.75, S D=1.71), t(6)=-4.20, p<.01$. OHI sessions consisted of more giving information $(M=70, S D=16.55)$ compared to MI sessions $(M=15.75, S D=3.86), t(6)=-6.38, p$ 
$<.01$. Counts of providing an opinion were similar in OHI sessions $(M=3.75, S D=3.78)$ and in MI sessions $(M=3.75, S D=2.99), t(6)=0, p=1.00$; however, this finding was not significant.

MI sessions were found to be adherent to behaviors consistent with MI. Asking permission occurred more often in MI sessions $(M=2.25, S D=.96)$ than in $\mathrm{OHI}$ sessions $(M=0$, $S D=.00), t(6)=4.7, p<.01$. More affirmations were provided in MI sessions $(M=23.25, S D$ $=9.54)$ than in OHI sessions $(M=7.25, S D=2.63), t(6)=3.24, p=.02$. More instances of providing support occurred in the MI sessions $(M=3, S D=1.83)$ than in the OHI sessions $(M=$ $1, S D=1.55), t(6)=1.85, p=.11$; however, this finding was not significant. Emphasizing control occurred more often in the OHI sessions $(M=1.50, S D=1)$ than in the MI sessions $(M=$ $.5, S D=.58), t(6)=-1.73, p=.13$, however, this finding was not significant.

Questions and reflections also were counted in both MI and OHI sessions. MI used more open-ended questions $(M=40.25, S D=23.33)$ than $\mathrm{OHI}(M=4.75, S D=4.92), t(6)=2.98, p=$ .03. Similarly, MI used more closed-ended questions $(M=23.5, S D=9.15)$ than $\mathrm{OHI}$ sessions $(M=19.25, S D=8.62), t(6)=.68, p=.52$; however, this finding was not significant. MI used more simple reflections $(M=15.25, S D=4.57)$ than $\mathrm{OHI}(M=1.25, S D=1.26), t(6)=5.9, p<$ .01. Similarly, MI used more complex reflections $(M=40.5, S D=6.46)$ than $\mathrm{OHI}(M=.25, S D$ $=.50), t(6)=12.43, p<.01$. Finally, both MI and OHI sessions were found to be consistent with the detailed protocols.

\section{Results}

The hypotheses of this study were addressed by assessing oral health care behaviors and oral health values in 85 pregnant women using a 2 (intervention group: motivational interviewing or oral hygiene education) X 2 (time of measurement: pre-test vs. post-test) mixed design with random assignment. Data analysis was conducted in six phases: (a) preliminary 
examination of data, (b) exploration of the psychometric properties of the primary dependent variable instruments, (c) examination of groups at baseline, (d) group comparisons, (e) exploratory analyses, and (f) correlational analyses. There were six primary dependent variables: (a) tooth brushing frequency, (b) flossing frequency, (c) dental visit frequency, (d) oral health values, as measured by the DNS, (e) dental knowledge, as measured by the DKI, and (f) level of Streptococcus mutans, as measured by the Dentocult. There were four variables that were included for exploratory purposes: (a) dental fear, as measured by the DFS, (b) oral health quality of life, as measured by the OHIP-14, (c) amount of toothpaste used, and (d) amount of floss used. Finally, ten variables were included to describe the sample or to serve as possible covariates: (a) importance of change at Time 1 and Time 2, (b) confidence in change at Time 1 and Time 2, (c) age, (d) socio-economic status, as measured by the Hollingshead Four-Factor Index, (e) marital status, (f) number of children, (g) months of pregnancy, and (h) weeks of pregnancy.

\section{Preliminary Examination of Data}

All measures were independently entered and $10 \%$ of the data was independently checked for accuracy. Patterns of missing values were examined and less than $5 \%$ of data were missing for any participant; moreover, none of the participants were missing any of the primary dependent variables (see Table 3). The assumptions of a mixed design ANOVA, including homogeneity of variance and a normal distribution, were verified statistically and by inspecting graphical representations of the data (Osborne, 2002) for the primary dependent variables and exploratory variables at the initial meeting (see Table 4 for skewness and kurtosis values) and at follow-up (see Table 5 for skewness and kurtosis values).

Exploration of the Psychometric Properties of the Primary Dependent Variable Instruments 
Psychometric analyses were conducted to ensure that the instruments on which the primary dependent variables are based were internally consistent and to determine if resulting scores were consistent with that of published norms. The OHIP and the DFS, administered during the initial meeting with women, were found to have good internal consistency. The OHIP had a Cronbach's alpha coefficient of .85 and the DFS had a Cronbach's alpha coefficient of .95. The DNS was found to have adequate internal consistency with a Cronbach's alpha coefficient of .59. Interesting, when item 5 of the DNS ("I control snacking between meals as well as I should") was excluded the DNS, had good internal consistency with a Cronbach's alpha coefficient of .68. The measures all had good test-retest reliability (see Table 6 for correlations). Examination of Groups at Baseline

The motivational interviewing and oral hygiene instruction groups were compared using a series of $t$ tests. Mean age, socio-economic status, marital status, number of children, weeks of pregnancy, and level of Streptococcus mutans were not statistically different among women in the motivational interviewing and oral hygiene instruction groups. Similarly, no statistically significant differences in importance of change and confidence in change ratings were observed. Responses on the self-report measures indicated that dental knowledge, oral health dysfunction or impairment, oral health values, and dental fear were statistically equivalent among the groups. Similarly, self-reported flossing frequency and dental visit behaviors did not differ between groups. Tooth brushing frequency, however, was significantly higher in the MI group $(M=4.8$, $S D=.41)$ than in the OHI group $(M=4.5, S D=.84), F(1,83)=3.4, p=.05$, partial eta squared $=$ .05 (see Table 7 for means and standard deviations and Table 8 for $t$-test data).

\section{Group Comparisons}


A series of eight two-way mixed design ANOVAs were conducted to determine if the mean scores on primary dependent measures (i.e., tooth brushing, flossing, dental visit frequency, general dental knowledge, dental knowledge related to pregnancy, and dental knowledge related to dental hygiene, as measured by the DKI, oral health values as measured by the DNS, and level of Streptococcus mutans, as measured by the Dentocult) differed significantly by intervention and at Time 1 (prior to the intervention) and Time 2 (at follow-up), and to determine if the interaction of the variables was statistically significant at the .05 level. Tukey post-hoc comparisons were performed as necessary. Finally, ten variables were explored as possible covariates: (a) importance of change at Time 1 and Time 2, (b) confidence in change at Time 1 and Time 2, (c) age, (d) socio-economic status, as measured by the Hollingshead FourFactor Index, (e) marital status, (f) number of children, (g) months of pregnancy, and (h) weeks of pregnancy.

Tooth brushing. A two-way mixed design ANOVA was conducted to compare tooth brushing frequency by intervention and at Time 1 (prior to the intervention) and Time 2 (at follow-up). The interaction effect between time and intervention was statistically significant, $F(1,83)=3.98, p=.05$, partial eta squared $=.05$. The main effect for intervention was not statistically significant, $F(1,83)=2.50, p=.12$. There was a statistically significant main effect for time, $F(1,83)=6.00, p=.02$, partial eta squared $=.07$. Mean tooth brushing frequency was higher at follow-up than before the interventions in both conditions. Tukey post-hoc comparisons revealed that tooth brushing frequency was significantly higher in the MI group at Time $1(M=4.8, S D=.41)$ than in the OHI group $(M=4.51, S D=.84), p=.01$. Tooth brushing frequency increased significantly from Time $1(M=4.51, S D=.84)$ to Time $2(M=4.76, S D$ $=.48$ ) in the OHI group, $p=.05$; however, tooth brushing frequency did not increase significantly 
from Time $1(M=4.80, S D=.41)$ to Time $2(M=4.82, S D=.47)$ in the MI group (see Figure 1$)$. The covariate, importance of change at Time 1 (prior to the intervention), was significantly related to tooth brushing frequency, $F(1,72)=14.59, p<.01$, partial eta squared $=.17$. Higher importance of change at Time 1 was associated with higher tooth brushing frequency at Time 1 , $t(72)=3.09, p<.01$, partial eta squared $=.12$, and at Time $2, t(72)=3.88, p<.01$, partial eta squared $=.17$

Flossing. A two-way mixed design ANOVA was conducted to compare flossing frequency by intervention and at Time 1 (prior to the intervention) and Time 2 (at follow-up). The interaction effect between time and intervention was not statistically significant, $F(1,83)=$ $.04, p=.85$. The main effect for intervention was not statistically significant, $F(1,83)=3.30, p$ $=.07$. There was a statistically significant main effect for time, $F(1,83)=10.28, p<.001$, partial eta squared $=.11$. Flossing frequency was significantly higher at Time $2(M=3.2, S D$ $=.98)$ than at Time $1(M=2.8, S D=1.06)$ (see Figure 2 , which shows the means by intervention and time for illustration purposes, as only the main effect for time was significant). The covariate, SES, was significantly related to flossing frequency, $F(1,72)=4.99, p=.03$, partial eta squared $=.07$. Lower SES was associated with higher flossing frequency at follow-up, $t(72)=$ $-2.23, p=.03$, partial eta squared $=.07$

Dental visit behavior. A two-way mixed design ANOVA was conducted to compare dental visit behavior by intervention and at Time 1 (prior to the intervention) and Time 2 (at follow-up). The interaction effect between time and intervention was not statistically significant, $F(1,83)=.38, p=.54$. The main effect for intervention was not statistically significant, $F(1,83)$ $=3.69, p=.06$. Similarly, a statistically significant main effect for time was not observed, $F(1$, $83)=.06, p=.81$. Mean dental visit behavior did not differ significantly in the MI group from 
Time $1(M=2.8, S D=1.4)$ to Time $2(M=2.7, S D=1.2)$ nor in the OHI group from Time $1(M=$ 3.1, $S D=1.3)$ to Time $2(M=3.2, S D=1.3)$ (see Figure 3$)$. The covariate, confidence in change at Time 1 (prior to the intervention), was significantly related to dental visit frequency, $F(1,72)$ $=7.98, p<.01$, partial eta squared $=.10$. Confidence in change at Time 2 (after the intervention) also was significantly related to dental visit frequency, $F(1,72)=5.12, p=.03$, partial eta squared $=.07$. Higher confidence in change at Time 1 was associated with lower dental visit frequency at follow-up, $t(72)=-2.86, p<.01$, partial eta squared $=.10$ whereas higher confidence in change at Time 2 was associated with higher dental visit frequency at follow-up, $t(72)=2.10$, $p=.04$, partial eta squared $=.06$.

Oral health values. A two-way mixed design ANOVA was conducted to compare oral health values, as measured by the DNS scores, by intervention and at Time 1 (prior to the intervention) and Time 2 (at follow-up). The interaction effect between time and intervention was statistically significant, $F(1,83)=7.36, p=.008$, partial eta squared $=.08$. The main effect for intervention was not statistically significant, $F(1,83)=.94, p=.76$. There was a statistically significant main effect for time, $F(1,83)=12.97, p=.001$, partial eta squared $=.14$. Tukey posthoc comparisons revealed that mean DNS scores increased significantly from Time $1(M=$ $22.89, S D=3.8)$ to Time $2(M=24.67, S D=2.7)$ in the OHI group, $p=.01$; however, a significant increase in mean DNS scores from Time $1(M=23.5, S D=3.42)$ to Time $2(M=23.7$, $S D=3.12$ ) was not observed in the MI group (see Figure 4). The covariate, importance of change at Time 1 (prior to the intervention), was significantly related to oral health values, $F(1$, $72)=4.64, p=.04$, partial eta squared $=.06$. Confidence in change at Time 2 (after the intervention) also was significantly related to oral health values, $F(1,72)=5.72, p=.02$, partial eta squared $=.07$. Higher confidence in change at Time 1 (before the intervention) was 
associated with higher oral health values at Time $1, t(72)=2.20, p=.03$, partial eta squared $=$ .16. Similarly, higher confidence in change at Time 2 (after the intervention) was associated with higher oral health values at follow-up, $t(72)=3.03, p<.01$, partial eta squared $=.11$. Higher importance of change at Time 1 was associated with higher oral health values at followup, $t(72)=2.02, p=.05$, partial eta squared $=.05$.

Dental knowledge. Three two-way mixed design ANOVAs were conducted to compare dental knowledge, as measured by the DKI total score, dental knowledge related to dental hygiene score, and dental knowledge related to pregnancy score, by intervention and at Time 1 (prior to the intervention), Time 2 (immediately after the intervention), and Time 3 (at followup). The interaction effect between time and intervention on the DKI total score was statistically significant, $F(1,83)=14.02, p<.01$, partial eta squared $=.15$. There was a statistically significant main effect for intervention, $F(1,83)=8.76, p<.01$, partial eta squared $=.10$. A statistically significant main effect for time on the DKI total score was observed, $F(2,166)=$ 32.63, $p<.001$, partial eta squared $=.29$. Tukey post-hoc comparisons revealed that DKI total scores were significantly higher in the OHI group at Time $2(M=7.09, S D=1.35)$ than in the MI group $(M=5.55, S D=1.34)$. Similarly, DKI total scores were significantly higher in the OHI group at Time $3(M=6.56, S D=1.75)$ than in the MI group $(M=5.62, S D=1.39)$. DKI total scores increased significantly from Time $1(M=5.00, S D=1.45)$ to Time $2(M=7.09, S D=1.35)$ in the OHI group, $p=.01$. Similarly, DKI total scores increased significantly from Time $1(M=$ $5.00, S D=1.45)$ to Time $3(M=6.56, S D=1.75)$ in the OHI group, $p=.01$ (see Figure 5).

The covariate, confidence in change at Time 1 (prior to the intervention), was significantly related to dental knowledge total score, $F(1,72)=4.07, p=.05$, partial eta squared $=.05$. SES also was significantly related to dental knowledge total score, $F(1,72)=3.87, p=$ 
.05 , partial eta squared $=.05$. Finally, marital status was significantly related to dental knowledge total score, $F(1,72)=7.82, p<.01$, partial eta squared $=.10$. Higher confidence in change at Time 1 (before the intervention) was associated with higher dental knowledge total score at Time 1 (before the intervention), $t(72)=1.97, p=.05$, partial eta squared $=.05$. Being married was associated with higher dental knowledge total score at Time $1, t(72)=1.98, p=.05$, partial eta squared $=.05$, at Time $2, t(72)=2.58, p=.02$, partial eta squared $=.08$, and at Time 3 , $t(72)=2.09, p=.04$, partial eta squared $=.06$.

The interaction effect between time and intervention on dental knowledge associated with dental hygiene items was statistically significant, $F(1,83)=31.81, p<.01$, partial eta squared $=$ .27. A significant main effect for intervention was observed, $F(1,83)=26.58, p<.01$, partial eta squared $=.24$. There was a statistically significant main effect for time on the DKI dental hygiene score, $F(1,83)=26.15, p<.001$, partial eta squared $=.24$. Tukey post-hoc comparisons revealed that DKI dental hygiene scores were significantly higher at Time 2 in the OHI group ( $M$ $=3.84, S D=.56)$ than in the MI group $(M=2.22, S D=1.07), p=.01$. Further, DKI dental hygiene scores were significantly higher at Time 3 in the OHI group $(M=3.33, S D=.95)$ than in the MI group $(M=2.4, S D=.95), p=.01$. DKI dental hygiene scores increased significantly from Time $1(M=2.38, S D=.92)$ to Time $3(M=3.33, S D=.95)$ in the OHI group, $p=.01$. DKI dental hygiene scores, however, decreased significantly from Time $2(M=2.38, S D=.92)$ to Time $3(M=3.33, S D=.95)$ in the OHI group, $p=.05$ (see Figure 6).

The covariate, confidence in change at Time 1 (prior to the intervention), was significantly related to dental knowledge associated with dental hygiene, $F(1,72)=4.53, p<.01$, partial eta squared $=.10$. Higher confidence in change at Time 1 was associated with higher 
dental knowledge associated with dental hygiene at Time $1, t(72)=2.79, p<.01$, partial eta squared $=.10$, and at Time 2, $t(72)=2.62, p=.01$, partial eta squared $=.09$.

The interaction effect between time and intervention on dental knowledge associated with pregnancy items was not statistically significant, $F(1,83)=.40, p=.67$. A significant main effect for intervention was not observed, $F(1,83)=.36, p=.55$. However, there was a statistically significant main effect for time, $F(1,83)=14.83, p<.001$, partial eta squared $=.15$. Tukey post-hoc comparisons indicated that DKI pregnancy scores increased significantly from Time 1 $(M=2.7, S D=.87)$ to Time $2(M=3.3, S D=.91), p=.05$. DKI pregnancy scores also increased significantly from Time 1 to Time $3(M=3.2, S D=1.1), p=.05$. Scores were not different between Time 2 and Time 3 (see Figure 7 which shows the means by intervention and time for illustration purposes, as only the main effect for time was significant).

The covariate, marital status, was significantly related to dental knowledge associated with pregnancy, $F(1,72)=10.68, p<.01$, partial eta squared $=.13$. Being married was associated with higher dental knowledge associated with pregnancy at Time $1, t(72)=2.68, p<$ .01 , partial eta squared $=.09$, at Time $2, t(72)=2.12, p=.04$, partial eta squared $=.06$, and Time $3, t(72)=2.56, p=.01$, partial eta squared $=.08$.

Streptococcus mutans. A two-way mixed design ANOVA was conducted to compare mean level of Streptococcus mutans, as measured by the Dentocult, by intervention and at Time 1 (prior to the intervention) and Time 2 (at follow-up). The interaction effect between time and intervention was not statistically significant, $F(1,83)=.27, p=.60$, partial eta squared $=.003$. A significant main effect for intervention was not observed, $F(1,83)=.02, p=.89$. Further, the main effect for time was not statistically significant, $F(1,83)=.27, p=.60$, partial eta squared $=$ 
.003. Mean Dentocult scores did not differ significantly by intervention nor time (see Figure 8). None of the covariates were significantly related to level of Streptococcus mutans. Exploratory Analyses

Exploratory analyses were conducted using a series of two-way mixed design ANOVAs to determine if the differences between the motivational interviewing and the oral hygiene instruction groups on the OHIP-14, the DFS, amount of toothpaste used, and amount of floss used were statistically significant at the .05 level. Tukey post-hoc comparisons were conducted as necessary.

Oral health quality of life. A two-way mixed design ANOVA was conducted to compare oral health dysfunction, as measured by the OHIP-14, by intervention and at Time 1 (prior to the intervention) and Time 2 (at follow-up). The interaction effect between time and intervention was not statistically significant, $F(1,83)=.03, p=.87$. A significant main effect for intervention was not observed, $F(1,83)=.43, p=.52$. Further, the main effect for time was not statistically significant, $F(1,83)=.03, p=.87$. Mean OHIP-14 scores did not differ significantly by intervention nor time (see Figure 9). The covariate, confidence in change at Time 1, was significantly related to oral health quality of life, $F(1,72)=9.17, p<.01$, partial eta squared $=$ .11. Higher confidence in change at Time 1 was associated with lower OHIP-14 scores at Time $1, t(72)=-3.62, p<.01$, partial eta squared $=.15$.

Dental fear. A two-way mixed design ANOVA was conducted to compare dental fear, as measured by the DFS, by intervention and at Time 1 (prior to the intervention) and Time 2 (at follow-up). The interaction effect between time and intervention was not statistically significant, $F(1,83)=.004, p=.95$. The main effect for intervention was not significant, $F(1,83)=.20, p=$ .66. Further, the main effect for time was not statistically significant, $F(1,83)=.28, p=.60$. 
Mean DFS scores did not differ significantly by intervention or time (see Figure 10). The covariate, marital status, was significantly related to dental fear, $F(1,72)=6.27, p=.02$, partial eta squared $=.08$. Number of children also was significantly related to dental fear, $F(1,72)=$ $5.26, p=.03$, partial eta squared $=.07$. Fewer children was associated with greater dental fear at Time $1, t(72)=-2.51, p=.01$, partial eta squared $=.08$. Being married was associated with less dental fear at Time $2, t(72)=-3.04, p<.01$, partial eta squared $=.11$.

Toothpaste use. A two-way mixed design ANOVA was conducted to compare amount of toothpaste used, as measured by toothpaste weight in grams, by intervention and at Time 1 (prior to the intervention) and Time 2 (at follow-up). The interaction effect between time and intervention was not statistically significant, $F(1,74)=2.73, p=.10$. A main effect for intervention was not statistically significant, $F(1,74)=2.73, p=.10$. A main effect for time was statistically significant, $F(1,74)=242.97, p<.01$, partial eta squared $=.77$. Toothpaste weight decreased significantly from Time $1(M=237.0, S D=0.0)$ to Time $2(M=170.9, S D=37.6), p$ $=.01$ (see Figure 11 which shows the means by intervention and time for illustration purposes, as only the main effect for time was significant). The covariate, marital status, was significantly related to amount of toothpaste used, $F(1,63)=4.83, p=.03$, partial eta squared $=.07$. Age also was significantly associated with amount of toothpaste used, $F(1,63)=8.28, p<.01$, partial eta squared $=.12$. Younger age was associated with greater toothpaste used, $t(63)=-2.88, p<.01$, partial eta squared $=.12$. Being married was associated with greater toothpaste used, $t(63)=$ $2.20, p=.03$, partial eta squared $=.07$.

Floss use. A two-way mixed design ANOVA was conducted to compare amount of floss used, as measured by floss length in inches, by intervention and at Time 1 (prior to the intervention) and Time 2 (at follow-up). The interaction effect between time and intervention 
was not statistically significant, $F(1,64)=.10, p=.76$. A main effect for intervention was not statistically significant, $F(1,64)=242.97, p<.01$. The main effect for time was statistically significant, $F(1,64)=94.33, p<.01$, partial eta squared $=.60$. Floss length decreased significantly from Time $1(M=1980.0, S D=0.0)$ to Time $2(M=1523.3, S D=379.6), p=.01$ (see Figure 12, which shows the means by intervention and time for illustration purposes, as only the main effect for time was significant). None of the covariates were significantly related to floss use.

\section{Correlational Analyses}

Correlational analyses were performed using Pearson product-moment correlation coefficients to investigate the relationship among demographic variables (e.g., marital status) with the dependent measures (e.g., Dental Neglect Scale score, self-reported tooth brushing frequency, self-reported flossing frequency) in the motivational interviewing and the oral hygiene instruction groups. Several variables were identified to significantly correlate with dependent variables: (a) socio-economic status, as measured by the Hollingshead Four-Factor Index, (b) age, (c) number of children, (d) education (e) marital status, and (f) importance of change, and (g) confidence in change (see Table 9).

\section{Discussion}

The primary purpose of the present study was to explore the effectiveness of motivational interviewing and didactic oral hygiene instruction to increase positive oral health behaviors (i.e., tooth brushing frequency, flossing frequency, and dental visit frequency) and to reduce the number of salivary Streptococcus mutans among pregnant women. Further, the effects of motivational interviewing and oral hygiene instruction on oral health values and dental knowledge were explored. The hypotheses of this study were addressed by assessing tooth 
brushing frequency, flossing frequency, dental visit frequency, Streptococcus mutans level, oral health values, dental knowledge in 85 pregnant women using a 2 (intervention group: motivational interviewing or oral hygiene instruction) X 2 (time of measurement: prior to the intervention vs. follow-up) mixed design with random assignment. Dental fear, oral health quality of life, toothpaste use, and floss use also were measured.

\section{Review of Hypotheses and Findings}

It was hypothesized that pregnant women would have a lower number of salivary Streptococcus mutans and would report engaging in a greater a frequency of tooth brushing and flossing, and an increased number of dental visits at follow-up after receiving motivational interviewing and oral hygiene instruction. Further, it was suggested that motivational interviewing would contribute to a greater reduction in number of salivary Streptococcus mutans and a greater increase in tooth brushing and flossing frequency, and dental visit attendance than oral hygiene instruction. However, women who received OHI demonstrated a significant increase in tooth brushing frequency whereas women who received MI did not. Flossing frequency differed by time but not intervention, such that flossing frequency was higher at follow-up than at baseline. Dental visit frequency and Streptococcus mutans levels, however, did not differ by intervention or time.

Pregnant women were expected to report improved oral health values at follow-up after both the motivational interviewing and oral hygiene instruction interventions. Further, it was indicated that pregnant women who received motivational interviewing would report improved oral health values compared to women who received oral hygiene instruction. However, women who received OHI reported higher oral health values, as measured by the DNS, at follow-up than women who received MI. 
It was suggested that pregnant women would demonstrate increased dental knowledge after both the motivational interviewing and oral hygiene instruction interventions. Further, pregnant women who received oral hygiene instruction were expected to demonstrate increased dental knowledge compared to women who receive motivational interviewing. Women who received $\mathrm{OHI}$ exhibited higher total dental knowledge and dental knowledge related to dental hygiene scores after the intervention and at follow-up than women who received MI. Further, a significant increase in total dental knowledge and dental knowledge related to dental hygiene was noted in the OHI group. Dental knowledge related to pregnancy increased significantly from before the intervention to after the intervention in both the OHI and MI groups.

Dental fear, oral health dysfunction, toothpaste use, floss use, importance of change, and confidence in change, also were explored among participants. Dental fear and oral health dysfunction did not differ by intervention or time. Toothpaste use and floss use did not differ significantly by intervention. Interestingly, importance of change and confidence in change emerged as important covariates in this study. Importance of change was significantly related to tooth brushing frequency and oral health values. Confidence in change was significantly related to dental visit frequency, oral health values, dental knowledge total score, dental knowledge associated with dental hygiene, and oral health quality of life. Importance of change was equated by Miller \& Rollnick (2002) as "the extent to which the person wants, desires, or will change" (p.10) whereas confidence in change refers to the belief and confidence that one can change. Miller \& Rollnick (2002) warn that although it would seem that high importance of change and high confidence in change would translate to behavior change, this is not always the case. Priorities often play a role in the decision to engage in behavior change by determining if one is ready to change. 
Association of Study with Previous Research and Limitations

The current study utilized a study design similar to Weinstein et al. (2004), but with several differences. As a review, Weinstein et al. (2004) compared the effects of MI and traditional dental health education on prevention of caries (i.e., cavities) in children of South Asian immigrants at high risk of developing early childhood caries in a South Asian, Punjabispeaking, community in Surrey, British Columbia. Mothers in the dental health education control group were given a pamphlet and viewed an 11-minute educational video. Women in the MI group received the same pamphlet and viewed the same video, but also received a 45-minute MI session, two brief follow-up phone calls (two weeks and one month after initial contact), four phone calls up to six months after initial contact, and two postcard reminders.

Similar to Weinstein et al. (2004), the current study randomly assigned women to either a dental health education (in this study, OHI) group or a MI group. A detailed research protocol was used in both studies. Women in the MI group in the Weinstein et al. (2004) study received a 45-minute MI intervention whereas women in the present study received a 30-minute MI intervention. Women in both studies were provided with a menu of oral health care options (Weinstein, 2002). Women in the OHI group in the current study received an intervention of equal length as the MI group and the intervention was provided in person, whereas in the Weinstein et al. study women in the education group viewed an 11-minute video and were given a pamphlet. Both studies reviewed audiotapes to ensure consistent MI delivery. Oral health outcomes were measured through self-report and objective measures in both studies. In Weinstein et al. women completed measures about oral health-related behavior and their children were given a dental exam whereas in the current study women completed measures about their oral health behavior and were asked to provide a saliva sample. Like Weinstein et al. (2004), the 
present study utilized two brief follow-up phone calls (also two weeks and one month after initial contact); this intervention, however, was provided to both the $\mathrm{OHI}$ and $\mathrm{MI}$ groups in the current study. Weinstein et al. also used reminder postcards and four additional follow-up phone calls which the present study did not utilize. The current study followed up with women six weeks after initial contact whereas Weinstein et al. completed follow-up evaluations after one-year.

At one-year follow-up Weinstein et al. (2004) found that children whose mothers were in the MI group showed significantly fewer carious surfaces than children whose mothers were in the control group. It is possible that additional, continued contact with women, a longer MI session, and a longer time period during which women could make oral health changes and see the effects of those changes might have contributed to the findings of the Weinstein et al. study.

Several limitations in the current study may have contributed to the unpredicted results. First, it is possible that the length of interventions was too short at 30 minutes. A longer session might have been more effective in increasing importance of change and confidence in change which may have resulted in greater behavior change. Further, additional focus on readjusting priorities might have contributed to additional behavior change among pregnant women who were already attempting to find balance among various life priorities. Second, although our sample size exceeded the number of participants recommended by a power analysis, it is possible that additional participants would have allowed us to better evaluate our primary dependent variables. Third, a ceiling effect was noted in that many participants had little room to improve oral health behaviors. Finally, because the current study only used one treatment provider per intervention, our ability to determine how personality, interpersonal skills, and other personal factors contributed to the effects of the interventions was limited.

\section{Conclusions and Future Directions}


The current study provides support for the use of OHI to increase some positive oral health behaviors (e.g., tooth brushing), oral health values, and dental knowledge among pregnant women. $\mathrm{OHI}$ is a brief intervention that may improve home oral health care and dental visit attendance as early as during pregnancy, perhaps preventing oral disease and improving the oral health of the mother and the baby. Providing women with oral health information is a important first step on the road to improving oral health. Although this study does not suggest that MI alone is as effective as $\mathrm{OHI}$ as a method to improve oral health among pregnant women, its value should not be ignored. OHI administered in an MI context might prove be a good combination to improve oral health.

The present study is one of the few studies utilizing MI to improve oral health among pregnant women. Although this study had several limitations, MI still seems indicated for a variety of target behaviors. Future research should focus on designing studies that have improved methodology, including standardized MI delivery and objective outcome measurement. Research should be directed at examining treatment integrity, MI effectiveness as related to motivation and behavior change, and underlying mechanisms of MI. Improved methodology should be integrated into future studies including control groups, larger numbers of participants, standardized training, and a standard MI protocol. It is suggested that studies explore the efficacy of MI and $\mathrm{OHI}$ interventions separately and in combination. It might be that education provided through the use of motivational interviewing might positively impact oral health more than either intervention individually. Studies can improve on the methods and design used in this study to further examine factors that contribute to oral health among pregnant women. Motivational interviewing is promising clinically, although practical considerations, such as time and cost, still need to be examined. In summary, although many barriers to oral health care exist, 
education and motivation-enhancing techniques may help pregnant women overcome some barriers. 


\section{References}

Alaluusua. S., Kleemola-Kujala, E., Grönroos, L., \& Evälahti, M. (1990). Salivary caries-related tests as predictors of future caries increment in teenagers. A three-year longitudinal study. Oral Microbiology and Immunology, 5, 77-81.

Alaluusua. S., \& Renkonen, O. V. (1983). Streptococcus mutans establishment and dental caries experience in children 2 to 4 years old. Scandinavian Journal of Dental Research, 91, 453-457.

Alaluusua. S., Savolainen, J., Tuompo, H., \& Grönroos, L. (1984). Slide-scoring method for estimation of Streptococcus mutans levels in saliva. Scandinavian Journal of Dental Research, 92, 127-133.

Allen, F., \& Locker, D. (2002). A modified short version of the oral health impact profile for assessing health-related quality of life in edentulous adults. The International Journal of Prosthodontics, 15, 446-450.

American Academy of Periodontology (2004). American Academy of Periodontology statement regarding periodontal management of the pregnant patient. Journal of Periodontology, 75, 495-495.

American Dental Association (1995). Women's oral health issues. Chicago: American Dental Association.

American Dental Hygienists' Association (2006). Proper brushing. Retrieved September 15, 2006 from, http://www.adha.org/oralhealth/brushing.htm

American Dental Hygienists' Association (2006b). Proper flossing. Retrieved September 15, 2006 from, http://www.adha.org/oralhealth/flossing.htm

Beck, J. D., \& Offenbacher, S. (2005). Systematic effects of periodontitis: Epidemiology of 
periodontal disease and cardiovascular disease. Journal of Periodontology, 11 Supplement, 2089-2100.

Belcher, L., Kalichman, S., Topping, M., Smith, S., Emshoff, J., Norris, F. et al. (1998).

A randomized trial of a brief HIV risk reduction counseling intervention for women. Journal of Consulting and Clinical Psychology, 66, 531-541.

Berkowitz, R. J., Jordan, H. V., \& White, G. (1975). Similarity of bacteriocins of streptococcus mutans from mother and infant. Archives of Oral Biology, 20, 725-730.

Bouwsma, O., Caton, J., Polson, A., \& Espeland, M. (1988). Effect of personal oral hygiene on bleeding interdental gingival: Histologic changes. Journal of Periodontology, 59, 80-86.

Burke, B. L., Arkowitz, H., \& Menchola, M. (2003). The efficacy of motivational interviewing: A meta-analysis of controlled clinical trials. Journal of Consulting and Clinical Psychology, 71, 843-861.

Burt, B. A., \& Eklund, S. A. (2005). Dentistry, dental practice, and the community (6 ${ }^{\text {th }}$ ed.). St. Louis, MO: Elsevier Saunders.

Carey, M. P., Maisto, S. A., Kalichman, S. C., Forsyth, A. D., Wright, E. M., \& Johnson, B. (1997). Enhancing motivation to reduce the risk of HIV infection for economically disadvantaged urban women. Journal of Consulting and Clinical Psychology, 65, 531541.

Carlsson, J., Grahnen, H., \& Jonsson, G. (1975). Lactobacilli and streptococci in the mouth of children. Caries Research, 9, 333-339.

Caufield, P. W., Cutter, G. R., \& Dasanayake, A. P. (1993). Initial acquisition of mutans streptococci by infants: Evidence for a discrete window of infectivity. Journal of Dental Research, 72, 37-45. 
Center for Disease Control (CDC) (1993). National health and nutrition examination survey III. Retrieved October 1, 2006, from http://www.cdc.gov/nchs/products/elec_prods/subject/nhanes3.htm Center for Disease Control (CDC) (2004). Dental visit: Adults aged 18+ who have visited a dentist or dental clinic in the past year. Retrieved September 27, 2006 from, http://apps.nccd.cdc.gov/nohss/ListV.asp?qkey=5\&DataSet=2

Chen, M. (1995). Oral health of disadvantaged populations. In L. K. Cohen \& H. C. Gift (Eds.), Disease prevention and oral health promotion (pp. 153-212). Copenhagen: Munksgaard.

Cirino, P. T., Chin, C. E., Sevcik, R. A., Wolf, M., Lovett, M., \& Morris, R. D. (2002). Measuring socioeconomic status: reliability and preliminary validity for different approaches. Assessment, 9, 145-155.

Cohen, J. (1988). Statistical power analysis for the behavioral sciences ( $2^{\text {nd }}$ ed.), Hillsdale, NJ: Lawrence Erlbaum.

Cohen, J. (1990). Things I have learned (so far). American Psychologist, 45, 1304-1312.

Cohen, J. (1992). A power primer. Psychological Bulletin, 112, 155-159.

Dasanayake, A. P. (1998). Poor periodontal health of the pregnant woman as a risk factor for low birth weight. Annals of Periodontology, 3, 206-212.

DiClemente, C. C., \& Prochaska, J.O. (1985). Processes and stages of change: Coping and competence in smoking behavior change. In S. Shiffman \& T. A. Wills (Eds.), Coping and substance abuse (pp. 319-342). New York: Academic Press.

Drury, T. F., \& Snowden, C. B. (1995). Community oral health promotion: Organizational, methodological, and statistical issues. In L. K. Cohen, \& H. C. Gift (Eds.), Disease prevention and oral health promotion (pp. 505-584). Copenhagen: Munksgaard. 
Faul, F., \& Erdfelder, E. (1992). G Power: Apriori, post-hoc, and compromise power analysis for MS-DOS [computer program]. Bonn, Germany: Bonn University, Department of Psychology.

Ferris, G. M. (1993). Alternation in female sex hormones: Their effect on oral tissues and dental treatment. Compendium, 14, 1558-1571.

Fitzsimons, D., Dwyer, J. T., Palmer, C., \& Boyd, L. D. (1998). Nutrition and oral health guidelines for pregnant women, infants, and children. Journal of the American Dietetic Association, 98, 182-189.

Genco, R., Offenbacher, S., \& Beck, J. (2002). Periodontal disease and cardiovascular disease. Journal of the American Dental Association, 133, 14S-22S.

Gift, H. C., Reisine, S. T., \& Larach, D. C. (1992). The social impact of dental problems and visits. American Journal of Public Health, 82, 1663-1668.

Griffin, S. O., Jones, K., \& Tomar, S. L. (2001). An economic evaluation of community water fluorination. Journal of Public Health Dentistry, 61, 78-86.

Günay, H., Dmoch-Bockhorn, K., Günay, Y., \& Geurtsen, W. (1998). Effect on caries experience of a long-term preventative program for mothers and children starting during pregnancy. Clinical Oral Observations, 2, 137-142.

Hertiage, J., \& Sefi, S. (1992). Dilemmas of advice: Aspects of delivery and reception in interactions between health visitors and first-time mothers. In P. Drew \& J. Heritage (Eds.), Talk at work: Interaction in institutional settings, (pp. 359-417). Cambridge: Cambridge University Press.

Hollingshead, A. B., \& Redlich, F. C. (1958). Social class and mental illness: A community study. New York: John Wiley. 
Ide, R., Mizoue, R., Tsukiyama, Y., Ikeda, M., \& Yoshimura, T. (2001). Evaluation of oral health promotion in the workplace: The effects on dental care costs and frequency of dental visits. Community Dentistry and Oral Epidemiology, 29, 213-219.

Jalil, R. A. (1995). Correlating streptococcus mutans counts in saliva with plaque amount, gingival inflammation and caries experience in school children. Singapore Dental Journal, 20, 16-20.

Jamieson, L. M., \& Thomson, W. M. (2002). The Dental Neglect and Dental Indifference scales compared. Community Dentistry and Oral Epidemiology, 30, 168-175.

Jansson, H., Lindholm, E., Lindh, C., Groop, L., \& Bratthall, G. (2006). Type 2 diabetes and risk for periodontal disease: a role for dental health awareness. Journal of Clinical Periodontology, 33, 408-414.

Jeffcoat, M. K., Guers, N. C., Reddy, M. S., Cliver, S. P., Goldenberg, R. L., \& Hauth, J. C. (2001). Periodontal infection and preterm birth. Journal of the American Dental Association, 132, 845-880.

Jeffcoat, M. K., Guers, N. C., Reddy, M. S., Goldenberg, R. L., \& Hauth, J. C. (2001). Current evidence regarding periodontal disease as a risk factor in preterm birth. Annals of Periodontology, 6, 183-188.

Jensen, B., \& Bratthall, D. (1989). A new method for the estimation of mutans streptococci in human saliva. Journal of Dental Research, 68, 468-471.

Jensen, J., Lilijmark, W., \& Bloomquist, C. (1981). The effect of female sex hormones on subgingival plaque. Journal of Periodontology, 52, 599-602.

Kay, E., \& Locker, D. (1998). A systematic review of the effective of health promotion aimed at improving oral health. Community Dental Research, 15, 132-144. 
Keppel, G., \& Wickens, T. D. (2004). Design and analysis ( $4^{\text {th }}$ ed.). Upper Saddle River, NJ: Pearson Education.

Kimbrough, V. J., \& Henderson, K. (2006). Oral health Education. Upper Saddle River, NJ: Pearson Education.

Kingman, A., Little, W., Gomez, I., Heifetz, S. B., Driscoll, W. S., Sheats, R. et al. (1988). Salivary levels of Streptococcus mutans and lactobacilli and dental caries experiences in a US adolescent population. Community Dentistry and Oral Epidemiology, 16, 98-103.

Kleinknecht, R. A., Klepac, R. K., \& Alexander, L. D. (1973). Origins and characteristics of fear of dentistry. Journal of the American Dental Association, 86, 842-848.

Köhler, B., Bjarnason, S., Care, R., Mackevica, I, \& Rence, I. (1995). Mutans streptococcus and dental caries prevalence in a group of Latvian preschool children. European Journal of Oral Science, 103, 264-266.

Köhler, B., Bratthall, D., \& Krasse, B. (1983). Preventative measures in mothers influence the establishment of the bacterium Streptococcus mutans in their infants. Archives of Oral Biology, 28, 225-231.

Laine, M. A.. (2002). Effect of pregnancy on periodontal and dental health. Acta Odontologica Scandanavica, 60, 257-264.

Lawrence, S. M. (2005). Dental values as a factor affecting attendance among patients with high dental fear. Unpublished masters thesis, West Virginia University, Morgantown, West Virginia.

Little, J. W., Falace, D. A., Miller, C. S., \& Rhodus, N. L. (2002). Dental management of the medically compromised patient. St. Louis, MO: Mosby.

Lobene, R. R., Soparkar, P. M., \& Newman, M. B. (1982). Use of dental floss: Effect on plaque 
and gingivitis. Clinical Preventive Dentistry, 4, 5-8.

Locker, D., \& Allen, P. F. (2002). Developing short-form measures of oral health-related quality of life. Journal of Public Health Dentistry, 62, 13-20.

Löe, H. (1965). Periodontal changes in pregnancy. Journal of Periodontology, 36, 209-217.

Madianos, P. N., Lieff, S., Murtha, A. P., Boggess, K. A., Auten Jr., R. L., Beck, J. D. et al. (2001). Maternal peritonitis and prematurity. Part II: Maternal infection and fetal exposure. Annals of Periodontology, 6, 175-182.

Madigan, A., Murray, P. A., Houpt, M., Catalanotto, F., \& Feuerman, M. (1996). Caries experience and cariogenic markers in HIV-positive children and their siblings. Pediatric Dentistry, 18, 129-136.

Martins, R. K., \& McNeil, D. W. (2008). Review of motivational interviewing in promoting health behaviors. Manuscript submitted for publication.

Masuda, N., Shimamoto, T., Kitamura, K., Sobue, S., \& Hamada, S. (1985). Transmission of Streptococcus mutans in some selected families. Microbios, 44, 223-232.

McGlynn, F. D., LeCompte, E. J., Thomas, R. G., Courts, F. J., \& Melamed, B. G. (1987). Effects of behavior self-management on oral hygiene adherence among orthodontic patients. American Journal of Orthodontics and Dentofacial Orthopedics, 91, 15-21.

McGlynn, F. D., McNeil, D. W., Gallagher, S. J., \& Vrana, S. (1987). Factor structure, stability, and internal consistency of the Dental Fear Survey. Behavioral Assessment, 9, 57-66.

McGrath, C., \& Bedi, R. (2001). Can dental attendance improve quality of life? British Dental Journal, 190, 262-265.

McNeil, D. W., Crout, R. J., Lawrence, S. M., Shah, P., \& Rupert, N. (2004, March). Oral health 
values in Appalachia: Specific dental-related fatalism [Abstract]? Journal of Dental Research, 83, A-203.

Miller, W. R., \& Rollnick, S. (2002). Motivational interviewing: Preparing people for Change ( $2^{\text {nd }}$ ed.). New York: Guilford Press.

Mills, L. W., \& Moses, D. T. (2002). Oral health during pregnancy. The American Journal of Maternal/Child Nursing, 27, 275-280.

Mojon, P. (2002). Oral health and respiratory infection. Journal of the Canadian Dental Association, 68, 340-345.

Moss, K. L., Beck, J. D., \& Offenbacher, S. (2005). Clinical risk factors associated with incidence and progression of periodontal conditions in pregnant women. Journal of Clinical Periodontology, 32, 492-498.

Moyers, T. B., Martin, T., Manuel, J. K., Hendrickson, S. M. L., \& Miller, W. R. (2005). Assessing competence in the use of motivational interviewing. Journal of Substance Abuse Treatment, 28, 19-26.

Moyers, T. B., Martin, T., Manuel, J. K., \& Miller, W. R. (2003). The motivational interviewing treatment integrity (MITI) code. Version 2.0. Retrieved October 1, 2005 from http://casaa.unm.edu/download/miti.pdf

Närhi, T. O., Kurki, N., \& Ainamo, A. (1999). Saliva, salivary micro-organisms, and oral health in the home-dwelling old elderly--a five-year longitudinal study. Journal of Dental Research, 78, 1640-1646.

National Rural Health Association (NRHA) (2005). Meeting oral health care needs in rural America. Retrieved September 27, 2006 from http://www.nrharural.org/advocacy/sub/policybriefs/oralhealth3-05.pdf 
Offenbacher, S. (1996). Periodontal disease: Pathogenesis. Annals of Periodontology, 1, 821878.

Offenbacher, S. (2004). Maternal periodontal infections, prematurity, and growth restriction. Clinical Obstetrics and Gynecology, 47, 808-821.

Offenbacher, S., Boggess, K. A., Murtha, A. P., Jared, H. L., Lieff, S., McKaig, R. G. et al. (2006). Progressive periodontal disease and risk of very preterm delivery. Obstetrics and Gynecology, 107, 29-36.

Offenbacher, S., Jared, H. L., O’Reilly, P. G., Wells, S. R., Salvi, G. E., Lawrence, H. P. et al. (1998). Potential pathogenic mechanism of periodontitis-associated pregnancy complications. Annals of Periodontology, 3, 233-250.

Osborne, J. W. (2002). Notes on the use of data transformations. Practical Assessment Research, and Evaluation., 8, 51-59.

Pedhazur, E. J. (1997). Multiple regression in behavioral research: Explanation and research ( $3^{\text {rd }}$ ed.). New York: Harcourt Brace.

Peterson, P. E. (2003). The World Oral Health Report 2003: continuous improvement of oral health in the 21st century--the approach of the WHO Global Oral Health Programme. Community Dentistry and Oral Epidemiology, 31, 3-23.

Ray, T. S. (2005). Oral infection control: toothbrushes and toothbrushing. In E. Wilkins (Ed.) ( $9^{\text {th }}$ ed.), Clinical practice of the dental hygienist (pp. 402-425). Baltimore, MD: Lippincott Williams \& Wilkins.

Richardson, L., McKibbins, S. M., Seilbert, W., \& Tyus, J. (1995). Salivary count of streptococcus mutans in elementary school children. National Dental Research Journal, $46,8-11$. 
Rollnick, S., Mason, P., \& Butler, C. (2002). Health behavior change: A guide for practitioners. London, England: Churchill Livingstone.

Rose, L. F., \& Kaye, D. (1983). Internal medicine for dentistry. St. Louis, MO: C. V. Mosby Co.

Shi, S., Liang, Q., Hayashi, Y., Yakushiji, M., \& Machida, Y. (1998). The relationship between caries activity and the status of dental caries: Application of the Dentocult SM method. Chinese Journal of Dental Research, 1, 52-55.

Skaret, E., Weinstein, P., Kvale, G., \& Raadal, M. (2003). An intervention program to reduce dental avoidance behavior among adolescents: A pilot study. European Journal of Paediatric Dentistry, 4, 191-196.

Slade, G. D., \& Spencer, A. J. (1994). Development and evaluation of the oral health impact profile. Community Dental Health, 11, 3-11.

Sorrell, J. T., McNeil, D. W., Vowles, K. E., Lawrence, S. M., Chrystan, J. A., \& Gochenour, L. (2003). Evidence-based Assessment and Patient Education using Informational Videotapes [Abstract]. Journal of Dental Research, 82, C-1004.

Tanni, D. Q., Habashneh, R., Hammad, M. M., \& Batieha, A. (2003). The periodontal status of pregnant women and its relationship with socio-demographic and clinical variables. Journal of Oral Rehabilitation, 30, 440-445.

Thomson, W. M., \& Locker, D. (2000). Dental neglect and dental health among 26-year-olds in the Dunedin Multidisciplinary Health and Development Study. Community Dentistry and Oral Epidemiology, 28, 414-418.

Thomson, W. M., Spencer, A. J., \& Gaughwin, A. (1996). Testing a child dental neglect scale in South Australia. Community Dentistry and Oral Epidemiology, 24, 351-356. 
Twetman, S., \& Frostner, N. (1991). Salivary mutans streptococci and caries prevalence in 8year-old Swedish schoolchildren. Swedish Dental Journal, 15, 145-151.

U.S. Census (2006). Health status, health insurance, and health services utilization: 2001.

Retrieved September 10, 2006 from http://www.census.gov/prod/2006pubs/p70-106.pdf

United States Department of Agriculture (USDA) (2006). State fact sheet: West Virginia.

Retrieved October 1, 2006, from http://ers/usda.gov/StateFacts/WV.HTM

U.S. Department of Health and Human Services (U.S. DHHS) (2000). Oral health in America: A report of the surgeon general. Retrieved October 1, 2005, from http://silk.nih.gov/public/hck1ocv.@www.surgeon.fullrpt.pdf

U.S. Department of Health and Human Services (U.S. DHHS) (2000b). Healthy people 2010. Retrieved October 31, 2005, from http://www.healthypeople.gov/Publications/

U.S. Department of Health \& Human Resources (U.S. DHHR) (2006). West Virginia healthy people 2010. Retrieved September 1, 2006 from http://www.wvdhhr.org/bph/hp2010/objective/final2010.pdf

U.S. Department of Health \& Human Resources (U.S. DHHR) (2006b). What are health disparities? Retrieved October 7, 2006, from http://www.omhrc.gov/templates/browse.aspx?lvl=1\&lvlID=6

Vowles, K. E., McNeil, D. W., Sorrell, J. T., McKee, D. R., Zvolensky, M. J., Graves, R. W. et al. (2005). Oral surgery appointment attendance: Effects from fears of dentistry and pain. In P. L. Gower (Ed.), New research on the psychology of fear (pp. 91-103). Hauppauge, New York: Nova Science Publishers.

Weinstein, P. (2002). Motivate your dental patients: A workbook. Seattle, WA: Author.

Weinstein, P., Harrison, R., \& Benton, T. (2004). Motivating parents to prevent caries in their 
young children: One-year findings. Journal of the American Dental Association, 135, 731-738.

Weinstein, P., \& Riedy, C. A. (2001). The reliability and validity of the RAPIDD scale: Readiness assessment of parents concerning infant dental decay. Journal of Dentistry for Children, 68, 129-135.

Wilkins, E. M. (2005). Clinical practice of the dental hygienist. Baltimore, MD: Lippincott Williams \& Wilkins.

Williams, L. C., Stevens, S., Marti, A., Koelbl, J., \& Wearden, S. (2005, March). Dentist's attitude on treatment of pregnant patients in West Virginia. Poster presented at the annual meeting of the American Association of Dental Research, Baltimore, MD.

Zambrana, R. E., Ell, K., Dorrington, C., Wachsman, L, \& Hodge, D. (1994). The relationship between psychosocial status of immigrant Latino mothers and the use of emergency pediatric services. Health \& Social Work, 19, 93-102. 
Table 1

Summary of Participant Recruitment Sources

\begin{tabular}{lcc} 
Recruitment Source & Total Participants Recruited & Percentage of Sample \\
\hline Newspaper advertisement & 35 & $41 \%$ \\
Right from the Start/Mountain Cap & 18 & $21 \%$ \\
Personal reference/Friend & 16 & $19 \%$ \\
West Virginia University E-News & 7 & $8 \%$ \\
Baby and Me Event & 5 & $6 \%$ \\
Dentist & 2 & $3 \%$ \\
Church & 1 & $1 \%$ \\
Flyer & 1 & $1 \%$ \\
\hline
\end{tabular}

Total

85

$100 \%$ 
Table 2

Summary of Motivational Interviewing Goals for Each Participant

\begin{tabular}{|c|c|c|c|c|c|c|}
\hline Participant & Maintenance & $\begin{array}{l}\text { Increase } \\
\text { Flossing }\end{array}$ & $\begin{array}{l}\text { Increase } \\
\text { Brushing }\end{array}$ & $\begin{array}{l}\text { Increase } \\
\text { Fluoride/ } \\
\text { Mouthwash } \\
\text { Use }\end{array}$ & $\begin{array}{l}\text { Increase } \\
\text { Dental } \\
\text { Visit }\end{array}$ & Other \\
\hline 4 & & $X$ & & & & $X$ \\
\hline 6 & $X$ & & & & & \\
\hline 7 & $X$ & & & & & \\
\hline 8 & & $X$ & & $X$ & & \\
\hline 9 & & & & & $X$ & \\
\hline 10 & & $X$ & & & & \\
\hline 11 & & $X$ & & & & \\
\hline 12 & & & $X$ & & $X$ & $X$ \\
\hline 13 & & $X$ & & & & \\
\hline 14 & & $X$ & & & $X$ & \\
\hline 15 & $X$ & & & & & \\
\hline 16 & & $\mathrm{X}$ & & $X$ & $X$ & \\
\hline 17 & & X & $X$ & & & \\
\hline 18 & & $X$ & & & & \\
\hline 19 & & & & & & XX \\
\hline 21 & $X$ & & & & & \\
\hline 22 & & $X$ & & $X$ & & \\
\hline 23 & & & & $\mathrm{X}$ & & \\
\hline 25 & $X$ & & & & & \\
\hline 26 & & & & & $X$ & \\
\hline 27 & & $X$ & & $X$ & $X$ & \\
\hline 28 & & $X$ & & & & \\
\hline 29 & & $X$ & $X$ & & & \\
\hline 30 & X & & & & & \\
\hline 31 & & $X$ & $X$ & & $X$ & \\
\hline 32 & & $X$ & & & & \\
\hline 33 & & & & $X$ & & \\
\hline 34 & & $X$ & & & $X$ & \\
\hline 35 & & & $X$ & $X$ & $X$ & \\
\hline 36 & & $X$ & $X$ & $X$ & & \\
\hline 37 & & $X$ & & & & \\
\hline 38 & $X$ & & & & & \\
\hline 39 & & $X$ & & & & \\
\hline 40 & & $X$ & & & & \\
\hline 41 & & $X$ & & & & \\
\hline 42 & & $X$ & $X$ & $X$ & & \\
\hline 43 & $X$ & & & & & \\
\hline 44 & & $X$ & & & $X$ & \\
\hline 47 & $X$ & & & & & \\
\hline 50 & $X$ & & & & & \\
\hline $\begin{array}{l}\text { Total/ } \\
\text { Percentage } \\
\text { of Women }\end{array}$ & $10 / 25 \%$ & $23 / 58 \%$ & $7 / 18 \%$ & $9 / 23 \%$ & $10 / 25 \%$ & $4 / 10 \%$ \\
\hline
\end{tabular}


Table 3

Summary of Missing Data per Participant

\begin{tabular}{|c|c|c|c|c|c|}
\hline Participant & Second Follow-up Call & Floss & Toothbrush & Toothpaste & $\log$ \\
\hline 4 & $X$ & $X$ & & & \\
\hline 15 & & $\mathrm{X}$ & $\mathrm{X}$ & $\mathrm{X}$ & \\
\hline 23 & & $\mathrm{X}$ & $\mathrm{X}$ & $\mathrm{X}$ & \\
\hline 28 & & & & & $\mathrm{X}$ \\
\hline 29 & & & & $X$ & \\
\hline 31 & & $\mathrm{X}$ & & & \\
\hline 40 & & $\mathrm{X}$ & $\mathrm{X}$ & & \\
\hline 43 & & $\mathrm{X}$ & $\mathrm{X}$ & $\mathrm{X}$ & \\
\hline 103 & & $\mathrm{X}$ & & & \\
\hline 106 & & $\mathrm{X}$ & & & \\
\hline 117 & & $\mathrm{X}$ & & & \\
\hline 119 & & $\mathrm{X}$ & & & \\
\hline 120 & & $\mathrm{X}$ & $\mathrm{X}$ & $\mathrm{X}$ & \\
\hline 121 & & $X$ & $\mathrm{X}$ & & $\mathrm{X}$ \\
\hline 125 & & $X$ & & & \\
\hline 134 & & $X$ & $\mathrm{X}$ & $\mathrm{X}$ & \\
\hline 138 & & $\mathrm{X}$ & & & \\
\hline 139 & & $\mathrm{X}$ & & $\mathrm{X}$ & \\
\hline 142 & & $\mathrm{X}$ & & & \\
\hline Total/Percer & $1 / 1 \%$ & $17 / 20 \%$ & $7 / 8 \%$ & $7 / 8 \%$ & $2 / 2 \%$ \\
\hline
\end{tabular}


Table 4

Skewness and Kurtosis of Primary Dependent Variables and Exploratory Variables before the Interventions

\begin{tabular}{|c|c|c|}
\hline Dependent Measure & Skewness & Kurtosis \\
\hline \multicolumn{3}{|l|}{ Tooth brushing frequency } \\
\hline Motivational Interviewing & -1.56 & 0.45 \\
\hline Oral Hygiene Instruction & -2.18 & 5.84 \\
\hline \multicolumn{3}{|l|}{ Flossing frequency } \\
\hline Motivational Interviewing & -0.20 & -1.44 \\
\hline Oral Hygiene Instruction & -0.15 & -1.07 \\
\hline \multicolumn{3}{|l|}{ Dental visit frequency } \\
\hline Motivational Interviewing & 0.20 & -1.07 \\
\hline Oral Hygiene Instruction & 0.11 & -0.77 \\
\hline \multicolumn{3}{|l|}{ Dental Neglect Scale } \\
\hline Motivational Interviewing & -0.40 & -1.03 \\
\hline Oral Hygiene Instruction & -0.73 & 0.20 \\
\hline \multicolumn{3}{|l|}{ Dental Knowledge Inventory Total } \\
\hline Motivational Interviewing & -0.04 & -1.02 \\
\hline Oral Hygiene Instruction & 0.00 & -1.10 \\
\hline \multicolumn{3}{|l|}{ Dentocult - Streptococcus mutans } \\
\hline Motivational Interviewing & 1.01 & -0.30 \\
\hline Oral Hygiene Instruction & 0.82 & -0.72 \\
\hline \multicolumn{3}{|l|}{ Oral Health Impact Profile -14 } \\
\hline Motivational Interviewing & 0.83 & 0.10 \\
\hline Oral Hygiene Instruction & 2.76 & 8.72 \\
\hline \multicolumn{3}{|l|}{ Dental Fear Survey } \\
\hline Motivational Interviewing & 1.39 & 1.44 \\
\hline Oral Hygiene Instruction & 0.96 & 0.27 \\
\hline
\end{tabular}


Table 5

Skewness and Kurtosis of Primary Dependent Variables and Exploratory Variables after the Interventions

\begin{tabular}{|c|c|c|}
\hline Dependent Measure & Skewness & Kurtosis \\
\hline \multicolumn{3}{|l|}{ Tooth brushing frequency } \\
\hline Motivational Interviewing & -2.64 & 6.87 \\
\hline Oral Hygiene Instruction & -1.84 & 2.74 \\
\hline \multicolumn{3}{|l|}{ Flossing frequency } \\
\hline Motivational Interviewing & -0.26 & 0.45 \\
\hline Oral Hygiene Instruction & -0.44 & -0.21 \\
\hline \multicolumn{3}{|l|}{ Dental visit frequency } \\
\hline Motivational Interviewing & 0.27 & -0.45 \\
\hline Oral Hygiene Instruction & 0.06 & -0.84 \\
\hline \multicolumn{3}{|l|}{ Dental Neglect Scale } \\
\hline Motivational Interviewing & 0.37 & 0.73 \\
\hline Oral Hygiene Instruction & 0.35 & 0.70 \\
\hline \multicolumn{3}{|l|}{$\begin{array}{l}\text { Dental Knowledge Inventory - } \\
\text { (After the intervention) }\end{array}$} \\
\hline Motivational Interviewing & 0.09 & 0.16 \\
\hline Oral Hygiene Instruction & -0.11 & -0.77 \\
\hline \multicolumn{3}{|l|}{$\begin{array}{l}\text { Dental Knowledge Inventory - } \\
\text { (At follow-up) }\end{array}$} \\
\hline Motivational Interviewing & -0.30 & 0.08 \\
\hline Oral Hygiene Instruction & -1.13 & 1.11 \\
\hline \multicolumn{3}{|l|}{$\begin{array}{l}\text { Dentocult - Streptococcus mutans } \\
\text { (Before the intervention) }\end{array}$} \\
\hline Motivational Interviewing & 1.40 & 0.89 \\
\hline Oral Hygiene Instruction & 1.30 & 0.54 \\
\hline \multicolumn{3}{|l|}{ Oral Health Impact Profile -14 } \\
\hline Motivational Interviewing & 1.09 & 0.68 \\
\hline Oral Hygiene Instruction & 2.27 & 4.50 \\
\hline \multicolumn{3}{|l|}{ Dental Fear Survey } \\
\hline Motivational Interviewing & 1.37 & 1.15 \\
\hline Oral Hygiene Instruction & 1.10 & 0.58 \\
\hline
\end{tabular}


Table 6

Correlations of Primary Dependent Variable Instruments

\begin{tabular}{lllllll}
\hline Measure & DNS-T1 & DNS-T2 & OHIP-T1 & OHIP-T2 & DFS-T1 & DFS-T2 \\
\hline DNS-T1 & 1.00 & $.68^{* *}$ & $-.45^{* *}$ & $-.44^{* *}$ & $-.42^{* * *}$ & $-.46^{* *}$ \\
DNS-T2 & & 1.00 & -.16 & -.20 & $-.33^{* *}$ & $-.37^{* *}$ \\
OHIP-T1 & & 1.00 & $.61^{* *}$ & $.26^{*}$ & .19 \\
OHIP-T2 & & & 1.00 & $.29^{* *}$ & $.35^{* *}$ \\
DFS-T1 & & & & 1.00 & $.88^{* *}$ \\
DFS-T2 & & & & & 1.00 \\
\hline
\end{tabular}

Note. DNS: Dental Neglect Scale; OHIP: Oral Health Impact Scale -14; DFS: Dental Fear

Survey; T1: Initial Meeting; T2: Follow-up

$* p \leq .05, * * p \leq .01$ 
Table 7

Mean (Standard Deviation) Values for the Primary Dependent and Exploratory Variables before the Interventions

Dependent Variable $\quad$ Mean (SD)

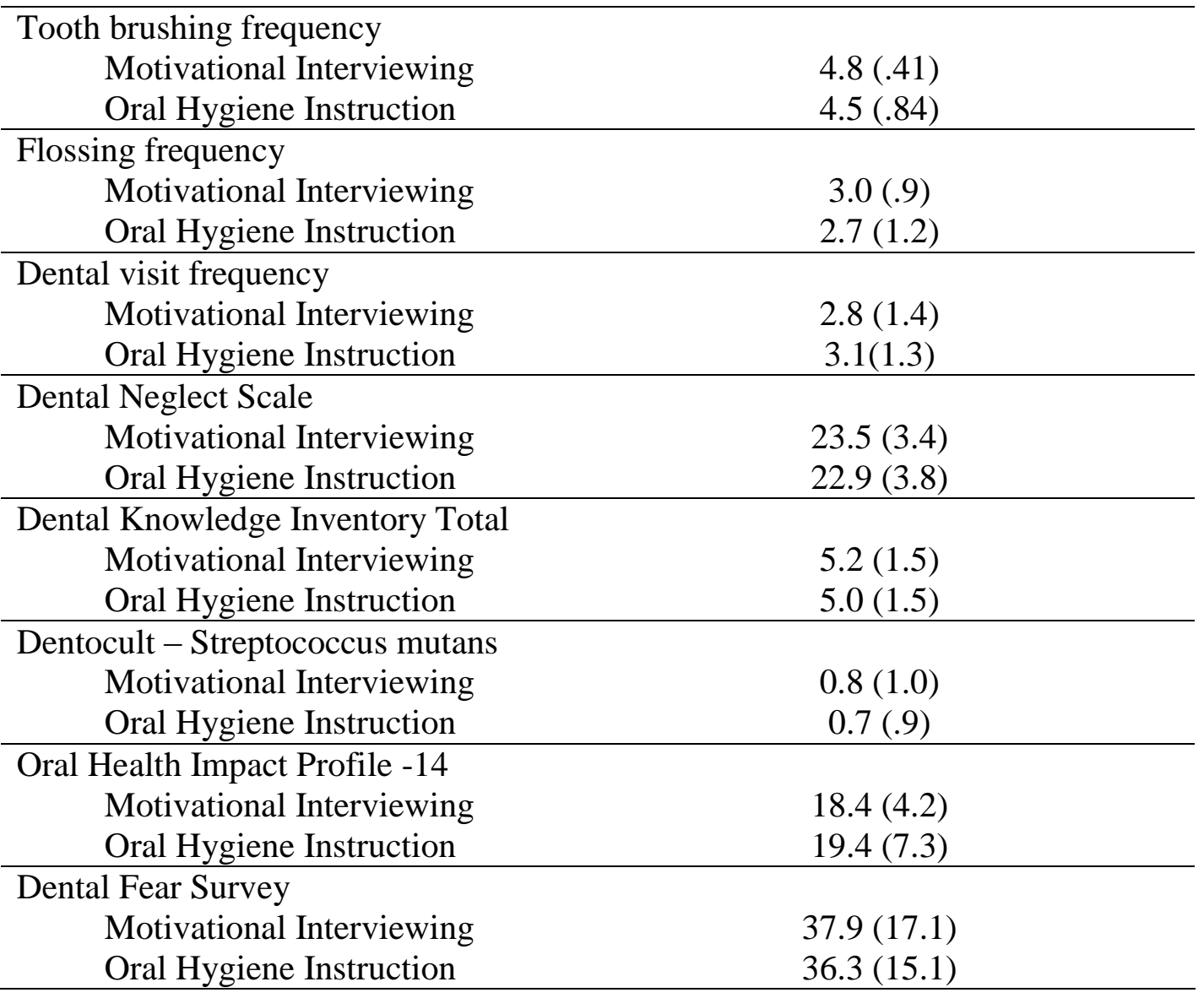


Table 8

T Test Values for the Primary Dependent and Exploratory Variables before the Interventions

\begin{tabular}{llll}
\hline Dependent Variable & df & $t$ & $p$ \\
\hline Tooth brushing frequency & 1,83 & 2.05 & .045 \\
Flossing frequency & 1,83 & 1.46 & .15 \\
Dental visit frequency & 1,83 & 1.08 & .29 \\
Dental Neglect Scale & 1,83 & 0.71 & .48 \\
Dental Knowledge Inventory Total & 1,83 & 0.47 & .64 \\
Dentocult - Streptococcus mutans & 1,83 & 0.19 & .85
\end{tabular}


Table 9

Intercorrelations among Possible Covariates and Dependent Measures

\begin{tabular}{|c|c|c|c|c|c|c|c|c|c|c|c|c|c|c|c|}
\hline Measure/Variable & 1 & 2 & 3 & 4 & 5 & 6 & 7 & 8 & 9 & 10 & 11 & 12 & 13 & 14 & 15 \\
\hline 1. Months of Pregnancy & 1.00 & & & & & & & & & & & & & & \\
\hline 2. Weeks of Pregnancy & $.99 * *$ & 1.00 & & & & & & & & & & & & & \\
\hline 3. SES & -.06 & -.06 & 1.00 & & & & & & & & & & & & \\
\hline 4. Age & .16 & .16 & $.36^{* *}$ & 1.00 & & & & & & & & & & & \\
\hline 5. Children & .01 & .01 & -.14 & $.33^{* *}$ & 1.00 & & & & & & & & & & \\
\hline 6. Education & .07 & .06 & $.61 * *$ & $.60 * *$ & -.06 & 1.00 & & & & & & & & & \\
\hline 7. Marital Status & .11 & .09 & $.34 * *$ & $.45^{* *}$ & .05 & $.41 * *$ & 1.00 & & & & & & & & \\
\hline 8. Brushing Frequency $\mathrm{T} 1$ & -.02 & -.01 & .13 & $.24 *$ & -.07 & $.25^{*}$ & .11 & 1.00 & & & & & & & \\
\hline 9. Brushing Frequency T2 & -.05 & -.04 & .07 & $.22 *$ & .10 & .09 & -.05 & $.70 * *$ & 1.00 & & & & & & \\
\hline 10. Flossing Frequency T1 & -.19 & -.18 & -.10 & .02 & .09 & -.02 & $.25 *$ & $.32 * *$ & $.26^{*}$ & 1.00 & & & & & \\
\hline 11. Flossing Frequency T2 & -.09 & -.09 & $-.27 *$ & -.16 & .03 & -.14 & -.15 & -.17 & $.28 * *$ & $.58^{* *}$ & 1.00 & & & & \\
\hline 12. Dental Visit Frequency T1 & .12 & .12 & -.07 & .11 & .05 & -.10 & .20 & -.13 & -.15 & -.01 & -.07 & 1.00 & & & \\
\hline 13. Dental Visit Frequency T2 & .05 & .02 & -.11 & -.04 & .14 & -.15 & -.06 & $-.25^{*}$ & -.15 & -.12 & -.16 & $.23^{*}$ & 1.00 & & \\
\hline 14. DKI-Total T1 & .10 & .12 & $.32 * *$ & $.23^{*}$ & -.09 & .19 & $.32 * *$ & $.30 * *$ & .16 & -.05 & -.14 & -.13 & -.19 & 1.00 & \\
\hline 15. DKI-Total T2 & -.11 & -.13 & .17 & .13 & -.03 & .20 & $.30 * *$ & -.05 & -.04 & -.15 & -.20 & -.09 & .12 & $.37 * *$ & 1.00 \\
\hline 16. DKI-Total T3 & -.02 & -.04 & $.22 * *$ & $.28 *$ & .03 & $.38 * *$ & $.33^{* *}$ & .20 & .02 & -.03 & -.17 & -.17 & -.17 & $.47 * *$ & $.58 * *$ \\
\hline 17. DKI-Pregnancy T1 & .13 & .13 & $.33 * *$ & .14 & -.17 & .20 & $.35^{* *}$ & $.33 * *$ & .06 & .01 & -.19 & -.09 & -.09 & $.76^{* *}$ & $.27 *$ \\
\hline 18. DKI-Pregnancy T2 & -.09 & -.10 & .13 & .02 & -.20 & .15 & $.25 *$ & .11 & .00 & .04 & .06 & -.08 & .02 & .19 & $.66^{* *}$ \\
\hline 19. DKI-Pregnancy T3 & .01 & -.01 & .19 & $.26^{*}$ & .00 & $.39 * *$ & $.36^{* *}$ & $.34 * *$ & .15 & .14 & .05 & $-.28 *$ & -.18 & $.39 * *$ & $.44 * *$ \\
\hline 20. DKI-Hygiene T1 & .03 & .06 & .19 & $.22 *$ & .07 & .11 & .16 & .15 & .19 & -.09 & -.04 & .12 & -.20 & $.82 * *$ & $.32 *$ \\
\hline 21. DKI-Hygiene T2 & -.07 & -.09 & .12 & .15 & .12 & .15 & .20 & -.14 & -.06 & $-.23^{*}$ & $-.30 * *$ & -.05 & .15 & $.34 * *$ & $.81 * *$ \\
\hline 22. DKI-Hygiene T3 & -.05 & -.06 & .15 & .17 & .05 & .20 & .17 & -.04 & -.12 & -.19 & $-.32 * *$ & .01 & -.08 & $.35^{* *}$ & $.46^{* *}$ \\
\hline 23. OHIP T1 & -11 & -.10 & -.10 & -.02 & $.23^{*}$ & -.08 & -.08 & -.17 & -.14 & -.11 & -.03 & -.03 & $.25^{*}$ & -.08 & -.01 \\
\hline 24. OHIP T2 & .02 & .03 & -.14 & -.01 & .18 & -.14 & $-.22 *$ & $-.26^{*}$ & -.12 & $-.24 *$ & .04 & .09 & $.32 * *$ & -.20 & -.13 \\
\hline 25. DNS T1 & -.03 & -.05 & .14 & .21 & .05 & $.31 * *$ & .14 & $.45^{* *}$ & $.38 * *$ & $.31 * *$ & .08 & -.04 & -.07 & -.09 & -.03 \\
\hline 26. DNS T2 & .05 & .04 & -.11 & .12 & .09 & .08 & -.01 & $.32 * *$ & $.41 * *$ & $.25^{*}$ & $.27 *$ & -.05 & -.06 & -.17 & .01 \\
\hline 27. DFS T1 & -.07 & -.05 & -.09 & -.16 & $-.23^{*}$ & -.17 & $-.24^{*}$ & -.17 & -.06 & -.06 & .08 & .06 & .12 & -.19 & -.15 \\
\hline 28. DFS T2 & -.06 & -.03 & -.04 & -.15 & -.18 & -.17 & $-.33 * *$ & $-.25^{*}$ & -.02 & -.10 & .11 & -.04 & .02 & -.18 & $-.22 *$ \\
\hline 29. Dentocult T1 & -.01 & .02 & .12 & -.11 & -.13 & -.02 & -.06 & -.02 & .00 & -.04 & .06 & -.10 & -.18 & .10 & .01 \\
\hline 30. Dentocult T2 & -.17 & -.17 & .03 & -.17 & -.04 & -.16 & -.15 & $-.37 * *$ & -.21 & -.01 & .14 & -.09 & -.20 & -.06 & -.05 \\
\hline 31. Toothpaste Used & -.02 & -.02 & .09 & $.25^{*}$ & -.09 & .15 & -.10 & $.29 *$ & $.28 *$ & .05 & .06 & .00 & .15 & -.13 & -.09 \\
\hline 32. Floss Used & -.03 & -.05 & -.14 & -.15 & -.13 & $-.26^{*}$ & -.04 & .07 & -.03 & $.34 * *$ & $.49 * *$ & .04 & -.10 & -.05 & -.11 \\
\hline 33. Importance of Change $\mathrm{T} 1$ & -.09 & -.12 & -.06 & .12 & .04 & .11 & .12 & $.52 * *$ & $.48 * *$ & $.27 *$ & .05 & -.02 & -.04 & -.02 & .09 \\
\hline 34. Importance of Change T2 & .04 & .00 & -.20 & .07 & .04 & -.01 & .01 & $.24 *$ & .18 & .08 & .02 & -.04 & .08 & -.14 & .04 \\
\hline 35. Importance of Change T3 & .13 & .10 & $-.28 * *$ & .08 & .15 & -.00 & .05 & $.39 * *$ & $.37 * *$ & .19 & .21 & -.18 & -.05 & -.02 & .04 \\
\hline 36. Confidence in Change $\mathrm{T} 1$ & -.02 & -.04 & .01 & .15 & -.05 & .21 & .04 & $.36^{* *}$ & $.39 * *$ & .14 & .10 & -.07 & -.20 & .07 & .20 \\
\hline 37. Confidence in Change T2 & .09 & .05 & -.05 & .10 & .18 & .13 & .04 & .14 & $.25 *$ & -.06 & .01 & .06 & .09 & -.12 & $.26^{*}$ \\
\hline 38. Confidence in Change T3 & .10 & .06 & $-.23 *$ & .04 & -.03 & .02 & .00 & $.35^{* *}$ & $.41 * *$ & .06 & .12 & -.07 & .06 & -.08 & $.22 *$ \\
\hline
\end{tabular}


Table 9 (continued)

\begin{tabular}{|c|c|c|c|c|c|c|c|c|c|c|c|c|c|c|c|}
\hline Measure/ Variable & 16 & 17 & 18 & 19 & 20 & 21 & 22 & 23 & 24 & 25 & 26 & 27 & 28 & 29 & 30 \\
\hline \multicolumn{16}{|l|}{ 1. Months of Pregnancy } \\
\hline \multicolumn{16}{|l|}{ 2. Weeks of Pregnancy } \\
\hline \multicolumn{16}{|l|}{ 3. SES } \\
\hline \multicolumn{16}{|l|}{ 4. Age } \\
\hline \multicolumn{16}{|l|}{ 5. Children } \\
\hline \multicolumn{16}{|l|}{ 6. Education } \\
\hline \multicolumn{16}{|l|}{ 7. Marital Status } \\
\hline \multicolumn{16}{|l|}{ 8. Brushing Frequency T1 } \\
\hline \multicolumn{16}{|l|}{ 9. Brushing Frequency T2 } \\
\hline \multicolumn{16}{|l|}{ 10. Flossing Frequency T1 } \\
\hline \multicolumn{16}{|l|}{ 11. Flossing Frequency T2 } \\
\hline \multicolumn{16}{|l|}{ 12. Dental Visit Frequency T1 } \\
\hline \multicolumn{16}{|l|}{ 13. Dental Visit Frequency T2 } \\
\hline \multicolumn{16}{|l|}{ 14. DKI-Total T1 } \\
\hline \multicolumn{16}{|l|}{ 15. DKI-Total T2 } \\
\hline 16. DKI-Total T3 & 1.00 & & & & & & & & & & & & & & \\
\hline 17. DKI-Pregnancy T1 & $.34 * *$ & 1.00 & & & & & & & & & & & & & \\
\hline 18. DKI-Pregnancy T2 & $.22 *$ & $.34 * *$ & 1.00 & & & & & & & & & & & & \\
\hline 19. DKI-Pregnancy T3 & $.78 * *$ & $.45^{* *}$ & $.41 * *$ & 1.00 & & & & & & & & & & & \\
\hline 20. DKI-Hygiene T1 & $.40 * *$ & $.25 *$ & -.02 & .19 & 1.00 & & & & & & & & & & \\
\hline 21. DKI-Hygiene T2 & $.59 * *$ & .08 & .09 & $.27 *$ & $.44 * *$ & 1.00 & & & & & & & & & \\
\hline 22. DKI-Hygiene T3 & $.78 * *$ & .08 & -.07 & $.23 *$ & $.44 * *$ & $.66^{*}$ & 1.00 & & & & & & & & \\
\hline 23. OHIP T1 & -.11 & -.16 & -.09 & -.14 & .03 & .06 & -.04 & 1.00 & & & & & & & \\
\hline 24. OHIP T2 & $-.36 * *$ & $-.32 * *$ & -.17 & $-.32 * *$ & -.02 & -.04 & $-.24 *$ & $.61^{* *}$ & 1.00 & & & & & & \\
\hline 25. DNS T1 & .12 & .06 & .03 & $.34 * *$ & -.19 & -.07 & -.15 & $-.45^{* *} *$ & $-.44 * *$ & 1.00 & & & & & \\
\hline 26. DNS T2 & .12 & -.09 & -.02 & $.25 *$ & -.17 & .03 & -.07 & -.15 & -.20 & $.68 * *$ & 1.00 & & & & \\
\hline 27. DFS T1 & $-.28 * *$ & -.09 & .04 & -.21 & -.20 & $-.23^{*}$ & $-.23^{*}$ & $.26 *$ & $.29 * *$ & $-.42 * *$ & $.33 * *$ & 1.00 & & & \\
\hline 28. DFS T2 & $-.36 * *$ & -.14 & -.08 & $.34 * *$ & -.16 & $-.23^{*}$ & $-.22 *$ & .19 & $.35^{* *}$ & $-.46^{* *}$ & $.37 * *$ & $.88 * *$ & 1.00 & & \\
\hline 29. Dentocult T1 & -.01 & -.05 & .01 & -.15 & .19 & .01 & .14 & .02 & .00 & $-.21 *$ & -.17 & .10 & .13 & 1.00 & \\
\hline 30. Dentocult T2 & .02 & -.18 & -.04 & -.08 & .07 & -.03 & .10 & .12 & .03 & $-.41 * *$ & $-.33 * *$ & .19 & $.28 * *$ & $.35^{* *}$ & 1.00 \\
\hline 31. Toothpaste Used & -.02 & -.19 & .01 & -.05 & -.04 & -.12 & .02 & -.02 & -.03 & .18 & .11 & -.01 & -.05 & .13 & .02 \\
\hline 32. Floss Used & -.13 & .00 & .00 & .02 & -.07 & -.15 & -.22 & .05 & .24 & -.08 & -.09 & .14 & .21 & .04 & .21 \\
\hline 33. Importance of Change $\mathrm{T} 1$ & .17 & .09 & .11 & $.33^{* *}$ & -.10 & .04 & -.06 & -.09 & $-.31 * *$ & $.52 * *$ & $.44 * *$ & $-.22 *$ & $-.33^{* *}$ & $-.27 *$ & $-.25^{*}$ \\
\hline 34. Importance of Change $\mathrm{T} 2$ & .21 & .06 & -.04 & $.30 * *$ & $-.27 *$ & .08 & .04 & -.03 & $-.34 * *$ & $.39^{* *}$ & $.45^{* *}$ & -.19 & $-.29 * *$ & -.18 & -.10 \\
\hline 35. Importance of Change T3 & $.22 *$ & -.02 & -.04 & $.29 * *$ & -.01 & .09 & .05 & -.11 & $-.24^{*}$ & $.42 * *$ & $.43 * *$ & $-.27 *$ & $.32 * *$ & -.20 & -.13 \\
\hline 36. Confidence in Change T1 & $.22 *$ & -.04 & .04 & $.23 *$ & .15 & $.24 *$ & .12 & $-.50 * *$ & $-.38^{* *}$ & $.56^{* *}$ & $.37 * *$ & $-.33^{*}$ & $-.31 * *$ & -.05 & $-.29 * *$ \\
\hline 37. Confidence in Change $\mathrm{T} 2$ & .21 & -.08 & .04 & .17 & -.11 & $.32 * *$ & .16 & $-.33^{* *}$ & $-.30 * *$ & $.45^{* *}$ & $.51 * *$ & $-.28 * *$ & $-.33^{* *}$ & .02 & $-.28 * *$ \\
\hline 38. Confidence in Change T3 & .20 & -.09 & .05 & .18 & -.04 & $.26^{*}$ & .14 & -.19 & $-.27 *$ & $.39 * *$ & $.54 * *$ & $-.33 * *$ & $-.41 * *$ & -.15 & $-.35 * *$ \\
\hline
\end{tabular}


Table 9 (continued)

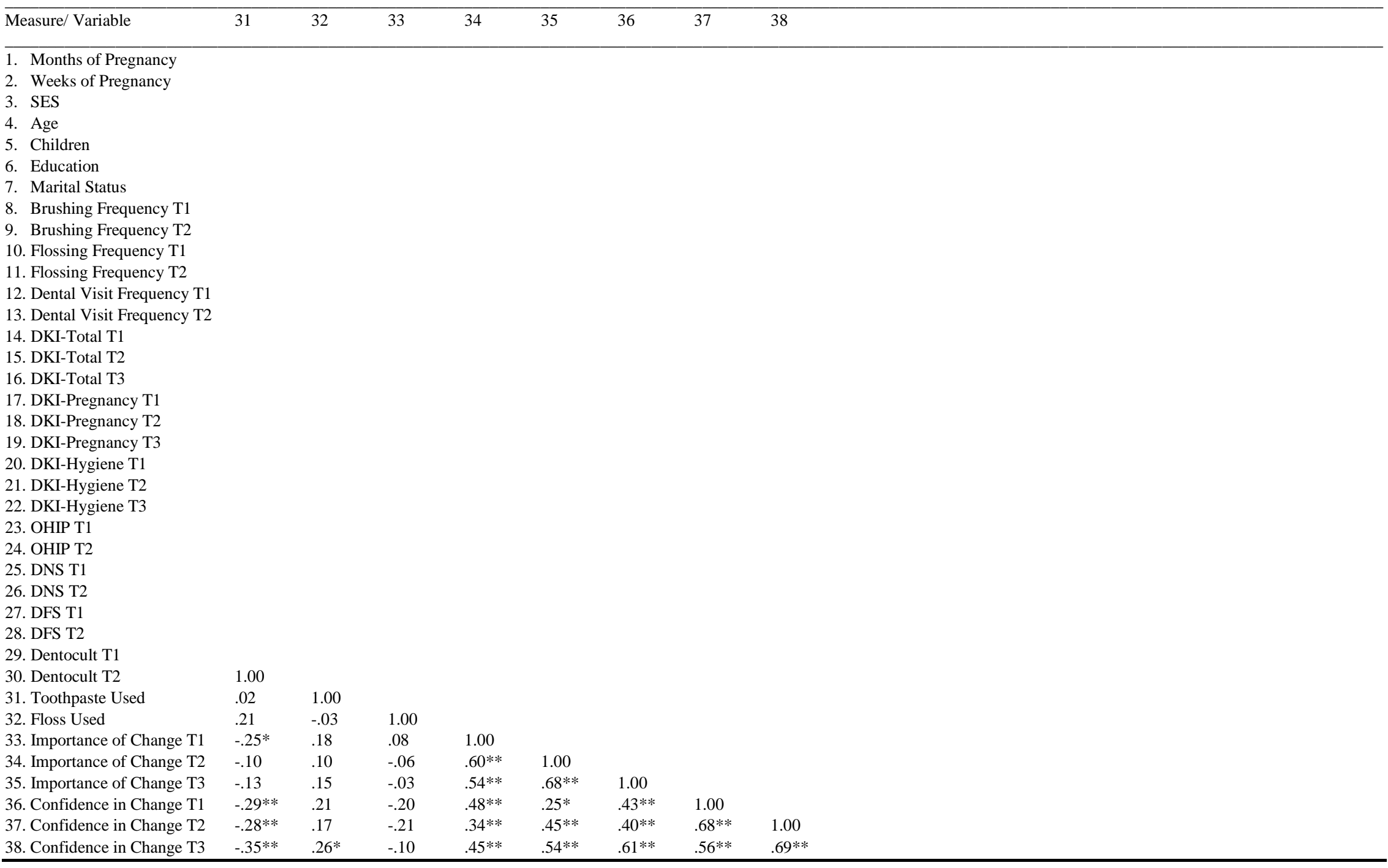

Note. $* p \leq .05, * * p \leq .01$ 


\section{Figure Captions}

Figure 1. Mean tooth brushing behavior pre-intervention and at follow-up for motivational interviewing and oral hygiene instruction groups.

Figure 2. Mean flossing behavior at pre-intervention and at follow-up for motivational interviewing and oral hygiene instruction groups.

Figure 3. Mean dental visit behavior pre-intervention and at follow-up for motivational interviewing and oral hygiene instruction groups.

Figure 4. Mean Dental Neglect Scale scores pre-intervention and at follow-up for motivational interviewing and oral hygiene instruction groups.

Figure 5. Mean Dental Knowledge Inventory total scores pre-intervention, post-intervention, and at follow-up for motivational interviewing and oral hygiene instruction groups.

Figure 6. Mean Dental Knowledge Inventory dental hygiene scores pre-intervention, postintervention, and at follow-up for motivational interviewing and oral hygiene instruction groups.

Figure 7. Mean Dental Knowledge Inventory pregnancy scores pre-intervention, postintervention, and at follow-up for motivational interviewing and oral hygiene instruction groups. Figure 8. Mean Dentocult scores pre-intervention and at follow-up for motivational interviewing and oral hygiene instruction groups.

Figure 9. Mean Oral Health Impact Profile scores pre-intervention and at follow-up for motivational interviewing and oral hygiene instruction groups.

Figure 10. Mean Dental Fear Survey scores pre-intervention and at follow-up for motivational interviewing and oral hygiene instruction groups.

Figure 11. Mean toothpaste use in grams pre-intervention and at follow-up for motivational interviewing and oral hygiene instruction groups. 
Figure 12. Mean floss use in inches pre-intervention and at follow-up for motivational interviewing and oral hygiene instruction groups. 


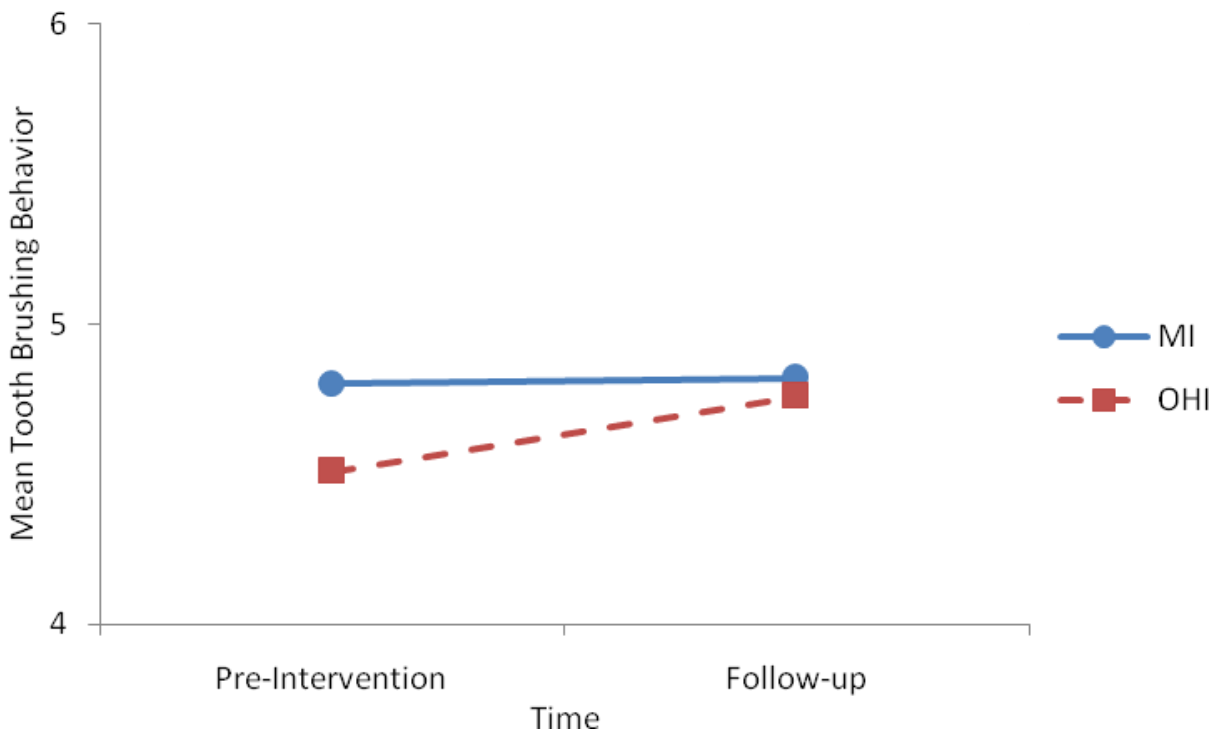




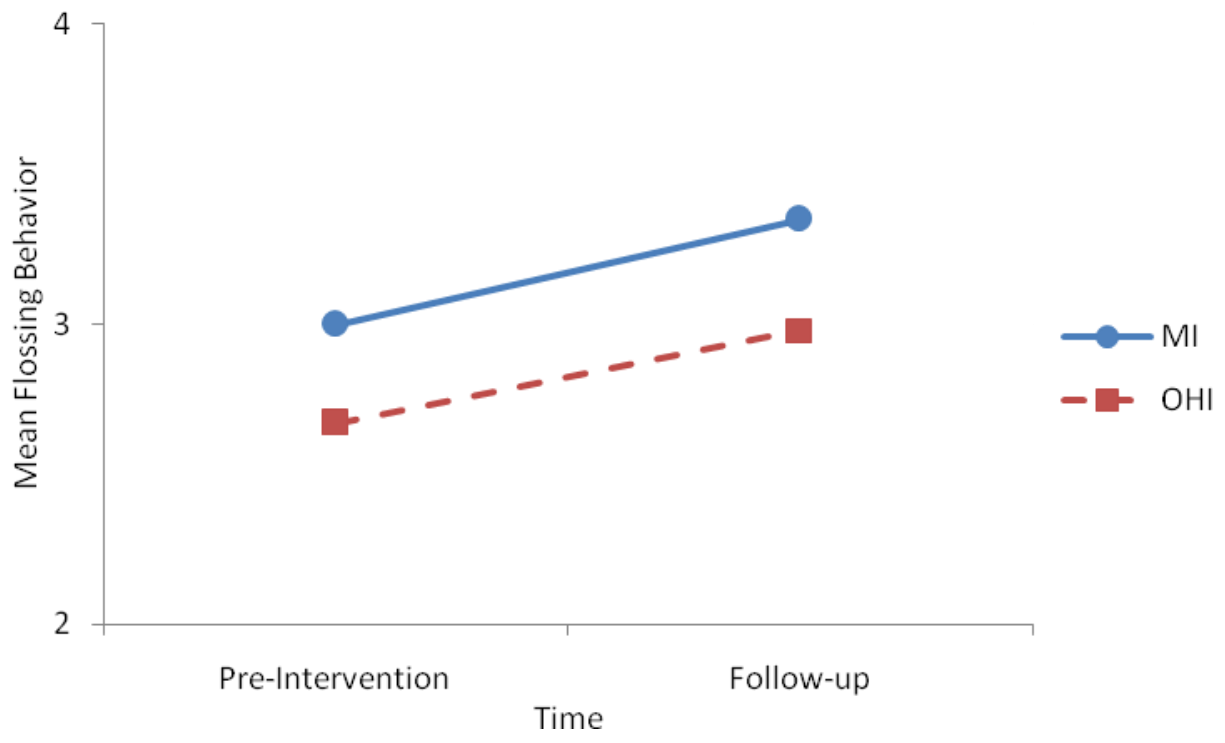




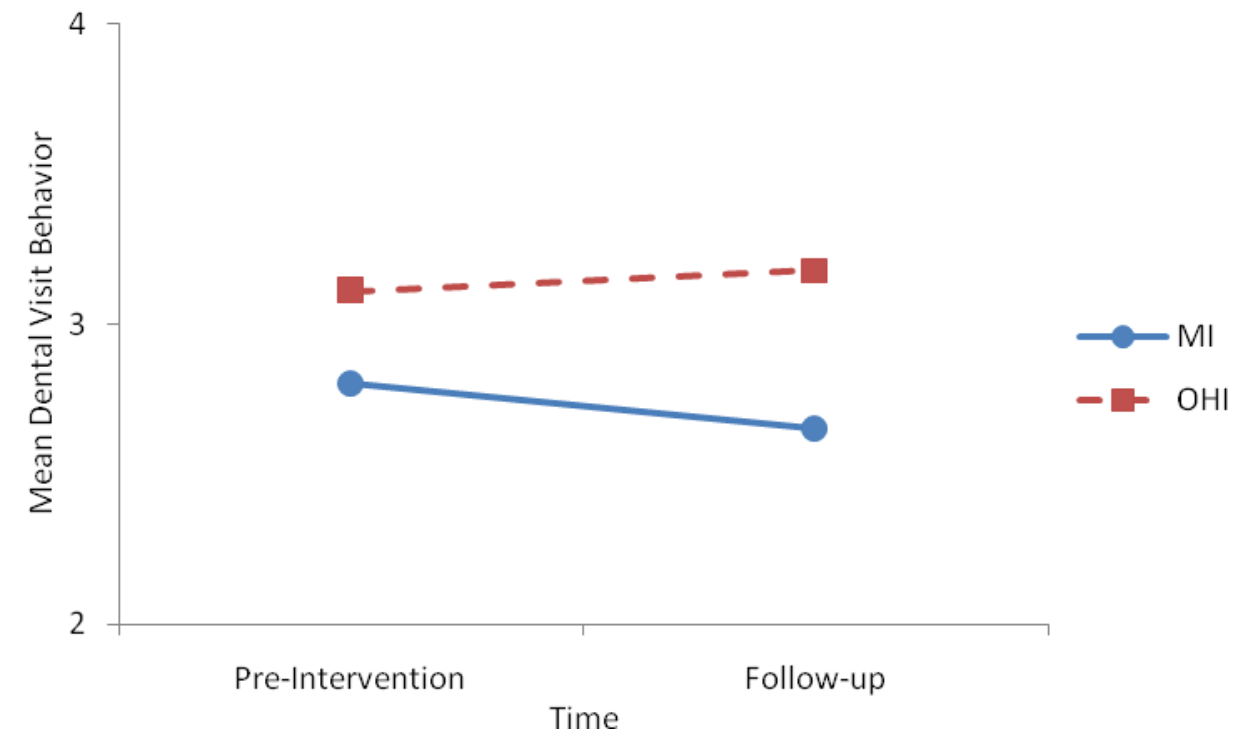




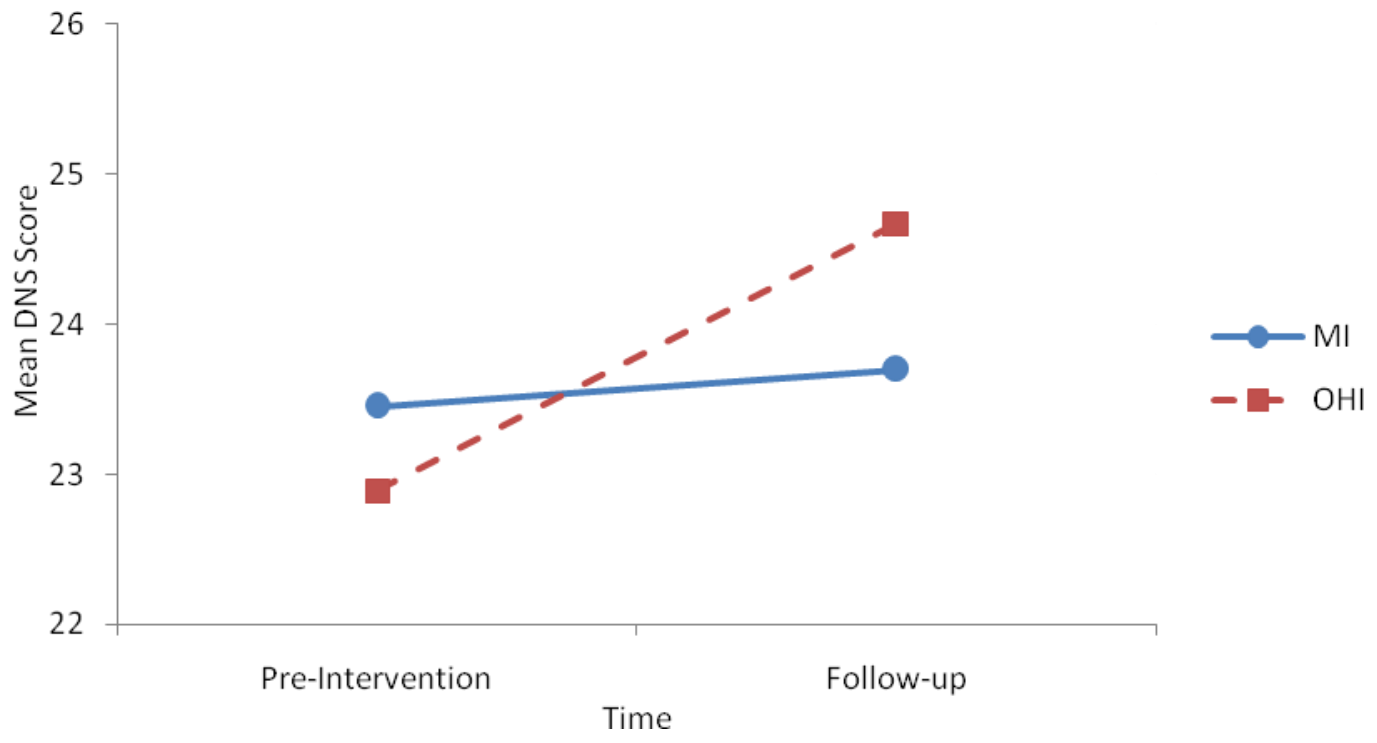




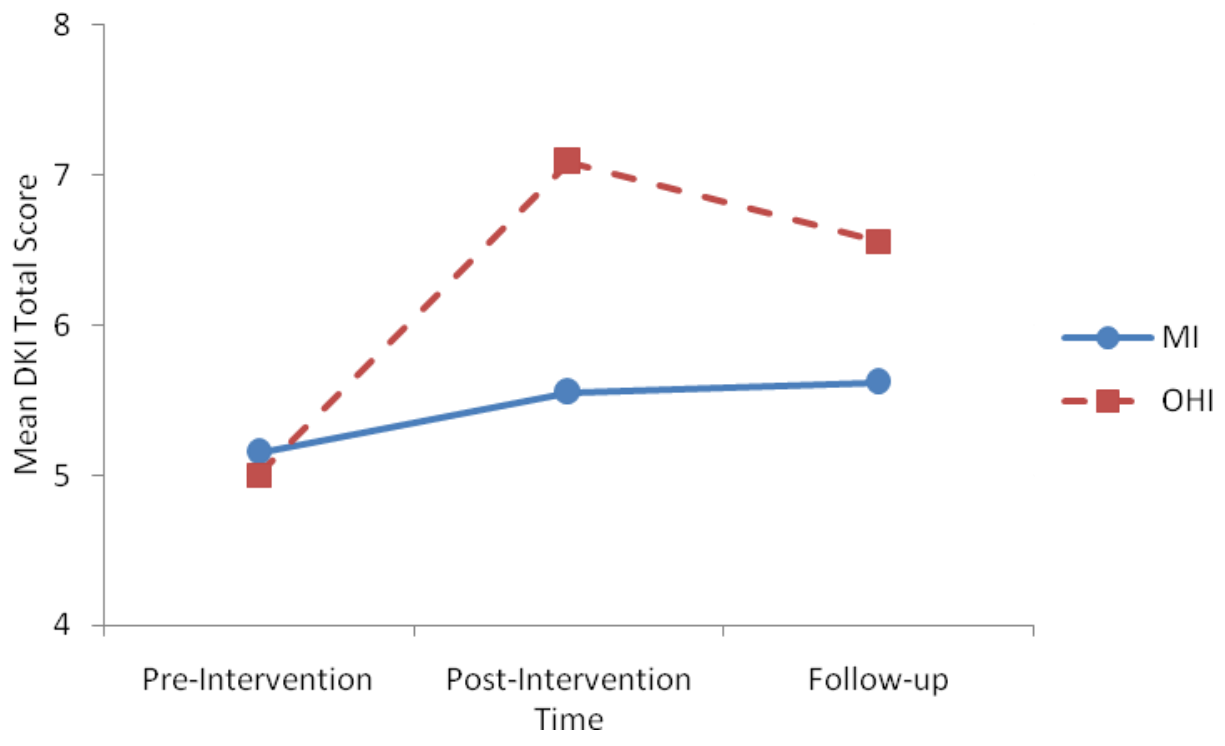




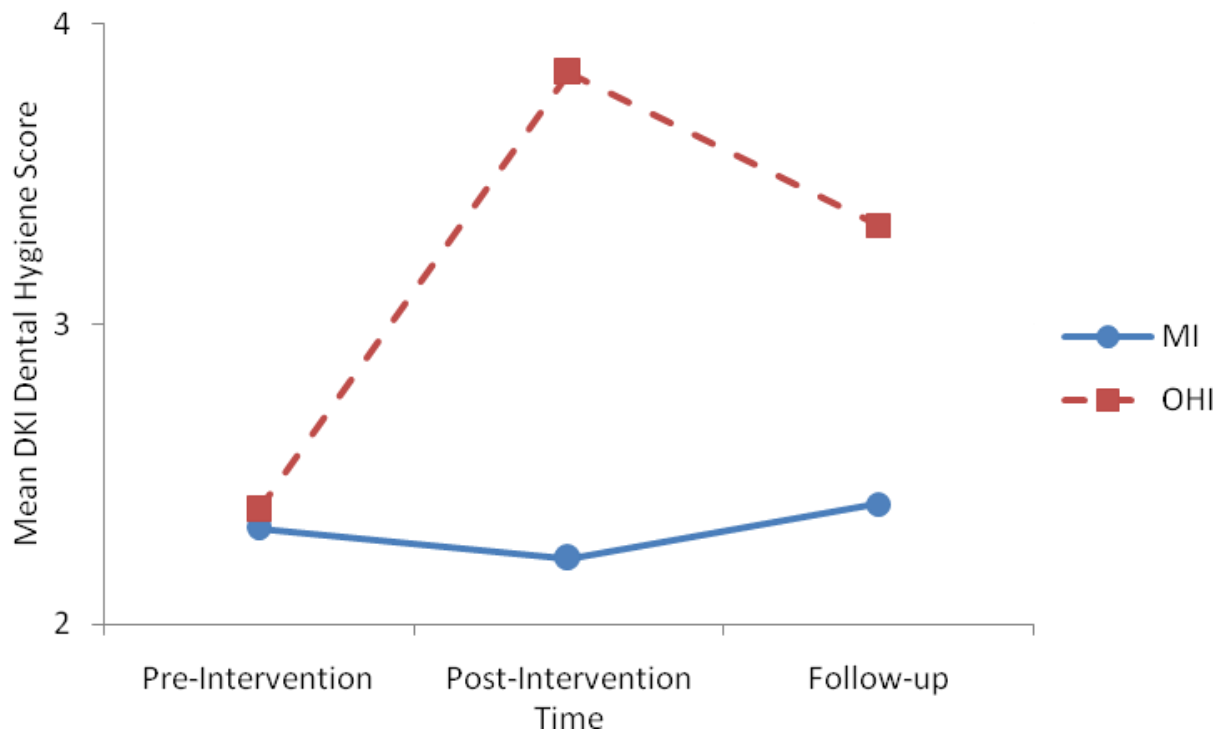




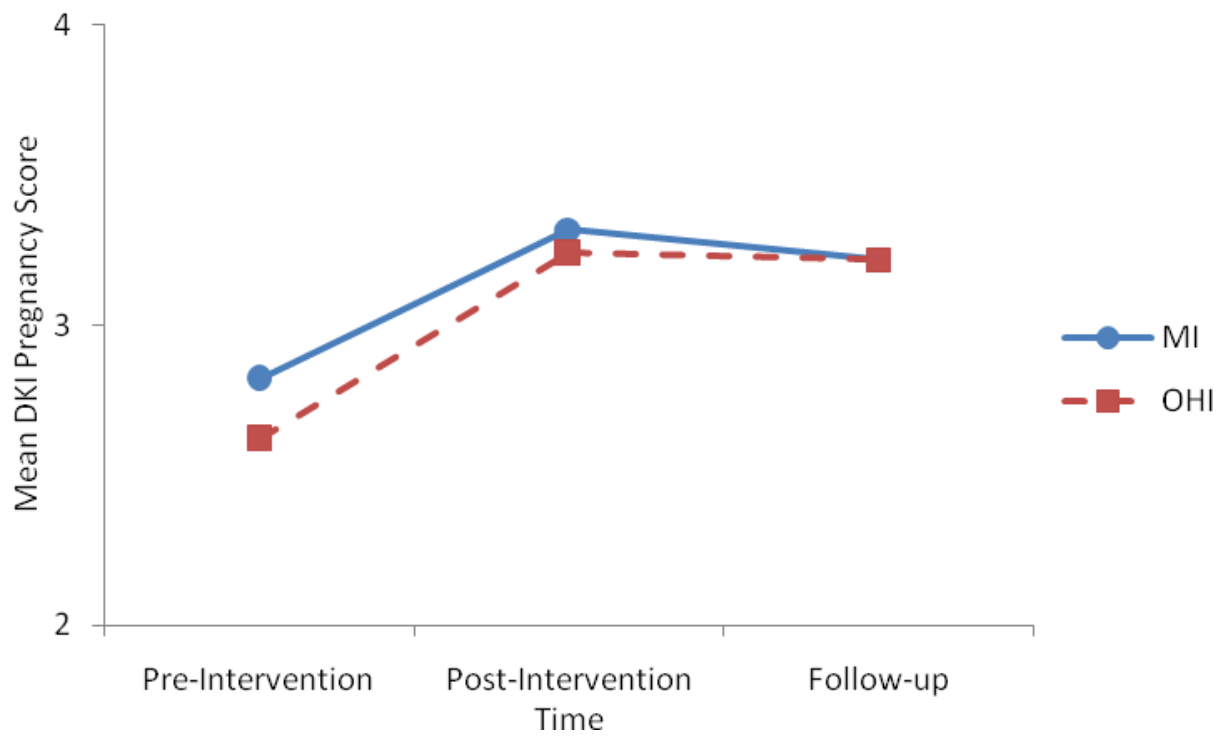




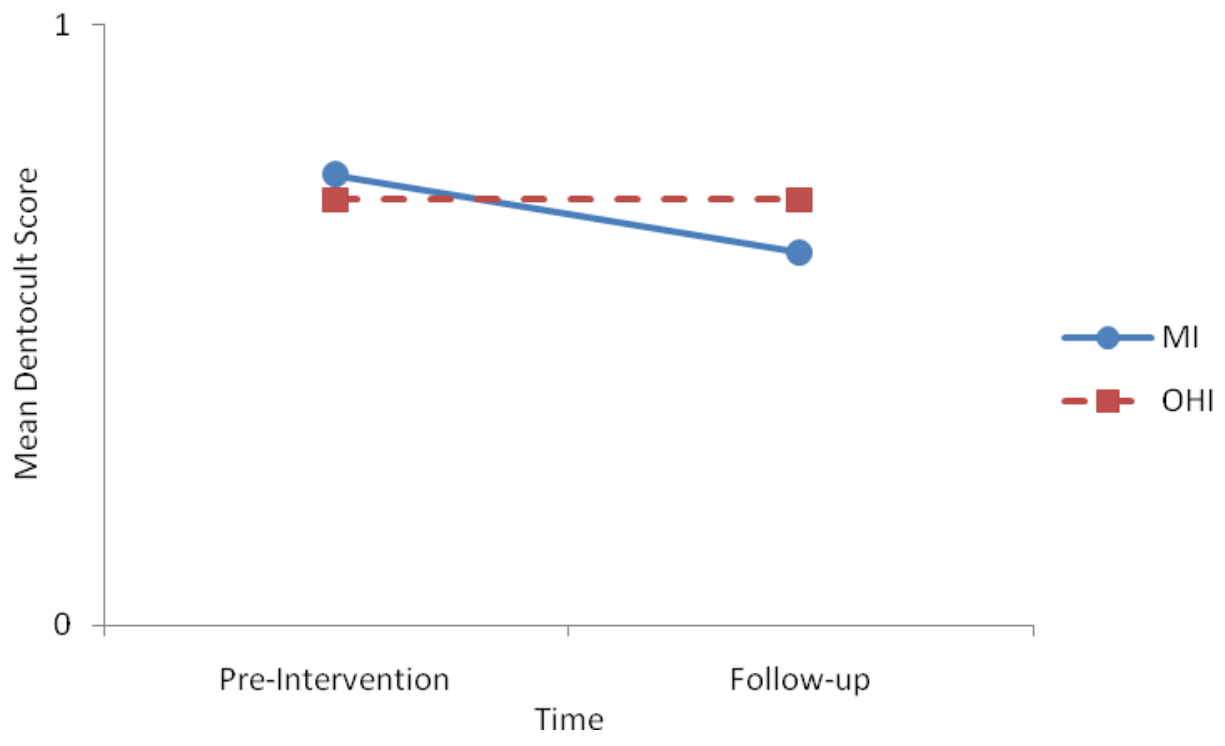




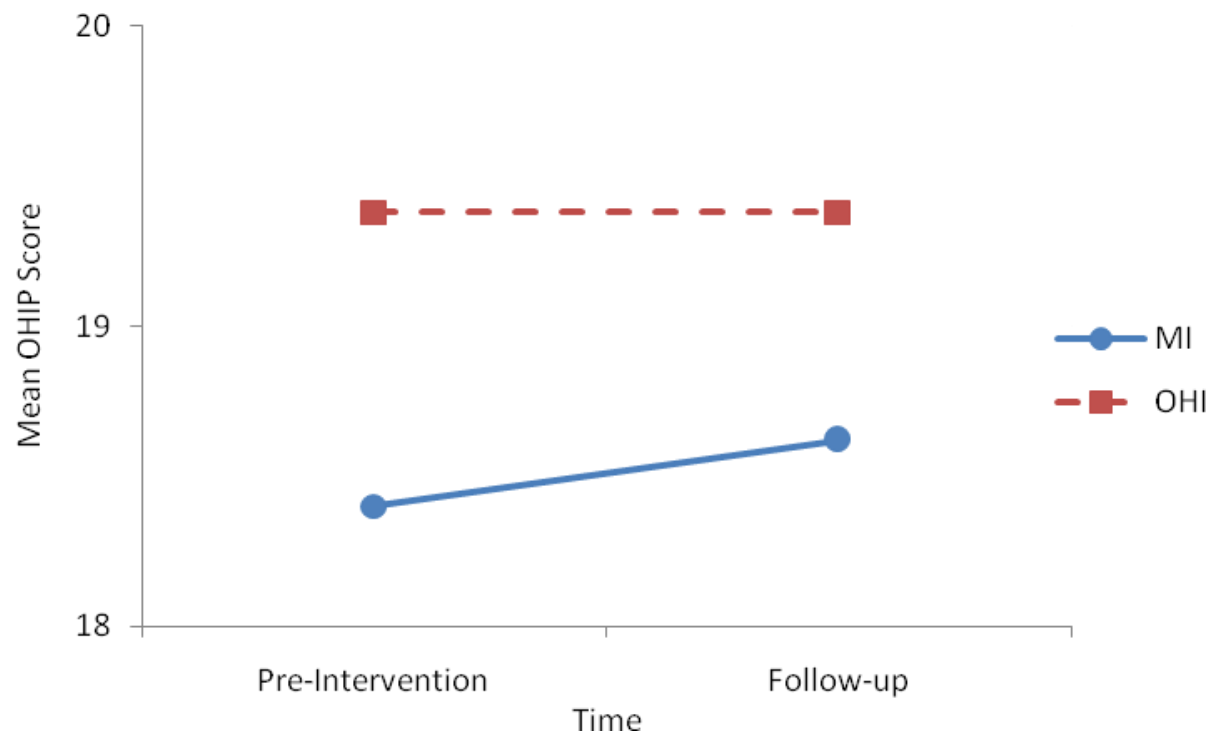




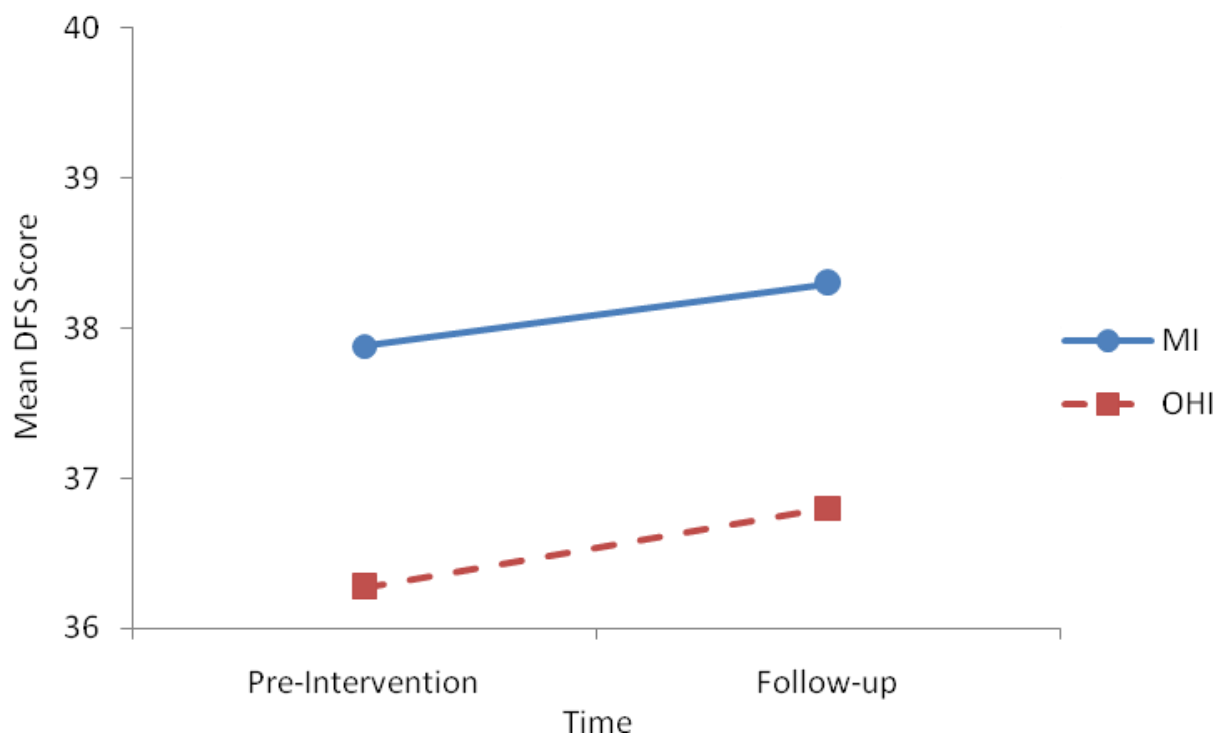




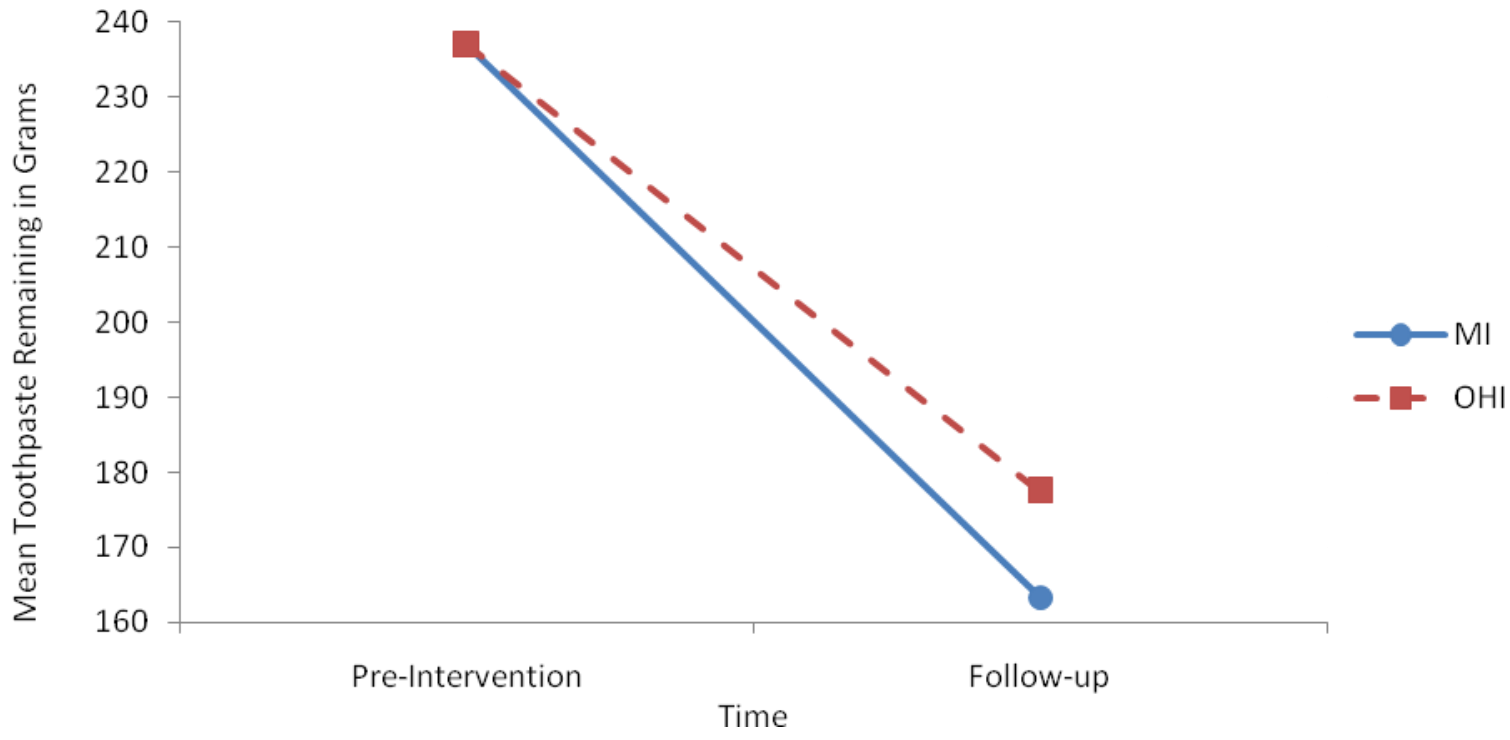




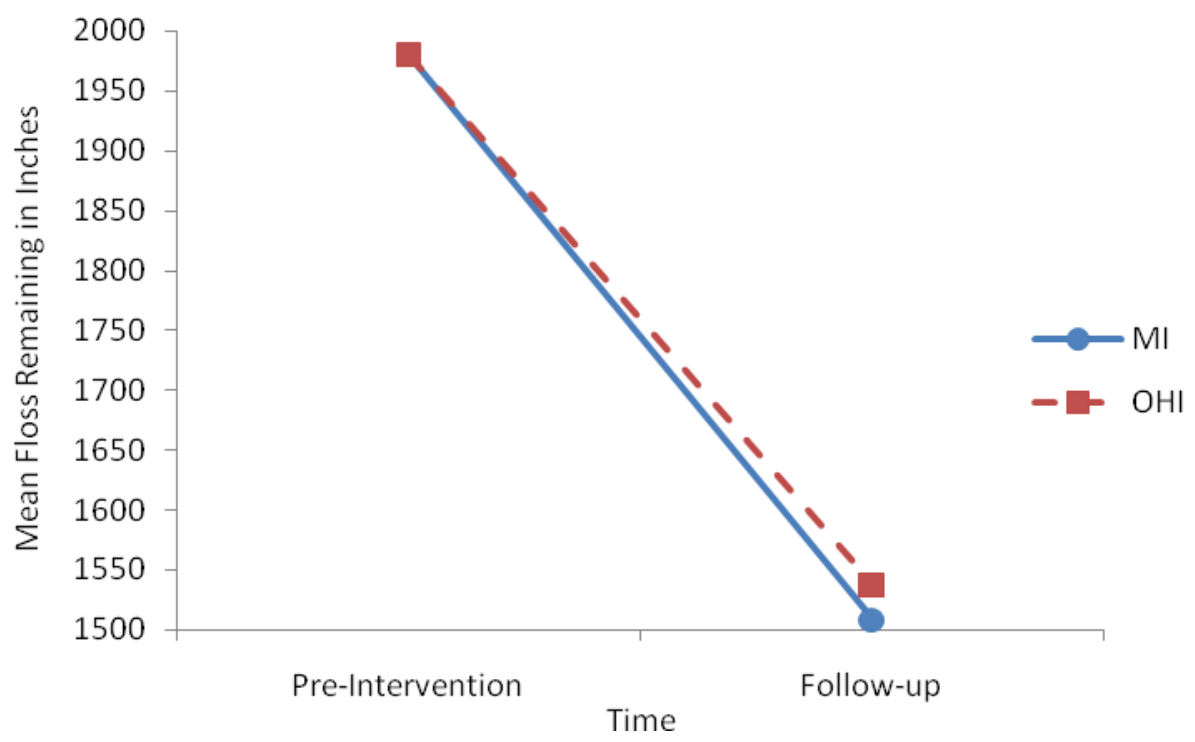


Appendix A

DNS

Directions: Please circle one number for each item to indicate your answer.

1. I keep up my home dental health.

\begin{tabular}{ccccc}
1 & 2 & 3 & 4 & 5 \\
\hline Definitely No & & & & Definitely Yes
\end{tabular}

2. I receive the dental care I should.

\begin{tabular}{ccccc}
1 & 2 & 3 & 4 & 5 \\
\hline Definitely No & & & & Definitely Yes
\end{tabular}

\section{I need dental care, but I put it off.}

\begin{tabular}{ccccc}
1 & 2 & 3 & 4 & 5 \\
\hline Definitely No & & & & Definitely Yes
\end{tabular}

\section{I brush as well as I should.}

\begin{tabular}{ccccc}
1 & 2 & 3 & 4 & 5 \\
\hline Definitely No & & & & Definitely Yes
\end{tabular}

5. I control snacking between meals as well as I should.

\begin{tabular}{ccccc}
1 & 2 & 3 & 4 & 5 \\
\hline Definitely No & & & & Definitely Yes
\end{tabular}

6. I consider my dental health to be important.

\begin{tabular}{ccccc}
1 & 2 & 3 & 4 & 5 \\
\hline Definitely No & & & Definitely Yes
\end{tabular}




\section{Appendix B}

\section{Oral Health Impact Profile}

These items refer to various situations and feelings related to having dental problems. Please rate your feeling or reaction to these items by circling the best number from the following scale:

\begin{tabular}{|c|c|c|c|c|}
\hline $\begin{array}{c}\text { Never/ } \\
\text { Not at all }\end{array}$ & $\begin{array}{c}\text { Once or twice/ } \\
\text { A little }\end{array}$ & $\begin{array}{c}\text { A few times/ } \\
\text { Somewhat }\end{array}$ & $\begin{array}{c}\text { Often/ } \\
\text { Much }\end{array}$ & $\begin{array}{c}\text { Nearly every time/ } \\
\text { Very much }\end{array}$ \\
\hline 1 & 2 & 3 & 4 & 5 \\
\hline
\end{tabular}

1. Have you had trouble pronouncing any words because of problems with your teeth, mouth, or dentures?

2. Have you felt that your sense of taste has worsened because of problems with your teeth, mouth, or dentures?

3. Have you had painful aching in your mouth?

4. Have you found it uncomfortable to eat any foods because of problems with your teeth, mouth, or dentures?

5. Have you been self-conscious because of your teeth, mouth, or dentures?

6. Have you felt tense because of problems with your teeth, mouth, or dentures?

7. Has your diet been unsatisfactory because of problems with your teeth, mouth, or dentures?

8. Have you had to interrupt meals because of problems with your teeth, mouth, or dentures?

9. Have you found it difficult to relax because of problems with your teeth, mouth, or dentures?

10. Have you been a bit embarrassed because of problems with your teeth, mouth, or dentures?

11. Have you been a bit irritable with other people because of problems with your teeth, mouth, or dentures?

12. Have you had difficulty doing your usual jobs because of problems with your teeth, mouth, or dentures?

13. Have you felt that life in general was less satisfying because of problems with your teeth, mouth, or dentures?

14. Have you been totally unable to function because of problems with your teeth, mouth, or dentures?

$\begin{array}{lllll}1 & 2 & 3 & 4 & 5\end{array}$

$\begin{array}{lllll}1 & 2 & 3 & 4 & 5\end{array}$

$\begin{array}{lllll}1 & 2 & 3 & 4 & 5\end{array}$

$\begin{array}{lllll}1 & 2 & 3 & 4 & 5\end{array}$

$\begin{array}{lllll}1 & 2 & 3 & 4 & 5\end{array}$

$\begin{array}{lllll}1 & 2 & 3 & 4 & 5\end{array}$

$\begin{array}{lllll}1 & 2 & 3 & 4 & 5\end{array}$

$\begin{array}{lllll}1 & 2 & 3 & 4 & 5\end{array}$

$\begin{array}{lllll}1 & 2 & 3 & 4 & 5\end{array}$

$\begin{array}{lllll}1 & 2 & 3 & 4 & 5\end{array}$

$\begin{array}{lllll}1 & 2 & 3 & 4 & 5\end{array}$

$\begin{array}{lllll}1 & 2 & 3 & 4 & 5\end{array}$

$\begin{array}{lllll}1 & 2 & 3 & 4 & 5\end{array}$

$\begin{array}{lllll}1 & 2 & 3 & 4 & 5\end{array}$ 


\section{Appendix C}

\section{Dental Fear Survey}

The items in this part of the questionnaire refer to various situations, feelings, and reactions related to dental work. Please rate your feeling or reaction on these items by using the numbers 1-5, from the following scale. Put the appropriate number which most closely corresponds to your reaction in the space to the left of each item.

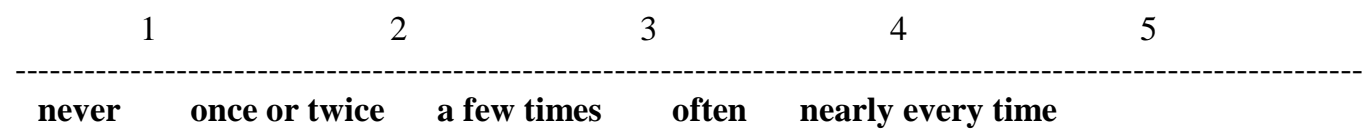

1. Has fear of dental work ever caused you to put off making an appointment?

2. Has fear of dental work ever caused you to cancel or not appear for an appointment?

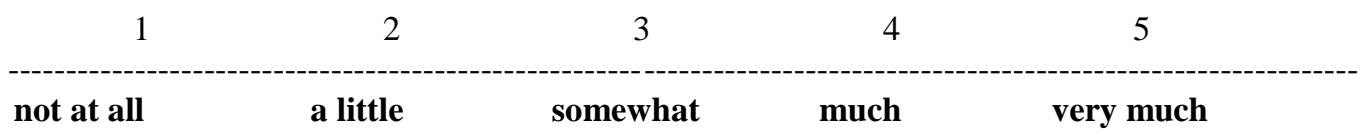

When having dental work done:

3. My muscles become tense...

4. My breathing rate increases...

5. I perspire ...

6. I feel nauseated and sick to my stomach ...

7. My heart beats faster...

Following is a list of things, and situations that many people mention as being somewhat anxiety or fear producing. Please rate how much fear, anxiety, or unpleasantness each of them causes you. Use the numbers 1-5, from the above scale. (If it helps, try to imagine yourself in each of these situations and describe what your common reaction is.)

8. Making an appointment for dentistry.

9. Approaching the dentist's office.

10. Sitting in the waiting room.

11. Being seated in the dental chair.

12. The smell of the dentist's office.

13. Seeing the dentist walk in.

14. Seeing the anesthetic needle.

15. Feeling the needle injected.

16. Seeing the drill.

17. Hearing the drill.

18. Feeling the vibrations of the drill.

19. Having your teeth cleaned.

20. All things considered, how fearful are you of having dental work done? 


\section{Appendix D}

\section{TFD}

\section{How often do you brush your teeth? (NMES-87)}

1. Never

2. Every few weeks

3. Every few days

4. Once a day

5. More than once a day

\section{How often do you use dental floss? (NMES-87)}

1. Never

2. Every few weeks

3. Every few days

4. Once a day

5. More than once a day

3. About how long has it been since you last visited a dentist? Include all types of dentists, such as, orthodontists, oral surgeons, and all other dental specialists, as well as dental hygienists. (NHANES IV)

1. 6 months or less

2. More than 6 months, but not more than 1 year ago

3. More than 1 year, but not more than 2 years ago

4. More than 2 years, but not more than 3 years ago

5. More than 3 years, but not more than 5 years ago

6. More than 5 years ago

7. Never have been

4. What was the main reason you last visited the dentist? (NHANES IV)

1. Went in on own for check-up, examination, or cleaning

2. Was called in by the dentist for check-up, examination, or cleaning

3. Something was wrong, bothering, or hurting me

4. Went for treatment of a condition that dentist discovered at earlier check-up or examination.

5. Other 
5. On average, about how many times a year do you see someone for dental care? (NHANES 82-84)

1. Less than once a year

2. Once

3. Twice

4. 3 or more times

5. No regular schedule

6. During the past 12 months, have you had a dental problem which you would have liked to see a dentist about but didn't see the dentist? (NHANES I)

1. Yes

2. No

7. If yes, why didn't you see a dentist? (NHANES I,IV)

1. Didn't have time

2. Would cost too much

3. Did not want to spend the money

4. Insurance wouldn't cover the recommended procedures

5. Couldn't get an appointment

6. Would have to travel too far

7. Didn't have a way to get there

8. Didn't have anyone to care for children or other family members

9. Dentist recommended not doing it

10. Afraid or do not like dentists

11. Unable to take time off from work

12. Some other reason: 


\section{Appendix E}

\section{DENTAL KNOWLEDGE INVENTORY}

1. Research has shown that a pregnant woman having gum (periodontal) disease makes it more likely that which of the following may happen?
a) premature birth
b) low brth weight baby
c) both of the above
d) none of the above

2. Because of changes in a woman's hormones during pregnancy, she is likely to get gingivitis (inflamed gums)?
a) More
b) Less
c) Much less
d) Doesn't matter

3. If a pregnant woman must have extensive dental work during pregnancy, it's best to have that work done when during pregnancy?
a) $1^{\text {st }}$ Trimester $\left(1^{\text {st }}\right.$ three months $)$
b) $2^{\text {nd }}$ Trimester $\left(2^{\text {nd }}\right.$ three months $)$
c) $3^{\text {rd }}$ Trimester ( $3^{\text {rd }}$ three months)
d) No dental work should ever be done during pregnancy

4. A woman is at increased risk to develop which of the following conditions during pregnancy, even if she did not have it before?
a) Diabetes
b) Gum Disease
c) High blood pressure
d) All of the above

5. If a woman has gum (periodontal disease), and is pregnant, what has research shown that can be helpful?

a) Brushing the teeth and gums at least four times a day

b) Getting a "deep" cleaning of the teeth

c) Both of the above

d) None of the above 
6. What is an ideal angle to hold your toothbrush when brushing your teeth?
a) About a 90 degree angle
b) About a 45 degree angle
c) About a 25 degree angle
d) About a 65 degree angle

7. What is the final step in good tooth brushing technique?
a) Brush your tongue
b) Brush the inside portions of your cheeks
c) Brush your gums
d) Brush your teeth again with fresh toothpaste

8. When you first start flossing every day, how long should you expect your gums to be sore?
a) For the first 5 days
b) For the first 10 days
c) For the first 2 days
d) For the first 7 days

9. What total length of dental floss should you first pull out when flossing?
a) About 24 inches
b) About 10 inches
c) About 14 inches
d) About 18 inches

10. How often should you replace your toothbrush?
a) Every month
b) Every 2 months
c) Every 3-4 months
d) Every 5-6 months 
Appendix F

\section{Motivational Interviewing Protocol}

\section{$\underline{\text { Initial Session }}$}

Duration of Session: Approximately 75 minutes

Duration of Intervention: 30 minutes ( \pm 5 minutes)

Preparation for participant:

Consent:

1. Place consent form and PHI form on clipboard.

Dentocult:

1. Remove round-tipped Dentocult strip from box and label with participant's number.

2. Label test tube with participant's number.

3. Place bacteria disk into blue broth.

4. Place a piece of paraffin wax on a tissue.

5. Have a tissue ready for participant to spit out paraffin wax.

Home-based oral hygiene:

1. Label toothpaste, floss, and toothbrush with participant's number.

2. Place toothpaste, floss, toothbrush, and 4 copies of the daily log in gift bag.

Tape recording:

1. Place recorder on desk.

2. Plug microphone into 'mic' hole on top of the recorder.

3. Turn microphone to 'on' and turn recorder on by releasing the 'hold' button.

4. Press record. 
Welcome participant, introduce self and project. (2 minutes)

"Thank you for coming to participate in our study today. We appreciate your time and effort. My name is and I will be meeting with you throughout the study."

Evaluate participant for exclusion criteria.

"I need to ask you a few questions before we begin. Ok?"

1. Are you under the age of 18 ?

2. Are you more than seven months, or 34 weeks, pregnant?

3. Have you ever been diagnosed with a developmental disability (e.g., problems with activities such as language, mobility, learning, self-help, and independent living)?

4. Have you ever been diagnosed with a neurological disorder, that is, a disorder that affects the brain or spinal cord (e.g., epilepsy, Parkinson's)?

5. Do you have any conditions that physically prevent you from caring for your mouth or teeth?

\section{DOES NOT MEET CRITERIA: WILL NOT PARTICIPATE}

"Thank you for taking the time to learn about our study. Although you cannot participate today because you indicated 'yes' to one or more of the previous questions, let me briefly tell you about the project and what we are hoping to learn. (Discuss project for about 5 minutes). Although you could not participate in the project, we would like to offer you a baby gift to thank you for taking the time to speak with us."

\section{OR \\ MEETS CRITERIA (SAID NO TO ALL EXCLUSION QUESTIONS): WILL PARTICIPATE}

Review consent form and PHI form with participant; obtain signature. (2 minutes)

"This form is called "informed consent." It explains the study in detail and your rights concerning participation. To summarize, the study involves this one-on-one meeting which lasts about an hour, 2 follow-up phone calls that last less than 10 minutes each, 
and a follow-up meeting to complete some questionnaires that lasts about 30 minutes. We estimate that the study takes about 2 hours to complete. As part of the study, I will ask you to press a stick onto the saliva on your tongue to estimate the amount of bacteria in your mouth. All of our sessions will be audiotaped to ensure that we are using the same protocol with each participant. At the end of the session today I will give you a new toothbrush, toothpaste, floss, and a log to keep track of your dental activities. You also will be able to pick a baby gift! After you complete both today's meeting and the followup meeting, you will receive $\$ 50$ cash for participating in the study. Do you have any concerns about what the study entails or your ability to complete the study? (IF SO, DISCUSS). IF NO: Please read this form carefully and let me know if you have any questions. Ok?" Allow participant to read and sign form.

"Also, because we are asking certain health information, such as how many months you have been pregnant, this form is important because it describes how your health information, or PHI, is protected. Please read it carefully and let me know if you have any questions. Ok?” Allow participant to read and sign form. "Do you have any questions about these forms?"

\section{Start audiotape, with the participant's permission}

"If it's ok with you, I will start recording now. In research we want to make sure we do the same thing with each person, so I'm going to use this guide to keep me on track, but anytime you have any questions or concerns, please let me know."

Ask participant demographic questions. (3 minutes)

"Now I will be asking you a few standard demographic questions." Complete 
demographics questionnaire. "Thank you."

Ask participant to complete assessment measures. (about 20 minutes)

"This is a set of five questionnaires that we would like you to complete. The questionnaires are important to our study because they add information to our data collection. The first questionnaire consists of 6 items and looks at oral health values, including self-care dental health behaviors, dental care use and dental health in general (DNS). The second consists of 14 items and measures dental problems, discomfort and disability related to oral conditions, and quality of life (OHIP). The third consists of 20 items assessing dental fear and anxiety (DFS). The fourth questionnaire consists of 7 items and asks about tooth brushing and flossing frequency, and dental visits (TFD). Finally, the last questionnaire consists of 10 items and measures your dental health and oral hygiene knowledge in general and during pregnancy (DKI). Would you prefer it if I asked you the questions on the questionnaire? IF NO, Please take your time completing the questionnaires to the best of your ability. Do you have any questions?"

- Dental Neglect Scale (DNS)

- Oral Health Impact Profile (OHIP)

- Dental Fear Survey (DFS)

- Tooth brushing, flossing, and dental visit behavior (TFD)

- Dental Knowledge Inventory (DKI) -A

Check questionnaires for completeness.

“Thank you! Let me just check to make sure we didn't miss any."

Ask participant to provide saliva sample using a Dentocult strip. (about 3 minutes)

"Thank you. Now we are going to collect a saliva sample so we can estimate the amount of bacteria in your mouth. First, I am going to ask you to chew on a piece of wax for one minute to increase the amount of saliva in your mouth. Then, I will ask you to swallow 
the excess saliva. I will hand you this test strip to place it on saliva still on your tongue. Then, simply remove the strip through your gently closed lips and hand it back to me." Hand participant a paraffin pellet. "Please chew on this piece of wax for one minute. It has no taste and you can spit it out after one minute." Allow participant to chew paraffin pellet for one minute. "Ok, please spit the wax out and swallow the excess saliva." Quickly hand the test strip to participant, rough side down. "Please place this side of the strip on your tongue. Then gently close your lips and hand the strip back to me." Take strip from participant and place in blue broth in the test tube labeled with the participant's number. "Thank you."

Provide overview of motivational interviewing session (about 1 minute)

"Before we begin, I want to give you an overview of what we will be talking about today. We'll talk about the health of your mouth and teeth, why it's important, and I will ask you if there are any changes you want to make in the way you care for your teeth and mouth.

Assess stage of change using Readiness to Change Rulers. (about 1 minute)

"But first, I would like to know how important dental care is to you right now, on a scale of 0 to 10, where 0 means not at all important and 10 means extremely important." Show participant importance readiness ruler. "On the same scale of 0 to 10 , how confident are you about what you're doing to take care of your teeth, where 0 means not confident at all and 10 means extremely confident." Show participant confidence readiness ruler.

Introduce the topic of oral health during pregnancy (about 2 minutes)

- 'Since you've been pregnant, what suggestions has your doctor made about things you can do to improve your health or the health of the baby?" 
- "Have you made any of these changes?

○ "What has helped you succeed in making those changes? OR "What has stood in your way?"

- 'Since you've been pregnant, what suggestions have your doctor or dentist made about things you can do to improve your dental health?

- Have you made any of these changes?

○ "What has helped you succeed in making those changes? OR "What has stood in your way?"

Discuss current oral health status (e.g., experience of gingivitis) and behaviors (e.g., tooth brushing) (about 5 -10 minutes)

- "Tell me about your teeth."

- "What do you like about your teeth? What difficulties have you had?"

- “What, if anything, do you wish was different about your teeth or mouth?” OR Suppose you were granted a "dental miracle" - what would happen?"

- "What is it like for you to have these dental problems? How does that problem affect your life?"

Conduct 24-hour Follow-Back Assessment - Go back 24 hours

- "When was the last time you brushed your teeth? When was the time before that?

- When was the last time you flossed? When was the time before that?

- Did you use any mouthwash during the last 24 hours? Did you do anything else to care for your teeth or mouth?"

Discuss pros and cons of current oral health behaviors (about 5-10 minutes)

- "How have you been caring for your teeth and mouth?" 
- Have participant generate pros and cons

- Provide additional pros and cons as needed:

○ Pros: e.g., save on immediate cost, save time

○ Cons: e.g., pain, long-term cost, related to other health problems (e.g., cardiovascular disease)

- "Would you be interested in learning about why dental care is particularly important during pregnancy?"

○ poor oral health during pregnancy has been associated with low-birth weight, pre-mature birth, and early childhood caries

Are there any oral health behaviors they would like to change? (about 5 -10 minutes)

- "What are some things you can do to improve your dental care?"

- Develop discrepancy

○ "Are you worried about your teeth or gums in any way?"

- If so, identify barriers for change. Identify support for change. Problem-Solve.

○.g., ways to remember to engage in behavior (put new behavior before well established behaviors).

- If not, ask follow-up questions, such as "Is there anything you don't like about your teeth?" or "If you were granted a dental miracle what would happen?"

Help participant develop a plan for change of oral health behaviors (about 3 minutes)

- Ask participant to generate changes they would like to make

- "Are you interested in making any changes to the way you care for your teeth or mouth?" 
- Provide a menu of possibilities if participant struggles (e.g., increase tooth brushing frequency) - "May I offer some ideas?"

Increase brushing to $2 \mathrm{x} /$ day

- Increase flossing to $1 \mathrm{x} /$ day

- Chew sugar-free gum

- Use a fluoride rinse

- Use mouthwash

- Get a dental checkup/cleaning/treatment

$\circ$ Improve nutrition - avoid foods high in carbs and sugars

- Complete two copies plan for change form (one for participant, one for the study) (if participant is interested in making a change.)

- Encourage participant to put new behaviors before well-established habits.

- Reinforce commitment to change - Affirm participant for behavior change

○ "I hope you're proud of yourself!"

○ "You seem like you're going to try."

○ "You seem dedicated"

Review plan for change and summarize discussion (about 2 minutes)

Assess stage of change using Readiness to Change Rulers. (about 1 minute)

"Remember those rulers I showed you before? I'm going to ask you for ratings again.

How important dental care is to you right now, on a scale of 0 to 10 , where 0 means not at all important and 10 means extremely important." Show participant importance readiness ruler. "And why is it you're not a__ ? On the same scale of 0 to 10, how confident are you about what you can do to take care of your teeth, where 0 means not confident at all and 10 means extremely confident." Show participant confidence readiness ruler. "And why is it you're not a ___?" 
- Wow, you said you were a _ on my 10 point scale of being ready. Great! How is it that you are not a 1 ?

- What would happen if you did nothing?

Ask participant to complete Dental Knowledge Inventory -B. (about 5 minutes) "I asked you to complete several questionnaires before. I would like to you to complete one more. It's the same questionnaire you completed before that consisted of 10 items and measures your dental health and oral hygiene knowledge in general and during pregnancy, but I would like you to complete it a second time. Please take your time and let me know if you have any questions."

Give participant toothbrush, toothpaste, floss, monitoring sheets, and instructions for use. (5 minutes)

"So I'm going to give you a toothbrush, a tube of toothpaste, and a container of floss to use over the next 6 weeks until we meet again. I have labeled each with your number, because I would like you to bring them back to me when I meet with you in six weeks. Please do not let others use these so we can get a clear estimate of how much one person uses. When we meet in six weeks I will give you a brand new toothbrush, another tube of toothpaste, and a new container of floss for you to keep! Does that sound ok? I also would like you to keep a daily log of your dental health activities, such as brushing and flossing. Just write down the date and anything you did to take care of your teeth or mouth. For example, if I used mouthwash today, I would write down today's date under 'date,' then write used mouthwash under 'activities.' Do you understand what I mean? I know it can be challenging to remember to complete the log every day, but please do your very best. We would like you to remain in the study regardless of whether you were 
about to complete the logs every day or not. Just do your best and bring back what you have. Please bring back the logs, toothpaste, toothbrush, and floss when we meet in six weeks."

Determine best time for a follow-up phone call in 2 weeks by completing the Contact Sheet "We're almost done. Please fill out this sheet with your name, address, and phone number where I can call you to follow-up in 2 weeks and then 4 weeks from today. Please indicate below if there are particular days and times that would be best for me to call. Ok. Thank you! Let's make an appointment to meet again in about 6 weeks."

Ask participant to pick a baby gift.

"Please pick a baby gift for you to take home!"

Thank participant for her participation.

"Thank you again for your participation in our study today. Your time and effort make our research possible and for that we are very grateful. Do you have any questions?" "I will call you in two weeks. Thank you."

Turn off audiotape. Turn off microphone. 


\section{Appendix G}

\section{Oral Hygiene Instruction Protocol}

\section{$\underline{\text { Initial Session }}$}

Duration of Session: Approximately 75 minutes

Duration of Intervention: 30 minutes ( \pm 5 minutes)

\section{Preparation for participant:}

Consent:

2. Place consent form and PHI form on clipboard.

\section{Dentocult:}

6. Remove round-tipped Dentocult strip from box and label with participant's number.

7. Label test tube with participant's number.

8. Place bacteria disk into blue broth.

9. Place a piece of paraffin wax on a tissue.

10. Have a tissue ready for participant to spit out paraffin wax.

Home-based oral hygiene:

3. Label toothpaste, floss, and toothbrush with participant's number.

4. Place toothpaste, floss, toothbrush, and 4 copies of the daily log in gift bag.

\section{Tape recording:}

5. Place recorder on desk.

6. Plug microphone into 'mic' hole on top of the recorder.

7. Turn microphone to 'on' and turn recorder on by releasing the 'hold' button.

8. Press record. 
Welcome participant, introduce self and project. ( 2 minutes)

"Thank you for coming to participate in our study today. We appreciate your time and effort. My name is and I will be meeting with you throughout the study."

Evaluate participant for exclusion criteria.

"I need to ask you a few questions before we begin. Ok?"

6. Are you under the age of 18 ?

7. Are you more than seven months, or 30 weeks, pregnant?

8. Have you ever been diagnosed with a developmental disability (e.g., problems with activities such as language, mobility, learning, self-help, and independent living)?

9. Have you ever been diagnosed with a neurological disorder, that is, a disorder that affects the brain or spinal cord (e.g., epilepsy, Parkinson's)?

10. Do you have any conditions that physically prevent you from caring for your mouth or teeth?

\section{DOES NOT MEET CRITERIA: WILL NOT PARTICIPATE}

"Thank you for taking the time to learn about our study. Although you cannot participate today because you indicated 'yes' to one or more of the previous questions, let me briefly tell you about the project and what we are hoping to learn. (Discuss project for about 5 minutes). Although you could not participate in the project, we would like to offer you a baby gift to thank you for taking the time to speak with us."

\section{OR \\ MEETS CRITERIA (SAID NO TO ALL EXCLUSION QUESTIONS): WILL PARTICIPATE}

Review consent form and PHI form with participant; obtain signature. (2 minutes)

"This form is called "informed consent." It explains the study in detail and your rights concerning participation. Please read it carefully and let me know if you have any 
questions. Ok? Also, because we are asking certain health information, such as how many months you have been pregnant, this form is important because it describes how your health information, or PHI, is protected. Please read it carefully and let me know if you have any questions. Ok?" Allow participant to read and sign forms. "Do you have any questions about these forms?"

\section{Start audiotape, with the participant's permission} "If it's ok with you, I will start recording now. In research we want to make sure we do the same thing with each person, so I'm going to use this guide to keep me on track, but anytime you have any questions or concerns, please let me know."

Ask participant demographic questions. (3 minutes)

"Now I will be asking you a few standard demographic questions." Complete demographics questionnaire. "Thank you."

Ask participant to complete assessment measures. (about 20 minutes)

"This is a set of five questionnaires that we would like you to complete. The questionnaires are important to our study because they add information to our data collection. The first questionnaire consists of 6 items and looks at oral health values, including self-care dental health behaviors, dental care use and dental health in general (DNS). The second consists of 14 items and measures dental problems, discomfort and disability related to oral conditions, and quality of life (OHIP). The third consists of 20 items assessing dental fear and anxiety (DFS). The fourth questionnaire consists of 7 items and asks about tooth brushing and flossing frequency, and dental visits (TFD). Finally, the last questionnaire consists of 10 items and measures your dental health and oral hygiene knowledge in general and during pregnancy (DKI). Would you prefer it if I 
asked you the questions on the questionnaire? IF NO, Please take your time completing the questionnaires to the best of your ability. Do you have any questions?"

- Dental Neglect Scale (DNS)

- Oral Health Impact Profile (OHIP)

- Dental Fear Survey (DFS)

- Tooth brushing, flossing, and dental visit behavior (TFD)

- Dental Knowledge Inventory (DKI) -A

Ask participant demographic questions. (3 minutes)

"Now I will be asking you a few standard demographic questions." Complete demographics questionnaire. "Thank you."

Ask participant to provide saliva sample using a Dentocult strip. (about 3 minutes)

"Thank you. Now we are going to collect a saliva sample so we can estimate the amount of bacteria in your mouth. First, I am going to ask you to chew on a piece of wax for one minute to increase the amount of saliva in your mouth. Then, I will ask you to swallow the excess saliva. I will hand you this test strip to place it on saliva still on your tongue. Then, simply remove the strip through your gently closed lips and hand it back to me." Hand participant a paraffin pellet. "Please chew on this piece of wax for one minute. It has no taste and you can spit it out after one minute." Allow participant to chew paraffin pellet for one minute. "Ok, please spit the wax out and swallow the excess saliva." Quickly hand the test strip to participant, rough side down. "Please place this side of the strip on your tongue. Then gently close your lips and hand the strip back to me." Take strip from participant and place in blue broth in the test tube labeled with the participant's number. "Thank you."

Provide overview of oral hygiene instruction session. (about 2 minutes) 
"Before we begin, I want to give you an overview of the information we will be covering today. I am going to talk to you about the health of your mouth and teeth, why it's important, and how you can take better care of your dental health. We also will discuss common myths that women have about dental health. I will also be demonstrating a good way of brushing and flossing your teeth using a big tooth model!"”

\section{Assess stage of change using Readiness to Change Rulers. (about 1 minute)}

"But first, I would like to know how important dental care is to you right now, on a scale of 0 to 10 , where 0 means not at all important and 10 means extremely important." Show participant importance readiness ruler. "On the same scale of 0 to 10 , how confident are you about what you're doing to take care of your teeth, where 0 means not confident at all and 10 means extremely confident." Show participant confidence readiness ruler.

\section{Conduct 24-hour Follow-Back Assessment - Go back 24 hours}

- "When was the last time you brushed your teeth? When was the time before that?

- When was the last time you flossed? When was the time before that?

- Did you use any mouthwash during the last 24 hours? Did you do anything else to care for your teeth or mouth?"

Provide education about oral health status (about 5 minutes)

"The mouth is a mirror that reflects our general health. It can be the body's silent alarm. Let's start by talking about different things that can happen to your teeth and your mouth that should sound the alarm for you. Cavities, for example, can be prevented by brushing and flossing your teeth, by reducing your carbohydrate and simple sugar intake, and visiting a dentist twice a year for a cleaning and checkup. Your gums are 
also called the gingiva. Gingivitis (or an inflammation of the gums) is the first stage of gum disease and it involves bleeding, puffy, red gums. Sometimes you also can have bad breath with gingivitis. If gingivitis is left untreated your gums may recede causing your teeth to become sensitive to hot or cold liquids or foods. If things get worse your teeth may become loose, you may have pus around your teeth, and bone loss. The good news is that gingivitis is treatable and reversible! It's important to see a dentist as soon as you can if you experience these problems."

Discuss importance of oral health care, oral hygiene, nutrition/diet, and tobacco cessation (about 5 minutes)

"It's important to take care of your teeth and mouth so that you and your baby can be as healthy as possible. You can take care of your dental health by brushing, flossing, and visiting the dentist. But you can also improve your general health and your dental health by eating healthier, not smoking, and avoiding smokeless tobaccos. Smoking during pregnancy can slow fetal growth and increases the chances of sudden infant death and premature birth. Many believe that smokeless tobacco is a safe alternative to smoking. This simply is not true. These products contain large amounts of nicotine and other ingredients that can affect the health of your gums and oral cavity not to mention your overall health.

It is very important to watch what you eat and drink. You need to watch your intake of carbohydrates and simple sugars. Things like soda pop and candy contain a lot of sugar. You also need to watch some of the juices and power drinks because many of them contain sugar as well. It is so important to drink plenty of water and beverages like milk and natural juices. Always consider healthy snacks including plenty of fruits and 
vegetables. And if you chew gum, always choose the sugar-free kind. Remember, sugar along with plaque on teeth can lead to cavities.

Provide information about the relation between oral health and pregnancy (about 2 minutes)

"So why it is important for you to take care of your dental health while you're pregnant? For starters, anything that damages a mother's health can affect her baby, so good dental health is important. Hormone changes in the body when you're pregnant sometimes causes women's gums to become swollen, red, and to bleed easily. This condition should go away after pregnancy, but if your gums are still swollen after birth, it's important to see your dentist. Also, dentists are learning that your dental health during pregnancy can affect your baby's health too. For example, if you have poor dental health when you're pregnant, it may result in low birth weight, pre-mature birth, or cavities early in childhood. Even after giving birth it's possible to pass bacteria from your mouth to the baby's mouth, especially during the first two years, for example, by putting your baby's hand in your mouth.'

Discuss common myths (about 3 minutes)

- It is normal to lose a tooth

$\circ$ Bleeding gums during pregnancy are normal

- Calcium is sucked out of the teeth

- It's unsafe to visit a dentist during pregnancy

○ It's not safe to take any medication while you're pregnant

"There are common myths you may have heard about pregnancy. For example, we may have heard that it is normal to lose teeth with every pregnancy. It's not normal. Losing 
teeth can be a sign of gum disease. However, during pregnancy teeth may get slightly loose but should tighten on their own after the baby arrives. This is due to the ligaments and joints relaxing as your body prepares for the birthing process. If they do not, see your dental provider as soon as possible. You also may have heard that bleeding gums during pregnancy are normal. It's not. Like I said before, it is common for pregnant women to experience bleeding gums, but it's a sign of infection. There are things you can do to make the condition better. Another myth is that the baby sucks calcium out of the mother's teeth. That's not true either because calcium is bonded within the tooth structure. The baby actually gets calcium from what you eat so it's important that you eat plenty of calcium so your baby will have strong teeth and bones. Women commonly think that it isn't safe to have dental treatment during pregnancy and that they can't take any medication at all. There is no evidence that dental exams or treatment should not be performed during pregnancy. Some dentists will suggest that you wait until your second trimester for routine checkups, but if you need emergency care you should call the dentist at any time during your pregnancy. Also, there are many medications that are safe to take during pregnancy, but you should talk with your doctor first."

Provide education about proper tooth brushing techniques using flipbook (about 3 minutes) "Two things you can do to improve your dental health at home are to brush and floss your teeth. Think of it as infection control. Sounds simple enough, right? Actually, most people don't know the basic instructions for brushing and flossing. Let's take a look at this picture. It's best if you hold your soft bristled tooth brush at a 45 degree angle gently pressing against the gum tissue. Where the gum tissue and teeth meet is an area we call the sulcus. This sulcus is kind of like a small ditch that surrounds every tooth. By 
pressing the brush against the gum tissue, you will be able to keep this area cleaned. Often, when people's gum tissue bleeds during brushing, they think they are doing something wrong and tend to stay away from the gum area. In reality, you need to brush better around the gum area. Avoid using straight back and forth strokes so you don't get areas of abrasion on your teeth. Always use small circles and light pressure. Always try to use fluoride toothpaste. You only need to put a pea-size amount of toothpaste on your brush. Large amounts of toothpaste do not help in the cleaning process. It is the motion of the brush that removes the plaque from the tooth surfaces. It's important to try to brush for 2 minutes total or about 10 seconds per tooth and to end by brushing your tongue. Finally, it's good to replace your toothbrush every 3-4 months. If you happen to have a cold or strep throat, it is important to change your brush after you have gotten over your illness to prevent reinfection."

Demonstrate proper tooth brushing techniques using tooth model (about 2 minutes) "Let me show you what I mean using this model of teeth. Always be sure to brush the outside, the inside, and chewing surfaces of your teeth." Demonstrate. Remember to brush around the gum area to keep the sulcus or ditch cleaned out. Demonstrate. "Also, for the inside of your lower front teeth you can use the tip of your brush, by pointing the handle to the ceiling and brushing up and down." Demonstrate.

Provide education about proper tooth flossing techniques using flipbook (about 3 minutes) "Let's talk about flossing now. When you floss you want to rip off about 18 inches of floss or about the length of your forearm. Gently wind the floss around both middle fingers. Sometimes it helps to use your index fingers to control and guide the floss. Gently place the floss between two teeth, slide it back and forth until you get between the 
teeth. Be careful not to snap the floss between your teeth as this can hurt the gum tissue. Then you want to gently floss around each tooth by forming a " $C$ " shape with the floss each time. The " $C$ " shape helps place the floss against the tooth. This is what removes the plaque from the tooth surface. It's important to use a new area of floss for each tooth side."

Demonstrate proper tooth flossing techniques using tooth model (about 2 minutes) "Let's go back to the model and I will show you what I mean." Be sure to reach the areas in the back of your mouth.

Summarize proper tooth brushing and tooth flossing techniques (about 2 minutes) "So to summarize, it's important to use a soft-bristled toothbrush held at a 45 degree angle to brush your teeth for 2 minutes at least twice a day using fluoridated toothpaste. Don't forget to brush your tongue. It's also good to floss at least once a day using about 18 inches of floss and remember to use a new section of floss on each tooth side. Do you have any questions?"

Assess stage of change using Readiness to Change Rulers. (about 1 minute) "Remember those rulers I showed you before? I'm going to ask you for ratings again. How important dental care is to you right now, on a scale of 0 to 10, where 0 means not at all important and 10 means extremely important." Show participant importance readiness ruler. "On the same scale of 0 to 10, how confident are you about what you can do to take care of your teeth, where 0 means not confident at all and 10 means extremely confident." Show participant confidence readiness ruler.

Ask participant to complete Dental Knowledge Inventory -B. (about 5 minutes) 
"I asked you to complete several questionnaires before. I would like to you to complete one more. It's the same questionnaire you completed before that consisted of 10 items and measures your dental health and oral hygiene knowledge in general and during pregnancy, but I would like you to complete it a second time. Please take your time and let me know if you have any questions."

Give participant toothbrush, toothpaste, floss, monitoring sheets, and instructions for use. (5 minutes)

"So I'm going to give you a toothbrush, a tube of toothpaste, and a container of floss to use over the next 6 weeks until we meet again. I have labeled each with your number, because I would like you to bring them back to me when I meet with you in six weeks. Please do not let others use these so we can get a clear estimate of how much one person uses. When we meet in six weeks I will give you a brand new toothbrush, another tube of toothpaste, and a new container of floss for you to keep! Does that sound ok? I also would like you to keep a daily log of your dental health activities, such as brushing and flossing. Just write down the date and anything you did to take care of your teeth or mouth. For example, if I used mouthwash today, I would write down today's date under 'date,' then write used mouthwash under 'activities.' Do you understand what I mean? Please bring back the logs when we meet in six weeks."

Determine best time for a follow-up phone call in 2 weeks by completing the Contact Sheet "We're almost done. Please fill out this sheet with your name, address, and phone number where I can call you to follow-up in 2 weeks and then 4 weeks from today. Please indicate below if there are particular days and times that would be best for me to call. Let's make an appointment to meet again in about 6 weeks." 
Ask participant to pick a baby gift.

"Please pick a baby gift for you to take home!"

Thank participant for her participation.

"Thank you again for your participation in our study today. Your time and effort make our research possible and for that we are very grateful. Do you have any questions?" "I will call you in two weeks. Thank you."

Turn off audiotape. Turn off microphone. 